

\section{DÉBORA GOMES}

\section{Avaliação eletrorretinográfica pré e pós-operatória em cães diabéticos submetidos à facoemulsificação}

Dissertação apresentada ao Programa de Pós-Graduação em Clínica Cirúrgica Veterinária da Faculdade de Medicina Veterinária e Zootecnia da Universidade de São Paulo para obtenção do título de Mestre em Ciências.

Departamento:

Cirurgia

Área de concentração:

Clínica Cirúrgica Veterinária

Orientadora:

Profa. Dra. Angélica de Mendonça Vaz

Safatle

São Paulo 
Autorizo a reprodução parcial ou total desta obra, para fins acadêmicos, desde que citada a fonte.

\section{DADOS INTERNACIONAIS DE CATALOGAÇÃO-NA-PUBLICAÇÃO}

(Biblioteca Virginie Buff D’Ápice da Faculdade de Medicina Veterinária e Zootecnia da Universidade de São Paulo)

Gomes, Débora

Avaliação eletrorretinográfica pré e pós-operatória em cães diabéticos submetidos à facoemulsificação. / Débora Gomes. -- 2013.

129 p. : il.

Dissertação (Mestrado) - Universidade de São Paulo. Faculdade de Medicina Veterinária e Zootecnia. Departamento de Cirurgia, São Paulo, 2013.

Programa de Pós-Graduação: Clínica Cirúrgica Veterinária.

Área de concentração: Clínica Cirúrgica Veterinária.

Orientador: Profa. Dra. Angélica de Mendonça Vaz Safatle.

1. Cão. 2. Catarata. 3. Diabete melito. 4. Eletrorretinograma. 5. Retinopatia diabética. I. Título. 


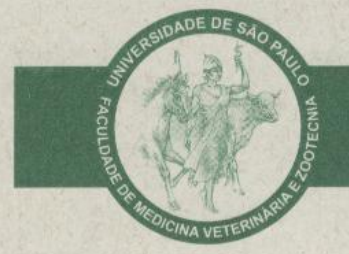

UNIVERSIDADE DE SÃO PAULO

FACULDADE DE MEDICINA VETERINÁRIA E ZOOTECNIA

Comissão de Ética no Uso de Animais

\section{CERTIFICADO}

Certificamos que o Projeto intitulado "Avaliação eletrorretinográfica em cães diabéticos pré e pós-operatória submetidos à facoemulsificação", protocolado sob o $\mathrm{n}^{\circ} 1675 / 2009$, utilizando 24 (vinte e quatro) cães, sob a responsabilidade da Dra. Angélica de Mendonça Vaz Safatle, está de acordo com os princípios éticos de experimentação animal da Comissão de Ética no Uso de Animais da Faculdade de Medicina Veterinária e Zootecnia da Universidade de São Paulo e foi aprovado em reunião de 20/5/2009.

We certify that the Research "Electroretinografic evaluation in diabetic dogs before and after facoemulsification", utilizing 30 (thirty) dogs, protocol number 1675/2009, under the responsibility Dra. Angélica de Mendonça Vaz Safatle, agree with Ethical Principles in Animal Research adopted by Ethic Committee in the Use of Animals of the School of Veterinary Medicine and Animal Science of University of São Paulo and was approved in the meeting of day $05 / 20 / 09$.

São Paulo, 5 de junho de 2013.

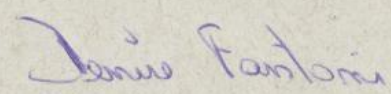

Denise Tabacchi Fantoni Presidente 
Nome: GOMES, Débora

Título: Avaliação eletrorretinográfica pré e pós-operatória em cães diabéticos submetidos à facoemulsificação

Dissertação apresentada ao Programa de Pós-Graduação em Clínica Cirúrgica Veterinária da Faculdade de Medicina Veterinária e Zootecnia da Universidade de São Paulo para obtenção do título de Mestre em Ciências.

Data:

Banca Examinadora

$\operatorname{Prof}(a) \cdot \operatorname{Dr}(a)$.

Instituição: Julgamento:

$\operatorname{Prof}(a) \cdot \operatorname{Dr}(a)$.

Instituição: Julgamento:

$\operatorname{Prof}(a) \cdot \operatorname{Dr}(a)$.

Instituição: Julgamento: 
À minha mãe Noemia Correia Gomes, por todo amor, dedicação e incentivo. Por sempre me incentivar a ir atrás dos meus objetivos e por me ensinar que não se deve comparar aos outros e sim ao melhor que podemos ser;

Ao meu irmão Aguinaldo Gomes Filho, que mesmo a 440 km de distância, sempre está presente;

Ao meu marido, Paulo José Moreira, pela compreensão, paciência e por estar incondicionalmente ao meu lado, principalmente nos momentos mais importantes da minha vida;

À minha cunhada, Aládia Roberta de Mello (Bel), pela amizade e por poder dividir momentos tristes e alegres;

As minhas sobrinhas Beatriz Mello Gomes e Thabata Mara Martins Leal Gomes, por me apoiarem em todos os meus projetos;

À minha sogra, Alda José Moreira (in memoriam) que com certeza continua lá de cima desejando meu sucesso; 
À minha orientadora Dra. Angélica de Mendonça Vaz Safatle, que dedica sua rotina profissional exclusivamente à Oftalmologia Veterinária. Agradeço por aceitar orientar este trabalho, seus ensinamentos, incentivos, troca de experiências e pelo exemplo de profissionalismo. 


\section{Agradecimentos}

À Deus, por iluminar meu destino e por me conceder a oportunidade de todo esse aprendizado;

Aos funcionários da Clínica Veterinária Vetmasters, Daniela Vieira, Deriana Pereira dos Santos (Deri), Luana Bispo e Militão Avelino dos Santos (Mili) pelo carinho, atenção e por estarem sempre dispostos a me ajudar;

À Profa. Dra. Aline Adriana Bolzan, um exemplo de profissionalismo e dedicação a esta profissão, gostaria de deixar um profundo agradecimento pelos conhecimentos transmitidos, pelo empenho, disponibilidade, carinho e atenção oferecidos nestes últimos meses;

Ao Prof. Paulo Sergio de Moraes Barros, por inicialmente me aceitar como orientada, por me conceder a oportunidade de todo o aprendizado que muito contribuíu para o meu progresso acadêmico;

À Carolina Barion, Natália Marcondes de Freitas Spinola, Paula Finkensieper Pacheco, pela amizade, apoio e pelas inúmeras vezes que nos auxílio na sedação dos animais deste projeto;

À Dra. Denise A. Otsuki, pelas sugestões, criticas construtivas e auxílio com a parte estatística deste trabalho;

Aos amigos Sthefânia Y. Mucilli e Antonio Luis dos Santos Junior por fazerem com que as algumas dificuldades parecessem menores do que realmente eram;

À Ana Rodrigues Eyherabide e Flávio Trigueiros Lins Britzky Roncati pela amizade e apoio na fase final deste projeto;

Obrigada Ana Carolina Almeida de Góes e Michelle Barboza Pereira Braga Sá por serem aquelas amigas;

Ao amigo Eduardo Perlmman, pelo carinho e confiança; 
Às médicas veterinárias, Andréa Cerqueira Andrade, Bruna Maria P. Coelho e Denise Maria Nunes Simões, pela amizade e auxílio com o acompanhamento clínico dos pacientes do projeto;

À amiga Adriana Cabral Lustoza, pela amizade e por me ensinar a sempre ver o lado bom de tudo;

À Jeanne Beluci Carletto por ser a amiga de todas as horas;

Ao Josenilson Martins Pereira, pelo auxílio técnico com o registro de alguns exames;

À funcionária da Biblioteca Virginie Buff D’Apice da FMVZ/USP, Elza Faquim, pela simpatia e auxílio na revisão deste trabalho;

Aos amigos, colegas e companheiros agradeço o carinho, a presença constante, e a troca de experiências;

À Universidade de São Paulo e a todos os voluntários desta pesquisa, sem a colaboração dos quais não seria possível estar aqui. A todos eles, o meu: Muito Obrigada!

Agradeço especialmente às minhas cachorrinhas, Brenda, Cindy e Pietra, sempre companheiras, por tornarem o meu esforço mais significativo a cada minuto e Fiorella, por tornar meus dias mais alegres e agitados. 
Apoio Financeiro

Projeto Fapesp 2009/07349-3

Bolsa Fapesp 2010/15694-0

Bolsa de Mestrado Capes 
“Embora ninguém possa voltar atrás e fazer um novo começo, qualquer um pode começar agora e fazer um novo fim.

\author{
Na vida, não vale tanto o \\ que temos, nem tanto importa \\ o que somos. \\ Vale o que realizamos com aquilo que \\ possuímos e, acima de tudo, \\ importa o que fazemos de nós!
}

Agradeço todas as dificuldades que enfrentei; não fosse por elas, eu não teria saído do lugar. As facilidades nos impedem de caminhar. Mesmo as críticas nos auxiliam muito."

\title{
Chico Xavier
}




\section{RESUMO}

GOMES, D. Avaliação eletrorretinográfica pré e pós-operatória em cães diabéticos submetidos à facoemulsificação. [Electroretinografic evaluation before and after phacoemulsification in diabetic dogs]. 2013. 129 p. Dissertação (Mestrado em Ciências) - Faculdade de Medicina Veterinária e Zootecnia, Universidade de São Paulo, São Paulo, 2013.

Diabete Melito (DM) é uma endocrinopatia frequentemente diagnosticada na clínica de pequenos animais e desenvolve-se pela deficiência relativa ou absoluta de insulina, sendo caracterizada pela hiperglicemia crônica. Complicações associadas ao DM são frequentes, dentre elas podemos citar catarata e retinopatia. A catarata, que é a oftalmopatia mais frequente nos cães, impossibilita à fundoscopia e nestes casos a avaliação da função retiniana pode ser feita com o auxílio do eletrorretinograma de campo total. O objetivo deste estudo foi avaliar a progressão da retinopatia diabética por meio de eletrorretinograma (ERG) de campo total pré e pós-operatória (180 dias) em cães portadores de catarata madura e hipermadura submetidos à facoemulsificação. Vinte e quatro cães (Grupo Diabético $(D M)=12$ cães; Grupo Não Diabético (NDM) = 12 cães) de raças diversas foram avaliados. Previamente ao ERG, todos os cães foram submetidos ao exame oftalmológico completo e ultrassom ocular. Todos os cães foram sedados seguindo o mesmo protocolo. ERG de campo total foi realizado com sistema eletrodiagnóstico Veris 2000 e cúpula de estimulação (Ganzfeld), segundo o protocolo da ISCEV contendo 5 respostas. Para obtenção dos registros utilizou-se eletrodo bipolar Burian Allen. Avaliou-se a amplitude pico a pico das 5 respostas e o tempo de culminação da onda- $b$ na resposta de bastonetes, máxima resposta, cones e flicker para cada registro em condições escotópicas e fotópicas. As respostas obtidas em cada olho no momento basal e após 6 meses foram comparadas por meio do teste de Wilcoxon. O teste de Mann-Whitney foi utilizado para comparação de respostas dos olhos operados (OP) com os olhos contralaterais (OC), assim como para comparação entre os grupos DM e NDM. O efeito da cirurgia e do tempo de DM foi ainda avaliado por meio do cálculo das diferenças entre as respostas no momento pré e pós 6 meses de cada olho (delta OP e delta OC). Observou-se diferenças entre $\mathrm{OP}$ e $\mathrm{OC}$, no momento pré, nas respostas dos bastonetes e da máxima resposta (amplitude e tempo de culminação onda-b). No momento pós, foram 
observados diferenças entre OP e OC no tempo de culminação dos bastonetes e flicker, e nas amplitudes do potencial oscilatório, cones e flicker. No grupo NDM, não foram observados diferenças entre os momentos pré e pós assim como entre OP e OC. Quando comparadas as respostas dos grupos DM e NDM, observou-se valores significativamente maiores no grupo DM, no tempo de culminação da onda- $b$ na máxima resposta do OP no momento pós, no tempo de culminação da onda- $b$ na máxima resposta $\mathrm{OC}$ no momento pós e no tempo de culminação da onda- $b$ da resposta de cones no momento pré cirurgia. Não foram observados diferenças entre delta OP e delta OC dentro de cada grupo e entre os grupos. Todos os pacientes que participaram do estudo recuperaram a visão após a cirurgia, sugerindo que a inflamação pós cirúrgica foi controlada com a medicação prescrita nos 2 grupos estudados. Conclui-se que a facoemulsificação representa mínimo impacto na evolução da retinopatia diabética em cães. A remoção cirúrgica da catarata não deve ser contraindicada nesta espécie, independentemente se o animal é ou não portador de DM, por resultar em melhoria da visão.

Palavras-chave: Cão. Catarata. Diabete melito. Eletrorretinograma. Retinopatia diabética. 
GOMES, D. Electroretinografic evaluation before and after phacoemulsification in diabetic dogs. [Avaliação eletrorretinográfica pré e pós-operatória em cães diabéticos submetidos à facoemulsificação]. 2013. 129 p. Dissertação (Mestrado em clínica cirúrgica) - Faculdade de Medicina Veterinária e Zootecnia, Universidade de São Paulo, São Paulo, 2013.

Diabetes mellitus (DM) is a common endocrinopathy in the small animals practice and it develops as a relative or absolute insulin deficiency characterized by a chronic hyperglycemia. There are frequent complications, such as cataracts, retinopathy, resulting in visual impairment. Cataracts are dog's most frequent ophthalmic affection and, since it prevents fundoscopic examination, full-field electroretinography is used for retinal functional evaluation. Therefore, to provide a better understanding of diabetic retinopathy (DR) progression in dogs with mature and hypermature cataracts undergoing phacoemulsification surgery, this study aims to analyze the full-field electroretinogram prior and 180 days post cataracts removal. Twenty four dogs (diabetic group $(\mathrm{DM})=12$ dogs and non-diabetic group $(\mathrm{NDM})=12$ dogs), from different breeds were evaluated. Before the ERG, all animals were submitted to a complete ophthalmic examination and ocular ultrasonography. All dogs were sedated following the same anesthetic protocol. The full-field ERG was recorded using 2000 VERIS system and a dome stimulator (ganzfeld) according to ISCEV five response standard. The recordings were obtained using bipolar Burian Allen electrodes. Peak to peak amplitude five response and b-wave culmination time in rod responses, maximum response, cone and flicker were evaluated in scotopic and photopic conditions. The responses obtained in each eye at baseline and after 6 months were compared using the Wilcoxon test. The Mann-Whitney test was used to compare the responses of the operated eyes (OP) and the contralateral eyes (OC) as well as for comparison between groups DM and NDMAs. The effect of surgery and duration of DM was assessed by calculating the differences between the responses prior and six months after surgery, of each eye (delta delta OP and OC). There were differences between $\mathrm{OP}$ and $\mathrm{OC}$, in the baseline values, in rod responses and maximum response (amplitude values and b-wave implicit time). After phacoemulsification, differences were observed between OP and OC in b-wave implicit time of rods and 
flicker, and the amplitudes of the oscillatory potentials, cone and flicker. In the NDM group, no differences were observed between pre and post evaluations between OP and OC. Comparing the responses of DM and NDM groups, there were significantly higher values in the DM group, in b-wave implicit time and in maximum response of OP after caratact removal, and also, of the b-wave implicit time in the maximum response in $\mathrm{OC}$ after surgery and, finally, in the b-wave implicit time of cone response prior to the surgery. No differences were observed between delta OP and delta OC within each group and between groups. All patients recovered vision after surgery, suggesting that post-surgery inflammation was controlled by the prescribed medication in both groups. The phacoemulsification surgery did not appear to have a great impact on diabetic retinopathy evolution in dogs. Cataract surgery should not be contraindicated in this species, regardless of the presence of DM, as it can result in sight improvement.

Keywords: Dog. Cataract. Diabetes mellitus. Electroretinogram. Diabetic retinopathy. 


\section{LISTA DE FIGURAS}

Figura 1 - Estruturas do bulbo ocular

Figura 2 - Representação esquemática das estruturas observadas à oftalmoscopia no fundo do cão.

Figura 3 - Corte histológico da retina de cão corado com hematoxilina e eosina onde se observa as dez camadas da retina.

Figura 4 - Representação esquemática da via visual 36

Figura 5 - Representação esquemática da fisiologia do fundo tapetal e não-tapetal

Figura 6 - Esquema representativo da mensuração da amplitude das ondas-a e tempo de culminação da onda- $b$ no eletrorretinograma de campo total.

Figura 7 - Eletrorretinograma de campo total, utilizando Eletrorretinógrafo Veris 2000, realizado em cão da raça Poodle, fêmea, com 9 anos de idade portadora de diabete melito pré cirurgia de catarata

Figura 8 - Eletrorretinograma de campo total, utilizando Eletrorretinógrafo Veris 2000, realizado em cão da raça Poodle, fêmea, com 9 anos de idade portadora de diabete melito 6 meses pós facoemulsificação........................................................................ 68

Figura 9 - Eletrodos bipolares Burian Allen de quatro tamanhos (neonato, pediátrico, infantil e adulto) e eletro-terra tipo ear-clip 


\section{LISTA DE TABELAS}

Tabela 1 - Duração do DM, valores de glicemia e frutosamina dos cães diabéticos durante o ERG.

Tabela 2 - Valores de glicemia dos cães não diabéticos durante o ERG

Tabela 3 - Valores obtidos do eletrorretinograma de campo total dos cães diabéticos

Tabela 4 - Tempo de US gerado durante a facoemulsificação e valores mínimos, máximos, médias e desvio padrão dos resultados obtidos no ERG de campo total do grupo DM

Tabela 5 - Valores obtidos do eletrorretinograma de campo total dos cães não diabéticos.

Tabela 6 - Tempo de US gerado durante a facoemulsificação e valores mínimos, máximos, médias e desvio padrão dos resultados obtidos no ERG de campo total do grupo NDM. 


\section{LISTA DE QUADROS}

Quadro 1 - Análise estatística, utilizando o teste Mann-Whitney, comparando os resultados obtidos dos animais operados com o aparelho Universal II e Laureate nos 2 grupos estudados

Quadro 2 - Análise estatística, utilizando o teste de Wilcoxon dos resultados obtidos no ERG pré OP versus pré OC e pós OP versus pós $\mathrm{OC}$ dos 24 animais avaliados neste estudo em cada grupo

Quadro 3 - Análise estatística realizada pelos métodos Wilcoxon e Mann-Whitney dos resultados obtidos no eletrorretinograma de campo total pré e pós facoemulsificação dos 24 animais avaliados neste estudo em cada grupo e entre os grupos. 


\section{LISTA DE GRÁFICOS}

Gráfico 1 - Representação gráfica em box plot das médias das amplitudes $(\mu \mathrm{V})$ e tempo de culminação da onda- $b$ (ms) na resposta de bastonete e desvio padrão nos 2 grupos (DM e NDM).

Gráfico 2 - Representação gráfica em box plot das médias das amplitudes $(\mu \mathrm{V})$ e tempo de culminação da onda-b (ms) na máxima resposta e desvio padrão nos 2 grupos (DM e NDM).

Gráfico 3 - Representação gráfica em box plot das médias da relação das ondas $b / a(\mu \mathrm{V})$ e desvio padrão nos 2 grupos (DM e NDM).

Gráfico 4-Representação gráfica em box plot das médias do delta das amplitudes $(\mu \mathrm{V})$ dos potenciais oscilatórios e desvio padrão nos 2 grupos (DM e NDM).

Gráfico 5 - Representação gráfica em box plot das médias das amplitudes $(\mu \mathrm{V})$ e tempo de culminação da onda- $b(\mathrm{~ms})$ nas respostas de cones e desvio padrão nos 2 grupos (DM e NDM).

Gráfico 6 - Representação gráfica em box plot das médias das amplitudes $(\mu \mathrm{V})$ e tempo de culminação da onda- $b(\mathrm{~ms})$ na resposta de flicker a 30 $\mathrm{Hz}$ e desvio padrão nos 2 grupos (DM e NDM) 
ABREVIATURAS E SIGLAS

$\begin{array}{ll}\text { AINE } & \text { anti-inflamatório não esteroidal } \\ \text { AMIR } & \text { anomalias microcirculatórias intraretinianas } \\ \text { bFGF } & \text { fator básico crescimento de fibroblasto } \\ \text { BHA } & \text { barreira hemato-aquosa } \\ \text { BHR } & \text { barreira hematorretiniana } \\ \mathrm{cd} / \mathrm{m}^{2} & \text { candelas por metro quadrado } \\ \mathrm{cm} & \text { centímetros }\end{array}$

CNCE cegueira noturna congênita estacionária

DM Diabete Melito

DMID Diabete Melito Insulino-dependente

DMNID Diabete Melito Não Insulino-dependente

DDI Diabete por deficiência primária de insulina

DRI Diabete por resistência primária à insulina

DP desvio padrão

ed edição

EPR epitélio pigmentado da retina

ERG eletrorretinograma

ETDRS Early Treatment Diabetic Retinopathy Study

et al. e colaboradores

$\mathrm{Hz} \quad$ hertz

IM intramuscular

ISCEV Sociedade Internacional de Eletrofisiologia Visual Clínica

$\mathrm{Kg} \quad$ Kilograma 


\begin{tabular}{ll} 
LED & light-emitting diode \\
LIOC & Laboratório de Investigação em Oftalmologia Comparada \\
Máx & máxima \\
Min & mínima \\
mg & miligrama \\
mg/dl & miligramas por decilitros \\
mg/kg & miligramas por kilograma \\
mm & milímetro \\
ms & milisegundos \\
nm & nanômetro \\
NO & nervo óptico \\
OC & olho controle \\
OP & olho operado \\
P & nível de significância \\
PERG & eletrorretinograma por padrão reverso \\
PIO & pressão intraocular \\
PKC & proteína quinase C \\
POs & potenciais oscilatórios \\
RD & retinopatia diabética \\
RDNP & retinopatia diabética não proliferativa \\
RDP & retinopatia diabética proliferativa \\
RDPP & retinopatia diabética pré-proliferativa \\
sf & segundo \\
\hline
\end{tabular}




$\begin{array}{ll}\text { SNC } & \text { sistema nervoso central } \\ \text { SRD } & \text { Sem Raça Definida } \\ \text { Tcb } & \text { tempo de culminação da onda- } b \\ \text { URE } & \text { uveíte recorrente equina } \\ \text { US } & \text { ultrassom } \\ \mu V & \text { microvolts } \\ \mu & \text { micro } \\ V & \text { volts } \\ \text { VEGF } & \text { fator de crescimento vascular endotelial } \\ \beta & \text { beta } \\ \% & \text { por cento } \\ : & \text { relação / proporção } \\ = & \text { igual }\end{array}$




\section{SUMÁRIO}

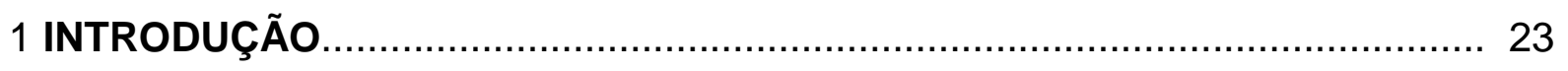

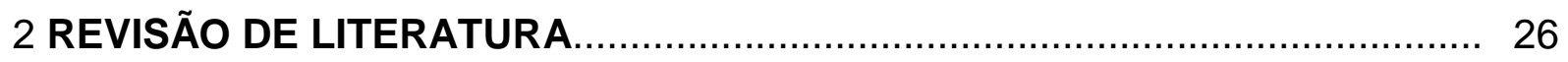

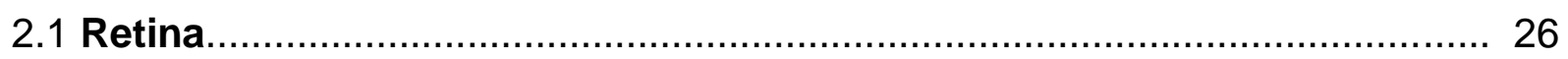

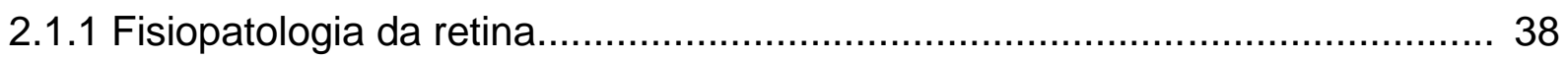

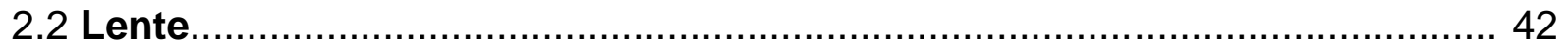

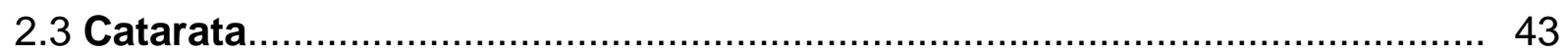

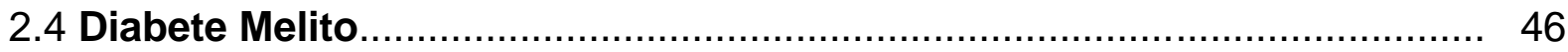

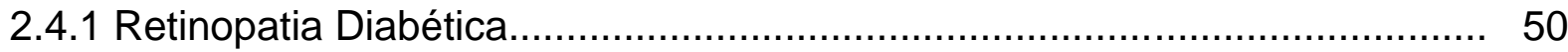

2.4.2 Retinopatia diabética no cão........................................................ 54

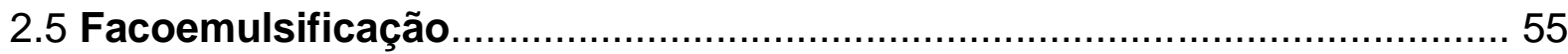

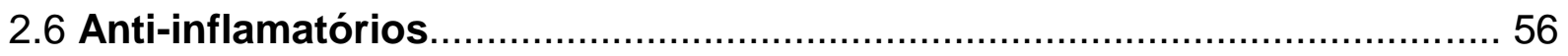

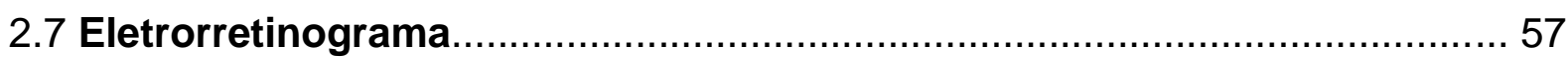

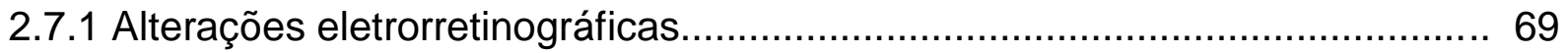

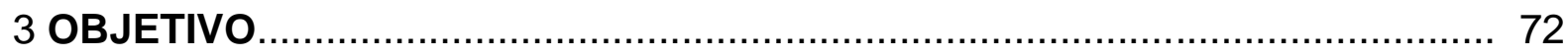

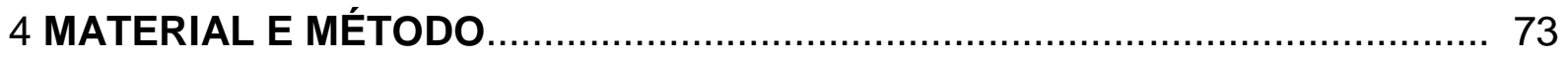

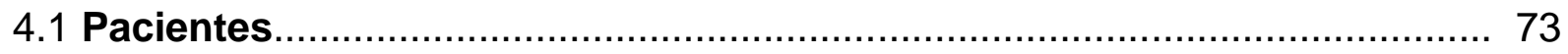

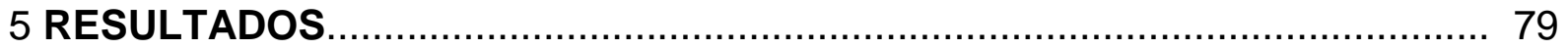

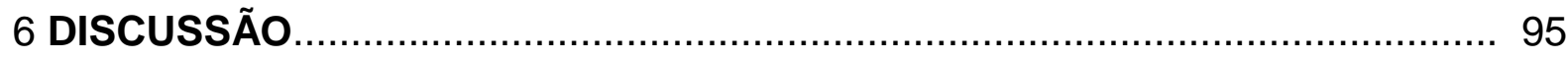

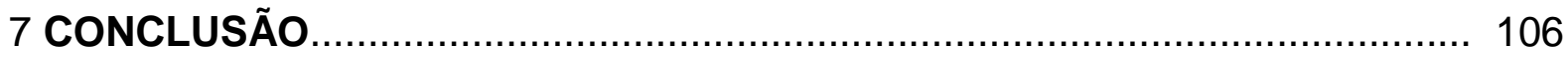

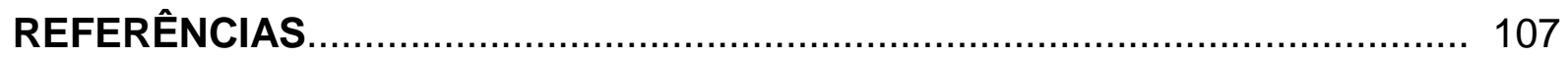

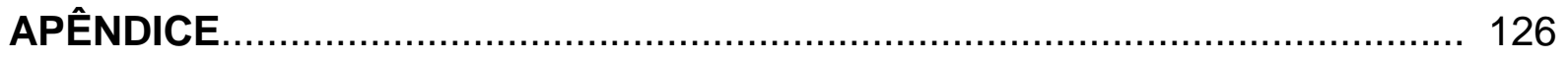




\section{INTRODUÇÃO}

Diabete Melito (DM) é uma doença hormonal complexa, multifatorial, caracterizada pela incapacidade ou ineficiência das ilhotas pancreáticas em secretarem insulina, causando um estado de hiperglicemia (>120 mg/dl). Esta incapacidade absoluta ou relativa de insulina é diagnosticada em várias espécies, inclusive nos cães. Esta deficiência de insulina resulta num metabolismo anormal ou inadequado da glicose, pois ela é responsável pela entrada da glicose nas células onde é armazenada ou transformada em energia para ser utilizada pelo organismo (LORENZ, 1996; BEAM et al., 1999; NELSON, 2001a, b; RAND et al., 2004).

Segundo Mazzaferro et al. (2003) e Blois et al. (2011) diabete melito é uma doença endócrina frequente na clínica de pequenos animais e acomete principalmente animais de meia idade a senis. A maior incidência da doença é relatada em fêmeas com mais de sete anos de idade. No cão a incidência do DM varia entre 1 em 100 até 1 em 500 (NELSON, 2010).

A classificação do diabete melito no cão não é um critério aceito mundialmente. O DM pode ser classificado em diabete melito insulino-dependente (DMID) ou não insulino-dependente (DMNID), no entanto, todos os cães necessitam da terapia com insulina. Na maioria dos cães diabéticos a causa da deficiência de insulina não é estabelecida, porém acredita-se que seja resultado de danos às células $\beta$ das llhotas de Langerhans associadas com pancreatite e/ou destruição imunomediada destas células (CATCHPOLE et al., 2008).

Atualmente classifica-se 0 diabete no cão com base na causa da hiperglicemia, ou seja, em diabete por deficiência primária de insulina (DDI) ou diabete por resistência primária à insulina (DRI). Diabete por deficiência primária à insulina ocorre quando há falha na produção de insulina à partir do pâncreas (deficiência absoluta de insulina), ao passo que por resistência primária à insulina ocorre quando a função de insulina nos tecidos é inadequada (deficiência relativa de insulina), que pode estar associado ao antagonismo à ação da insulina por outros hormônios. A hiperglicemia prolongada no cão pode induzir o diabete por resistência primária à insulina (CATCHPOLE et al., 2008). 
No homem a classificação do diabete baseia-se nos mecanismos fisiopatológicos e nas alterações patogênicas que afetam as células $\beta$ e pode ser classificado como tipo 1 e tipo 2. O diabete melito tipo 1 caracteriza-se pela destruição ou perda de células $\beta$, no qual a hiperglicemia é decorrente da hipoinsulinemia e o diabete melito tipo 2 caracteriza-se pela resistência insulínica ou produção inadequada (MARASCHIN et al., 2010).

O diagnóstico pode ser feito por meio da dosagem da glicose sanguínea, que nestes animais apresenta-se aumentada. Os principais sinais clínicos da doença são poliúria, polidipsia, polifagia e perda de peso (NELSON, 2004).

O DM pode provocar várias oftalmopatias, sendo a retinopatia diabética e catarata as mais frequentes. Catarata é muito frequente no cão diabético, resultando em cegueira, diferentemente do homem, cuja a principal causa de cegueira é a retinopatia diabética (PARK et al., 2009). Retinopatia diabética (RD) é uma microangiopatia que afeta primariamente as arteríolas pré-capilares, capilares, vênulas pós-capilares e vasos de maior calibre, sendo mais frequente na do tipo I (40\%) do que na do tipo II (20\%) (LANDRY et al., 2004; BOSCO et al., 2005).

Pacientes com catarata, o exame oftalmoscópico para avaliar alterações retinianas secundárias ao $\mathrm{DM}$, não pode ser realizado sendo necessário utilizar-se de outros meios de diagnóstico como o Eletrorretinograma de Campo Total (ERG). Este exame é objetivo, não invasivo, capaz de avaliar a função retiniana, detectando precocemente lesões nas suas camadas mais externas e precedendo alterações na fundoscopia (KOMAROMY et al., 1998a, b; VILELA et al., 1998; TZEKOV; ARDEN, 1999; BOSCO et al., 2005; CHEN et al., 2008; SAFATLE et al., 2010b, d).

$\mathrm{O}$ tratamento para a catarata é cirúrgico. Antes da indicação cirúrgica é feita uma triagem para a seleção dos pacientes com exame oftalmológico minucioso, ultrassom ocular e eletrorretinograma de campo total. A seleção objetiva escolher pacientes com exames compatíveis para o restabelecimento da visão. A técnica indicada para a remoção da catarata é a facoemulsificação por apresentar menores complicações pós cirúrgicas (KLEIN et al., 2011; LIM et al., 2011). No entanto, estudos em humanos sugerem que a facoemulsificação pode acelerar a retinopatia diabética, interferindo na visão (HENRICSSON et al., 1996; 1996; MITRA et al., 2000; HONG et al., 2009).

$\mathrm{Na}$ medicina veterinária não foram realizados estudos para observar se a intervenção cirúrgica agrava a retinopatia diabética. Este estudo buscou, por meio 
do eletrorretinograma de campo total, verificar possíveis alterações eletrorretinográficas que pudessem ocorrer após a facoemulsificação decorrentes da retinopatia diabética. 


\section{REVISÃO DE LITERATURA}

A revisão de literatura foi dividida em alguns tópicos relevantes descritos a seguir:

\subsection{Retina}

Durante o desenvolvimento embriológico, o tecido retiniano, originado a partir da invaginação da vesícula óptica primária, é constituído por uma camada externa, o epitélio pigmentado da retina e por uma camada interna, a complexa neurorretina (WALDE et al., 1998).

Macroscopicamente, a retina assemelha-se a uma membrana ligeiramente opaca e vascularizada que se encontra suportada por pressão do humor vítreo contra o epitélio pigmentado da retina (EPR), coroide e esclera (Figura 1) (WILCOCK, 2007).

Figura 1 - Estruturas do bulbo ocular

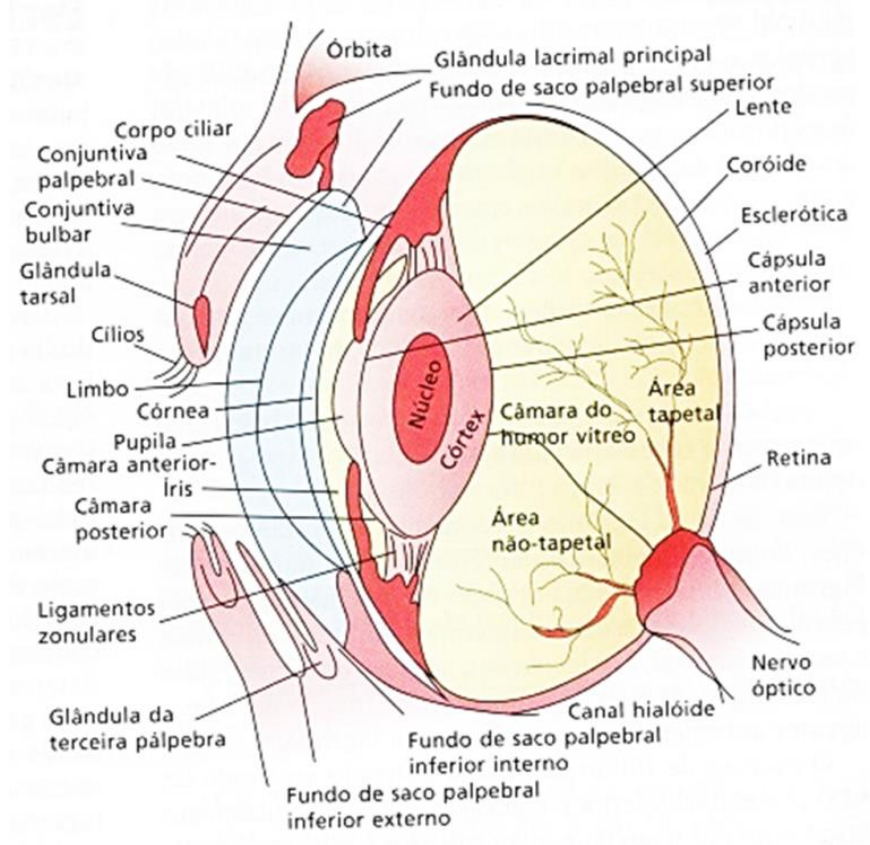

Fonte: LAUS (2009) 
A retina corresponde à túnica nervosa do bulbo ocular e é uma camada fotossensível que limita o segmento posterior do olho. Sua superfície interna está em contato com o humor vítreo e a externa com a coroide. Está localizada próximo a coriocapilar e diante da membrana de Bruch. Seu limite anterior, próximo ao corpo ciliar e aos segmentos externos dos fotorreceptores, é conhecido como ora ciliares retinae e localiza-se atrás do limbo, à distância de $8 \mathrm{~mm}$ da parte dorsal e $4 \mathrm{~mm}$ da parte ventral. A neurorretina é mais espessa centralmente e mais delgada próximo à ora ciliares retinae (BEDFORD, 2007).

A retina central se estende do canto nasal até o disco óptico. Nessa região, as células ganglionares possuem mais de uma camada de núcleos e é o local onde se encontram os cones. Os cones representam $5 \%$ dos fotorreceptores dos cães. $\mathrm{Na}$ retina periférica predominam os bastonetes. Nessa região, os segmentos dos cones são mais finos do que na retina central (WALDE et al., 1998; HONSHO et al., 2004).

O epitélio pigmentado da retina (EPR) é uma camada única de células que se estende da margem do nervo óptico, posteriormente, até a ora serrata, anteriormente; ponto no qual se funde com a neurorretina (WALDE et al., 1998). O EPR está aderido à membrana coriocapilar pela membrana de Bruch e a neurorretina que advém da camada interna, composta por nove camadas. O epitélio pigmentado da retina funciona como um condutor nutricional entre a vasculatura coroidal e as estruturas mais externas da neurorretina, além de possibilitar fagocitose dos segmentos externos dos fotorreceptores e manutenção da posição da retina (KOMAROMY et al., 1998a).

As células em geral contém melanina, exceto onde sobrepõe-se ao tecido tapetal e é transparente para permitir o reflexo da luz no processo de fototransdução. A superfície basal do epitélio pigmentado se deposita sobre a membrana basal de Bruch e a superfície apical é projetada para dentro dos microvilos, os quais circundam e se depositam entre os segmentos dos fotorreceptores externos dentro da camada celular visual (BEDFORD, 2007).

As camadas da neurorretina são identificadas histologicamente como: camada de fotorreceptores, membrana limitante externa, camada nuclear externa, camada plexiforme externa, camada nuclear interna, camada plexiforme interna, camada de células ganglionares, camada de fibras nervosas e membrana limitante interna (WALDE et al., 1998). 
A camada de fotorreceptores apresenta dois tipos de células: cones e bastonetes. Os cones trabalham em condições fotópicas e os bastonetes em condições escotópicas (DANTAS, 1995).

À oftalmoscopia, o fundo ocular (Figura 2) é composto pela cabeça do nervo óptico (NO), pela retina e pelas áreas tapetal, não-tapetal, vênulas e arteríolas. O fundo tapetal fica na parte dorsal da cabeça do nervo óptico, e neste ponto, a retina não pigmentada reveste a camada celular intracoroideana refletiva do tapetum. $\mathrm{O}$ fundo não-tapetal fica na parte ventral da cabeça do nervo óptico, e neste local, o epitélio pigmentado da retina geralmente apresenta pigmentação. A quantidade de tecido tapetal e a densidade do pigmento retiniano são variáveis (BEDFORD, 2007).

Figura 2 - Representação esquemática das estruturas observadas à oftalmoscopia no fundo do cão

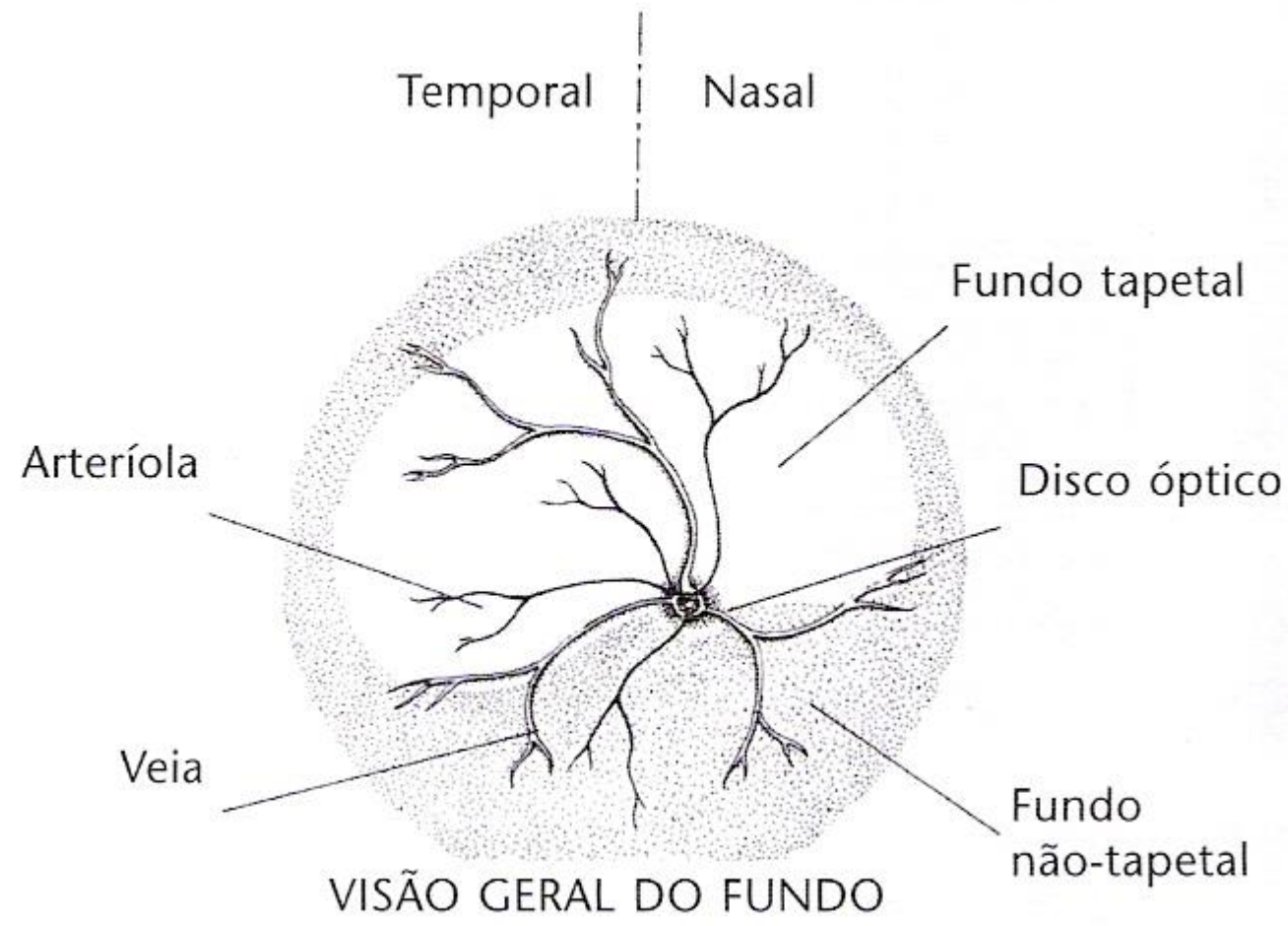

Fonte: SLATTER (2005)

A camada neuroblástica da retina é contínua ao pedículo óptico. Os axônios originam-se das células ganglionares e se estendem em direção ao pedículo óptico, formando o que mais tarde se tornará o nervo óptico. O nervo óptico (II par de nervo craniano) é um nervo sensorial que contém axônios das células ganglionares da 
retina e fibras vegetativas, formando uma parte do trajeto visual (BROOKS et al., 1999).

A cabeça do nervo óptico (NO) é mielinizada e pode possuir diferentes formas: triangular a circular, pode ainda ser identificada à oftalmoscopia como um disco claro, de contornos bem definidos e cuja coloração pode ser branca, vermelhopálido, em decorrência de inúmeros capilares pequenos, ou cinza-azulado. O grau de mielinização altera o tamanho do disco óptico e existe algum grau de variação do tamanho do NO entre indivíduos e entre raças, mas não se verifica uma relação estreita entre o tamanho do NO e o tamanho do cão (GELATT, 2007).

A posição é constante, mas pode parecer variável de acordo com o desenvolvimento tapetal. O tapetum pode terminar brevemente no disco ou o cercar, podendo ter margem estreita de fundo não-tapetal. Halos hiperreflexivos ao redor da margem do disco, o cone peripapilar, são comuns em cães idosos e em cães mais jovens (BEDFORD, 2007).

Em alguns animais, um padrão em forma de rede pode ser visto no disco, devido a fenestrações na esclera, na porção da lâmina crivosa, através da qual passam as fibras do nervo óptico. Acima da cabeça do nervo óptico e temporal a ele, encontra-se a área de melhor acuidade visual, que é a área central da retina (SLATTER, 2005).

O nervo óptico (NO), formado pelas células ganglionares da retina, faz a comunicação entre esta e o cérebro. Seu trajeto sinuoso entre o pólo óptico e o forame óptico faz com que esse nervo seja maior que a distância real entre estes dois pontos. Esta conformação é necessária para garantir a movimentação normal do olho e, ao mesmo tempo, proteger o nervo de possíveis danos. De acordo com sua localização, o nervo óptico é dividido em quatro regiões: intraocular, intraorbitário, intracanalicular e intracraniano (BROOKS et al., 1999).

O suporte metabólico para a retina interna vem da rede vascular arteríola/capilares e pós-capilares, que atravessam a camada ganglionar e se estendem até a camada plexiforme externa, enquanto as camadas mais externas são supridas por vasos da coroide (FORRESTER et al., 2002; SAMUELSON, 2007). A retina também possui colunas de sustentação, compostas pelas células gliais (ou fibras de Müller), que sustentam o metabolismo dos neurônios da retina (FORRESTER et al., 2002; SAMUELSON, 2007). 
O suporte para a retina externa é dado por difusão por meio dos vasos da coroide que possuem o endotélio fenestrado e estão adjacentes ao epitélio pigmentado da retina. Os vasos da retina de humanos e animais são caracterizados por células endoteliais contínuas, não fenestradas, com junções intercelulares impermeáveis, que se apresentam para formar a barreira hematorretiniana (BHR). A interação entre as células endoteliais forma a barreira que permite ao tecido, assim como ao endotélio capilar e ao epitélio pigmentado da retina, criarem condições para um tecido com integridade funcional. A junção intercelular representa um pequeno poro com cerca de 9 a $11 \mathrm{~nm}$ (nanômetros) que é responsável pelas trocas transcapilares de água e outras moléculas hidrofílicas. São encontradas três tipos de junções intercelulares que fazem essa mediação no endotélio: as junções ou zonas de oclusão (tight junctions), as zonas de adesão e as junções gap. Esta barreira não permite a entrada de macromoléculas, fazendo da retina neural um tecido imunologicamente privilegiado e propiciando mecanismo para controlar fluxo de fluidos e metabólitos (FORRESTER et al., 2002; SAMUELSON, 2007). As barreiras hematorretinianas interna e externa impedem o transporte passivo dos elementos nutritivos pelos espaços intercelulares. Ruptura na barreira hematorretiniana durante degenerações retinianas expõe antígenos retinianos para o sistema imune (SECCHI et al., 1985; MILLICHAMP, 1990).

Os capilares retinianos são normalmente constituídos por células endoteliais, que os revestem, e células murais (pericitos) que se localizam na cápsula da membrana basal perivascular. Os pericitos são capazes de se contrair, regulando desta forma o calibre vascular e o fluxo da microcirculação retiniana (CORRÊA; EAGLE JR, 2005).

Entre as células endoteliais dos vasos da retina existem apenas zonas de oclusão entremeadas com desmossomos. No DM, encontramos com frequência ruptura destas junções, principalmente das junções de oclusão (ENGERMAN; KERN, 1995; BOSCO et al., 2005). A ruptura destas junções, a chamada quebra da BHR, indica a retinopatia diabética e pode acarretar complicações como, por exemplo, edema macular em humanos. Além disso, precede a neovascularização que pode levar à cegueira (BOSCO et al., 2005). Nos capilares retinianos dos pacientes com DM, com a microscopia eletrônica é possível observar: inúmeros capilares com as junções interendoteliais abertas; aumento na vacuolização citoplasmática (aumento do transporte vesicular); pericitos com alterações 
degenerativas e espessamento da membrana (lâmina) basal do capilar. Este espessamento altera a função celular e/ou a difusão de oxigênio e reduz o contato entre os pericitos e a célula endotelial, contribuindo para as alterações vasculares dos diabéticos (ENGERMAN; KERN, 1995; BOSCO et al., 2005; HONG et al., 2009). Em alguns casos é possível também observar nos vasos da retina um afilamento focal do citoplasma, formando fenestras. Tanto os capilares quanto as vênulas podem apresentar fenestras cujo diâmetro pode variar entre 50 e $60 \mathrm{~nm}$. As fenestras são normalmente fechadas por um fino diafragma que pode ser simples ou duplo. O tecido na região dos vasos fenestrados encontra-se em geral atrófico. Os vasos retinianos de indivíduos normais apresentam conexões intercelulares compactas e não contêm células endoteliais fenestradas (BOSCO et al., 2005).

A irrigação arterial do olho é fornecida pela artéria oftálmica externa, um ramo da artéria maxilar interna que deriva, por sua vez, da carótida externa. Comparativamente à situação verificada em humanos e primatas, a contribuição da carótida interna para a irrigação do olho do cão é pequena e resume-se à artéria oftálmica interna que entra no bulbo ocular através do canal óptico, junto com o nervo óptico. Nas espécies domésticas, onde se inclui o cão, a partir da artéria oftálmica externa ramificam-se numerosas pequenas artérias ciliares posteriores que penetram a esclera ao redor do disco óptico. Estas são as artérias que vão irrigar a coroide e a retina. A drenagem venosa é assegurada pelas veias e venulas da retina que correm desde a periferia em direção ao disco óptico, onde formam um círculo venoso que pode ser completo ou incompleto no cão (SLATTER, 2008).

As arteríolas retinianas (em torno de vinte) emergem de porções mais externas e da margem do disco, além disso, são consideravelmente menores do que as veias (KOSKINEN et al., 1985). Da anastomose das artérias oftálmicas partem as artérias ciliares medial, lateral e posterior longa, que vão emitir as artérias coriorretinianas, que correm sobre a superfície externa do disco óptico. As artérias coriorretinianas penetram na esclera próximo à cabeça do nervo óptico. Elas se dividem e se anastomosam entre si, formando o arco arterioso de Zinn-Haller (círculo arterioso do nervo óptico). Algumas das artérias do círculo arterioso do nervo óptico penetram no bulbo e suprem a retina e a coroide (WALDE et al., 1998). As arteríolas apresentam uma cor mais clara comparativamente às vênulas e podem ser mais tortuosas que estas. Em situações de atrofia hereditária da retina, as 
artérias são os primeiros vasos a sofrerem atrofia e redução de calibre (SLATTER, 2005).

As vênulas que emergem próximo à cabeça do nervo óptico e as veias coriorretinianas (antes denominadas veias ciliares posteriores) realizam a drenagem do sangue para o interior do plexo oftálmico. As veias penetram a lâmina crivosa com as fibras nervosas, mas logo deixam o nervo e adentram à órbita. No cão, essas vênulas formam o círculo venoso do nervo óptico, que pode ser completo ou incompleto (KOSKINEN et al., 1985). Há três vênulas retinianas principais: superior, ínfero-nasal e ínfero-temporal. Veias adicionais e variações são comuns. No fundo não-tapetal, os vasos retinianos exibem um brilho acinzentado ou um reflexo no centro dos vasos, que não é visto sobre o tapetum (WALDE et al., 1998).

A retina é o tecido neural com metabolismo extremamente ativo, com grande consumo de oxigênio e a sua vasculatura pode ser classificada como holangiótica, merangiótica, paurangiótica e anangiótica (FORRESTER et al., 2002; SAMUELSON, 2007). Em cães o padrão vascular é do tipo holangiótico, ou seja, as artérias retinianas são formadas a partir dessa rede e não a partir de uma artéria central da retina. Por este motivo, elas aparecem na superfície do disco óptico como arteríolas ciliares ou coroidais (WALDE et al., 1998).

As principais veias são de maior calibre e geralmente em número de três. Apresentam uma cor vermelha mais escura comparativamente às arteríolas. Nos cães as vênulas terminam muitas vezes num círculo venoso incompleto por cima do disco óptico, mas também podem serem encontradas cobertas parcialmente por tecido do disco óptico. À oftalmoscopia, é visível uma ramificação arboriforme de vasos que resulta da coalescência de várias vênulas com veias de maior calibre (GELATT, 2007).

$\mathrm{Na}$ região dorso-temporal ao disco óptico existe uma área central de contornos mal definidos e desprovida de vasos sanguíneos, mas rodeada por pequenas ramificações destes, onde a concentração de cones é superior comparativamente ao restante da retina (GELATT, 2007).

Os cães possuem tapetum lucidum que reflete uma parte de luz não absorvida pela retina. Em raças pequenas, o tapetum é frequentemente menor do que em raças de grande porte. A variedade de cores do tapetum é resultante de diferentes interações de luz com a estrutura física do mesmo. A coloração do tapetum pode variar desde o amarelo-ouro até o verde-azulado e marrom- 
alaranjado. Em cães jovens (sete a dez dias), logo após os olhos abrirem, o fundo é acinzentado, passando para lilás e azul claros sucessivamente até atingir a coloração da fase adulta, quando o cão tem cerca de quatro meses e meio de idade (OLLIVIER et al., 2004; SLATTER, 2005).

O tapetum tem aparência granular e suas granulações aumentam com a idade e com a distância do disco óptico. A junção entre as áreas tapetal e nãotapetal é irregular. O fundo não-tapetal é marrom-escuro devido ao pigmento no epitélio pigmentado da retina. A coloração varia de marrom-claro até aparência ligeiramente manchada. Em animais albinos, subalbinos e de coloração clara, o pigmento do fundo não-tapetal pode estar reduzido ou ausente, permitindo que os vasos maiores da coroide subposta sejam vistos (BEDFORD, 2007).

A primeira camada é formada pelo epitélio pigmentado da retina, sendo composta por uma camada de células poligonais derivadas embriologicamente da vesícula óptica e está localizada entre a coroide e a camada de fotorreceptores. As células contêm melanina, exceto na região tapetal, onde é transparente (Figura 3) (WALDE et al., 1998).

A segunda camada corresponde aos fotorreceptores: cones e bastonetes, que possuem pigmentos visuais (Figura 3) (SLATTER, 2005).

A terceira camada é a membrana limitante externa formada por barras terminais que unem as membranas celulares de cones, bastonetes e das células de Müller. As células de Müller se estendem da membrana limitante externa até a membrana limitante interna e são as maiores células da retina. Os núcleos localizam-se na camada nuclear interna (Figura 3) (WALDE et al., 1998).

A quarta camada corresponde à nuclear externa. Essa camada é composta por núcleos dos cones e bastonetes e fibras conectoras que unem a célula aos segmentos internos de fotorreceptores na membrana limitante externa (Figura 3) (BEDFORD, 2007).

A quinta camada, denominada plexiforme externa, é composta por extensões dos axônios de fotorreceptores, localizados no citoplasma das células de Müller (Figura 3) (BEDFORD, 2007).

A sexta camada é a nuclear interna e contém quatro tipos de núcleos (células bipolares, Müller, horizontais e amácrinas) (Figura 3) (WALDE et al., 1998). 
A sétima camada, denominada plexiforme interna, é composta por axônios de células bipolares, horizontais e amácrinas e dendritos de células ganglionares (Figura 3) (SLATTER, 2005).

A oitava camada é constituída pelas células ganglionares e contém os corpos celulares das células ganglionares e seus dendritos. Os dendritos fazem sinapse com os axônios de células bipolares na camada plexiforme interna, fonte de saída da retina (projeta axônios através do nervo óptico) (Figura 3) (SLATTER, 2005).

A nona camada é constituída pelos axônios das células ganglionares, que formam bandas de fibras nervosas (Figura 3) (WALDE et al., 1998).

A décima camada é composta pela membrana limitante interna - uma membrana basal, na qual as extremidades internas das células de Müller estão aderidas (Figura 3) (SLATTER, 2005; BEDFORD, 2007).

Figura 3 - Corte histológico da retina de cão corado com hematoxilina e eosina com aumento de 400

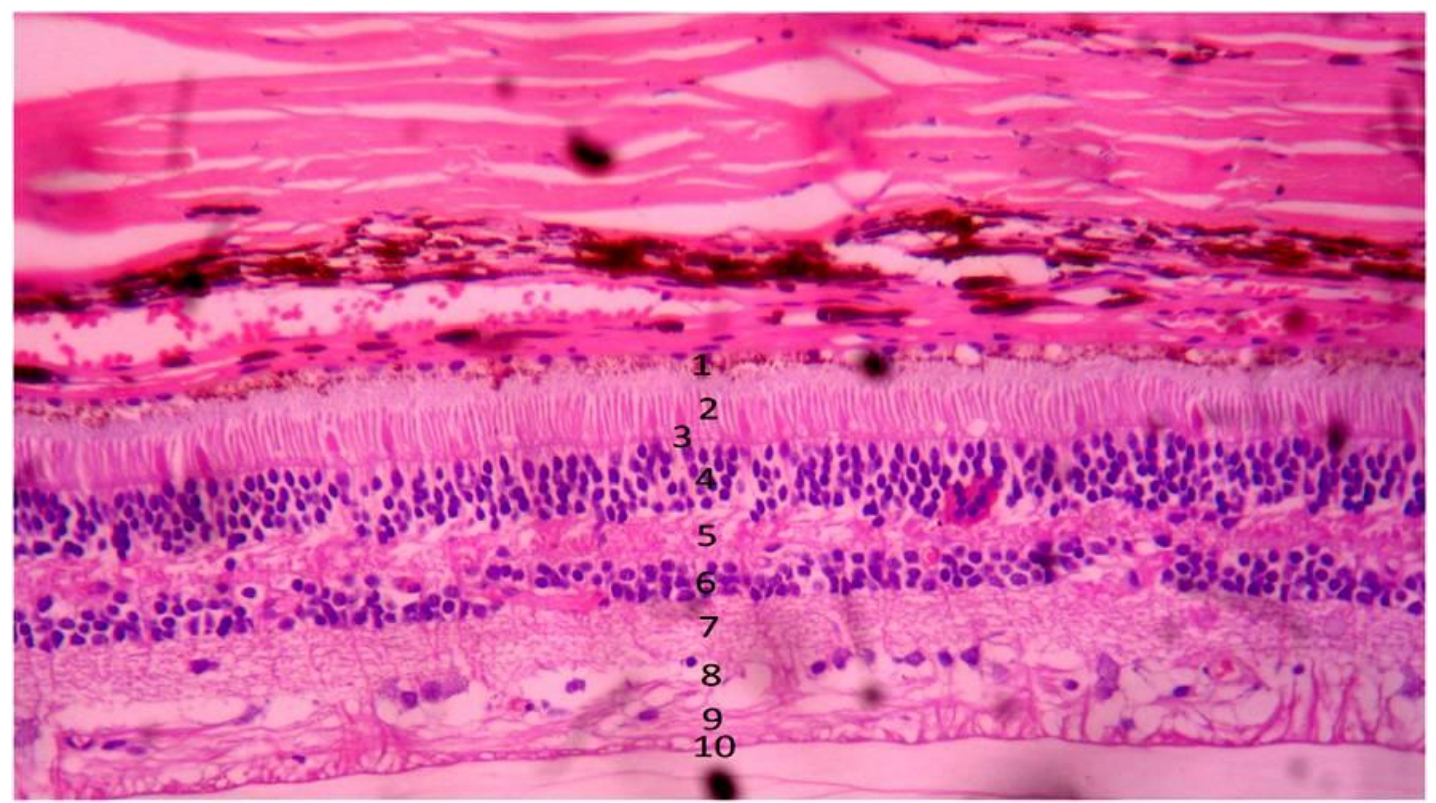

Fonte: cortesia EDUARDO PERLMANN (2013)

1 - epitélio pigmentado da retina; 2 - camada de fotorreceptores; 3 -membrana limitante externa; 4 - camada nuclear externa; 5 -plexiforme externa; 6 - nuclear interna; 7 - plexiforme interna; 8 - células ganglionares; 9 - axônios células ganglionares (fibras nervosas); 10 - membrana limitante interna 
A neurorretina é responsável por converter a luz em energia química e elétrica por meio de impulsos nervosos, à medida que atravessam o nervo óptico,de modo a tornar possível a visão (CHEN et al., 2006).

Após a fotorrecepção, o sinal é conduzido para as células bipolares (camada nuclear interna) que transmitem os sinais para a camada de células ganglionares, cujos axônios se agrupam na superfície interna da retina para formar o nervo óptico. A camada mais externa da retina é o epitélio pigmentado da retina, o qual está em íntimo contato com os segmentos externos dos fotorreceptores (FORRESTER et al., 2002; GELATT, 2003; CHAUDIEU; MOLON-NOBLOT, 2004; SLATTER, 2005).

Os feixes luminosos que incidem sobre a córnea são focalizados na retina, onde se forma uma imagem invertida. O processamento visual primário (Figura 4) é realizado nos fotorreceptores da retina, que transformam os estímulos luminosos em impulsos nervosos. Os fotorreceptores, quando excitados pela energia luminosa, estimulam as células nervosas adjacentes, gerando um impulso nervoso que se propaga pelo nervo óptico. Em seguida, estes impulsos são transmitidos para o quiasma óptico e para o trato óptico por meio de sinapses entre as células bipolares e as células ganglionares da retina, que formam o nervo óptico. Do quiasma óptico e do trato óptico, eles são transmitidos para o corpo geniculado lateral e para a área óptica no pólo occipital do SNC, onde são interpretados (percepção luminosa). Como um segmento do sistema nervoso, a função da retina é, dessa forma, capturar estímulos de luz, transformá-los em estímulos elétricos e conduzí-los ao córtex cerebral para serem interpretados. Este processo é conhecido como fototransdução (WALDE et al., 1998).

Os bastonetes agem em condições de pouca iluminação (visão escotópica) e são caracterizados pela definição visual pobre, nenhuma percepção de cor, extrema sensibilidade às alterações de intensidade luminosa e percepção de movimento. Localizam-se em número maior na retina periférica. Nos bastonetes existe uma substância sensível a luz, a rodopsina, produzida a partir da vitamina A (BEDFORD, 2007).

Os cones são responsáveis pela resolução de detalhes finos e pela percepção de cor, além disso, são rapidamente adaptados a estímulos de luz intensos, altamente repetidos e longos. Possuem ainda, baixa sensibilidade à pequenas variações da intensidade de luz, visão fotópica (SLATTER, 2005). 
Os cães possuem cones com dois tipos de fotopigmentos, cujos picos espectrais se encontram entre $429 \mathrm{~nm}$ e $555 \mathrm{~nm}$. Portanto, é possível concluir que tenham visão dicromática (SLATTER, 2005).

Figura 4 - Representação esquemática da via visual

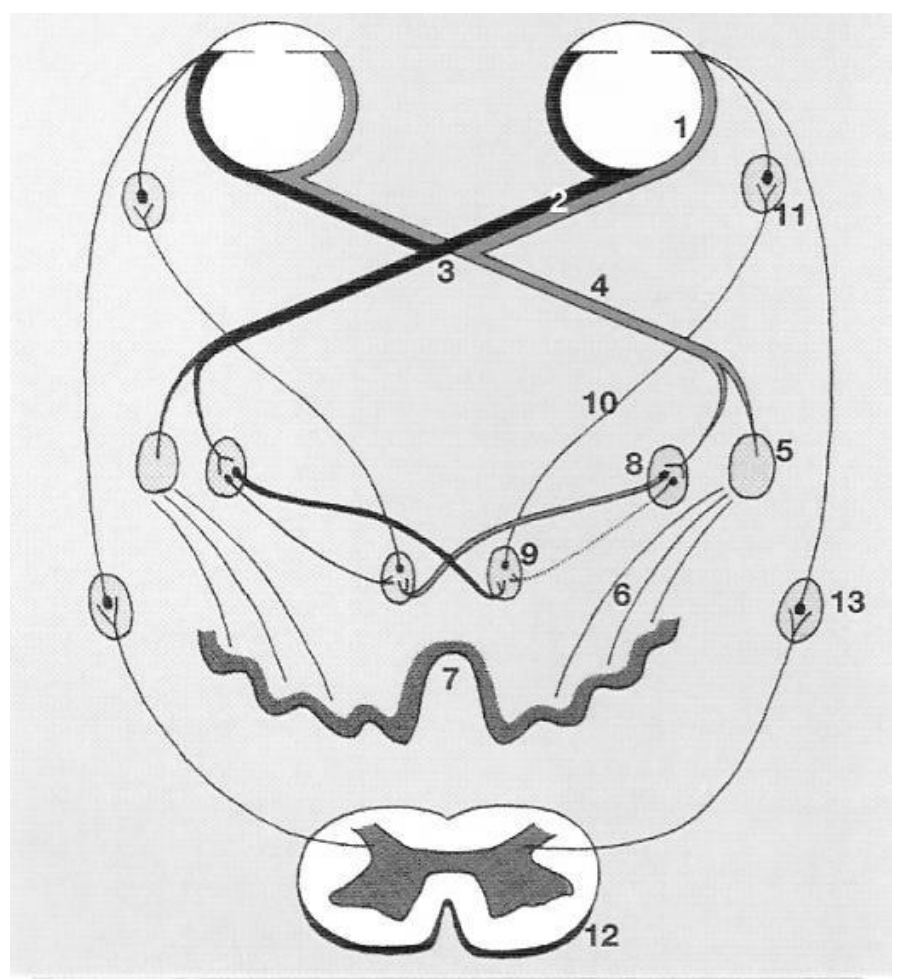

Fonte: BEDFORD (2007)

1- retina; 2- nervo óptico; 3- quiasma óptico; 4- trato óptico; 5- núcleo geniculado lateral; 6 - radiações ópticas; 7 - córtex occipital; 8- núcleo pré- tectal; 9- núcleo oculomotor; 10 nervo oculomotor (III par); 11- gânglio ciliar; 12- medula espinhal (T1, T2 e T3); 13- gânglio cervical cranial

A localização dorsal do tapetum (Figura 5) pode melhorar a visão de um campo mais escuro e a região não-tapetal, altamente pigmentada e localizada ventralmente, pode reduzir a dispersão de luz originada de um campo brilhante (OLLIVIER et al., 2004; SLATTER, 2005). 
Figura 5 - Representação esquemática da fisiologia do fundo tapetal e não-tapetal

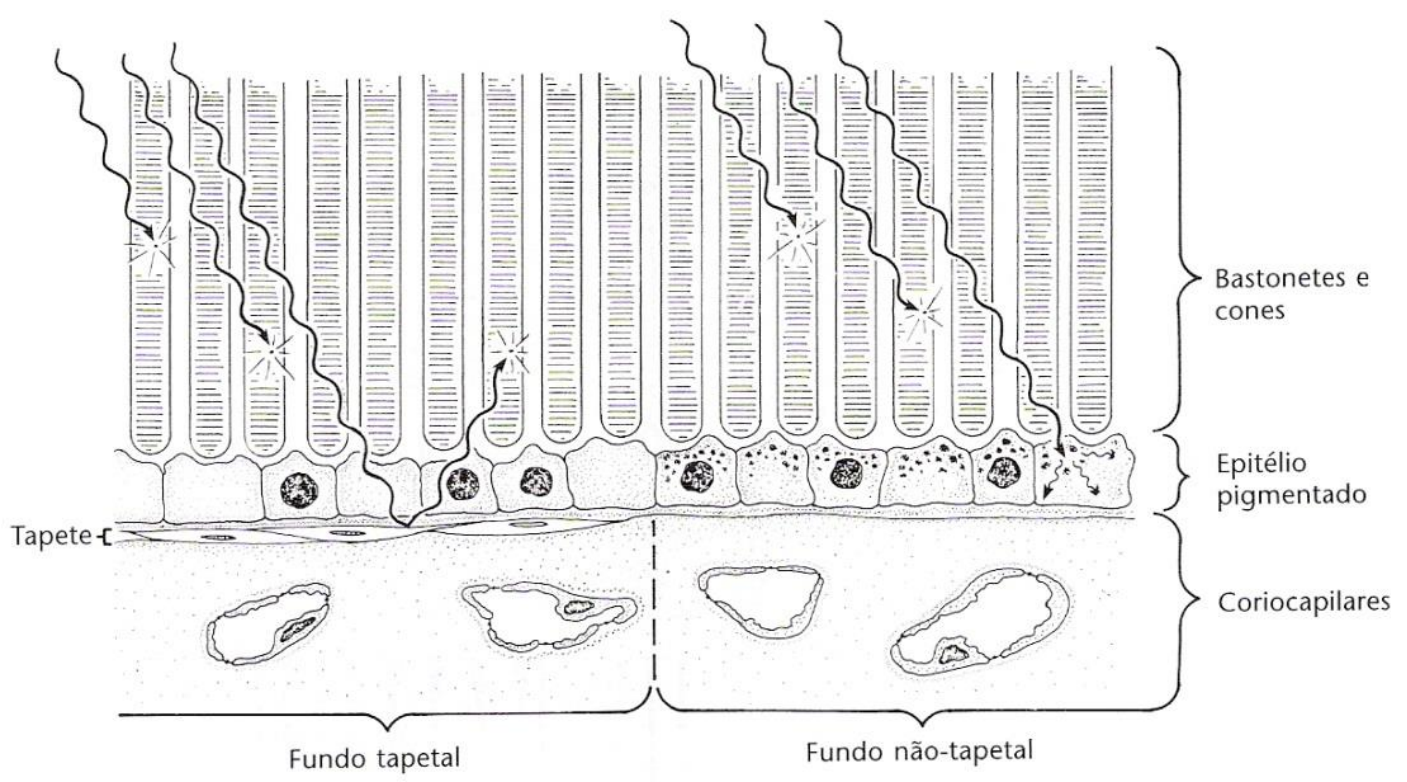

Fonte: SLATTER (2005)

A acuidade visual na maioria dos mamíferos domésticos está limitada pela retina e não pelas propriedades ópticas do olho (córnea, humor aquoso, lente, humor vítreo) ou pelo processamento neuronal pós-retiniano, que ocorre no cérebro (SLATTER, 2005).

O estágio de desenvolvimento da retina, ao nascimento, está relacionado à espécie. Em cães, o eletrorretinograma (ERG) aparece durante a primeira semana de vida e alcança a amplitude adulta entre a quinta a oitava semana (SLATTER, 2005).

A relação cone/bastonete, no cão, depende da região da retina a ser estudada. Na retina central, a relação é de 11:1, enquanto na retina periférica é de 1:65 a 1:100 (MARTIN, 2005). Primatas, maioria das aves e algumas espécies de répteis possuem uma região da retina com alta concentração de cones e ausência de bastonetes, denominada de fóvea. A função da fóvea é a percepção de várias cores com alta resolução e fixação binocular (SAMUELSON, 2007; SLATTER, 2008).

Nos animais domésticos, a ausência da fóvea é compensada pela área centralis onde se encontra uma maior concentração de cones localizada 3 a $4 \mathrm{~mm}$ 
dorso-lateral ao disco. Petersen-Jones et al. (2006) afirmam que a área centralis contém grande concentração de células ganglionares da retina, sendo usada para uma visão mais detalhada.

Em meados do século XX, Parry (1953) estudou os cones na área central da retina de vários cães e estimou que estes constituem cerca de $20 \%$ do total de fotorreceptores, considerando significativo $o$ fato de a densidade de cones ser notavelmente constante na região que constituiu a retina central. Em estudos semelhantes, Koch e Rubin (1972) documentaram uma redução de cones nas regiões periféricas em relação à area central da retina.

\subsubsection{Fisiopatologia da retina}

Os processos fisiopatológicos da retina assemelham-se aos do cérebro. Assim como no sistema nervoso central (SNC), os elementos neuronais da retina adulta dos mamíferos não se regeneram. Contudo, os segmentos externos dos fotorreceptores possuem um rápido turn over e são as células com maior taxa metabólica do organismo. Enquanto o corpo celular dos fotorreceptores se mantiver viável na camada nuclear externa, estes podem regenerar com facilidade (WILCOCK, 2007).

EPR mantém-se mitoticamente ativo durante a vida e, à semelhança dos outros epitélios, tem capacidade de autorreparação. Este processo ocorre por deslocamento de células para a região onde o epitélio sofreu agressão, seguido de mitose dessas mesmas células (WILCOCK, 2007).

Os elementos da glia que se encontram na retina, as células de Müller (astrócitos), têm capacidade de proliferar e reparar o tecido necrosado deixando uma densa cicatriz de células da glia; as vezes pode ocorrer migração de células do EPR, que também sofre metaplasia fibroblástica. A migração de células de Müller e a metaplasia das células do EPR podem levar à formação de membranas subretinianas, entre a camada de fotorreceptores e o EPR, observadas nos descolamentos de retina crônicos (WILCOCK, 2007). 
Lewis et al. (2010) estudaram o comportamento das células de Müller em situações de descolamento da retina e concluíram que, como resultado da lesão, os núcleos das células de Müller migram para a camada nuclear externa da retina e sofrem mitoses.

Após o processo de divisão celular, forma-se uma célula binucleada. Um dos núcleos pode migrar de volta para a camada nuclear interna. O segundo, que permanece na camada nuclear externa, pode migrar para o espaço sub-retiniano (e formar tecido de cicatrização glial) ou mantém-se na retina e diferencia-se em células precursoras da retina. Estas podem, eventualmente, vir a repor fotorreceptores perdidos. Um fenômeno semelhante foi descrito por Fischer e Reh (2003), após lesão ou exposição da retina de galinhas a fatores de crescimento. Nesta espécie, as células de Müller diferenciam-se, proliferam e expressam fatores de transcrição que se encontram normalmente em retinas embrionárias, podendo originar ou células da glia ou neurônios da retina.

A retina tem uma elevada taxa metabólica e por isso é muito sensível à hipóxia. A morte das suas células ocorre rapidamente após o início de uma oxigenação deficiente em situações de inflamação, descolamento da retina, redução da circulação sanguínea na órbita secundária trauma e aumento da pressão intraocular (PIO). Da morte celular segue-se desintegração, atrofia e gliose da retina (SLATTER, 2005).

As doenças que conduzem à lesões graves e disseminadas da retina (especialmente com consequências para as células ganglionares) irão, eventualmente, provocar lesão dos axônios que formam o NO levando à atrofia desta estrutura. Uma das causas apontadas para a atrofia do nervo e disco óptico é a redução do fluxo axoplasmático e consequente má nutrição destes neurônios. As lesões dos fotorreceptores também podem conduzir à perda de células ganglionares e das camadas celulares intermédias, com consequente atrofia do nervo e disco ópticos, ao mesmo tempo que lesões crônicas do nervo óptico podem causar atrofia das fibras nervosas e células ganglionares (SLATTER, 2005).

Processos infecciosos no vítreo levam à alterações graves da retina. As coroidites estendem-se frequentemente à retina e vice-versa, tal como se verifica nas retinites neurotróficas induzidas ou nos processos neoplásicos da coroide que se estendem à retina (SLATTER, 2008). 
A grande maioria das lesões da retina pode ser classificada em três categorias: inflamatórias (retinites), não inflamatórias e destrutivas (WILCOUCK, 2007).

Processos inflamatórios primários da retina são muito raros. As retinites secundárias podem resultar da extensão de endoftalmites ou de encefalites (SLATTER, 2008).

A patogenia da retinite é semelhante à verificada nos processos inflamatórios do SNC onde observa-se necrose neuronal, cuffing perivascular e gliose. Uma característica particular da inflamação na retina é a sua susceptibilidade para se descolar como consequência da acumulação de exsudatos no espaço sub-retiniano virtual que a separa do EPR e vasos da coroide. Secundariamente à retinite, verificase necrose dos fotorreceptores resultante de isquemia e contato com os produtos inflamatórios (SLATTER, 2008).

A degeneração não inflamatória dos fotorreceptores pode resultar de doenças metabólicas hereditárias, descolamento da retina e exposição a substâncias tóxicas. Histopatologicamente não se observam alterações características entre estes três processos (SLATTTER, 2008).

Os processos destrutivos podem ocorrer nas situações de glaucoma (aumento da PIO) onde há destruição dos elementos neuronais da camada interna da retina (conjunto de fibras nervosas, células glanglionares e camada nuclear interna), colapso da retina e dos vasos sanguíneos da coroide. Nesses casos ocorrem também alterações no transporte axoplasmático de nutrientes dentro do nervo óptico e nas camada de fibras nervosas (SLATTER, 2008).

Quando possível, a oftalmocospia direta e consensual auxilia na avaliação e diagnóstico destas alterações ocasionadas pelos processos patológicos (GELATT, 2003).

Nas situações inflamatórias ou neoplásicas, a observação oftalmoscópica regular das estruturas do fundo do olho está comprometida devido ao espessamento dos tecidos resultante da infiltração de células inflamatórias e/ou neoplásicas e exsudatos. Este tipo de alteração é visível no fundo tapetal onde observam-se regiões de opacificação (escuras ou acinzentadas), de limites por vezes mal definidos e que podem dificultar a observação do tapetum (MILLICHAMP, 1990). 
Nos processos degenerativos, observam-se alterações na apresentação de determinada camada celular em consequência de perda e redução da espessura de tecidos subjacentes (MILLICHAMP, 1990).

Quando ocorre proliferação das células epiteliais pigmentadas em resposta a um processo inflamatório com hiperplasia ou hipertrofia e aumento da concentração de pigmento, observam-se focos de retina com uma pigmentação exacerbada. Estes focos são visíveis na região tapetal e não tapetal igualmente e são acompanhados pela perda de cones e bastonetes (SLATTER, 2008). A hiperpigmentação difusa é geralmente hereditária ou resulta de situações de toxicidade (MILLICHAMP, 1990).

Os vasos sanguíneos podem surgir elevados ou mascarados por infiltrados. $O$ cuffing perivascular, com leves infiltrados celulares, é bem visível no fundo não tapetal. As hemorragias são achados frequentes em situações de vasculite, coagulopatias e isquemia (MILLICHAMP, 1990). O acúmulo de exsudatos ou transudados no espaço sub-retiniano provoca elevação e descolamento da retina (que surge na oftalmoscopia como um véu cinzento colado à cápsula posterior da lente - leucocoria) (SLATTER, 2008).

Lesões degenerativas do fundo tapetal resultam numa redução da espessura da retina sob essa porção do tapetum lucidum. Consequentemente verifica-se um aumento da refletividade tapetal, porque há maior quantidade de luz a ser refletida de volta para o obsevador. A hiperrefletividade tapetal é geralmente bilateral e simétrica e mais difusa nos casos de atrofia progressiva da retina (hereditária). Em estágios avançados, além da hiperrefletividade tapetal, são observáveis a atrofia do NO e dos vasos sanguíneos (MILLICHAMP, 1990).

Em situações de retinite, neurite do NO e descolamento da retina aoftalmoscopia direta e consensual permitem observar: lesões assimétricas, irregulares; opacidades cinzentas/escuras sobre o tapetum lucidum; alterações da cor do tapetum lucidum; opacidades brancas/cinzentas da região não tapetal (edema); alterações primárias da região não tapetal; cuffing perivascular na região não tapetal; hemorragias pré, intra e sub-retinianas; relevo da retina/descolamento da retina (leucoria); edema/hemorragia do NO (MILLICHAMP, 1990).

$O$ espaço virtual existente entre a neurorretina e o EPR é um remanescente do lúmen da vesícula óptica primária e persiste por toda a vida (WILCOCK, 2007). 
Nos cães, várias condições congênitas e hereditárias da retina podem favorecer o descolamento da retina. A progressão da catarata hipermadura e/ou a cirurgia de cataratas são igualmente fatores predisponentes ao desenvolvimento de soluções de descontinuidade na retina e descolamentos regmatogênicos da mesma (MILLICHAMP, 1990).

Os tipos mais frequentes de descolamento da retina são: regmatogênico, exsudativo e de tração. No regmatogênico o descolamento é causado por fendas na retina, resultantes de trauma ou degenerescência que levam à acúmulo de humor vítreo liquefeito no espaço sub-retiniano. No exsudativo o acúmulo de um exsudato seroso, fibrinoso ou celular (hemorragia) no espaço sub-retiniano ocorre em consequência de coroidite, retinite ou hipertensão dos vasos da retina. O descolamento por tração ocorre quando há maturação de hemorragias ou de fibrina dentro do vítreo provocando uma tração da retina, afastando-a da coroide. A combinação de tecido fibroso, fibrina e a retina tracionada forma uma membrana, denominada por membrana epirretiniana, que se estende desde o corpo ciliar dorsal à lente até ao corpo ciliar ventral à lente (WILCOCK, 2007).

\subsection{Lente}

A lente é uma estrutura transparente, avascular, elástica e biconvexa e está localizada entre a face posterior da íris e a face anterior do corpo vítreo. É constituída por cápsula semipermeável (anterior e posterior), epitélio anterior e fibras da lente, e dividido em região cortical, que corresponde à área periférica, e nuclear área central (DAVISON; NELMS, 2007).

O núcleo da lente é mais rígido que o córtex e ambas são constituídas de longas lamelas concêntricas. Com a idade, as fibras lamelares subepiteliais são continuamente produzidas, de modo que a lente vai tornando-se gradativamente maior e menos elástica (SLATTER, 2005).

A lente é constituída de cerca de $65 \%$ de água, $35 \%$ de proteína e quantidade mínima de minerais comuns a outros tecidos do corpo (SLATTER, 2005). 
É mantida em posição pelos ligamentos zonulares que são fibras colágenas que unem a zona equatorial ao processo ciliar, mantendo-a suspensa. Alterações na tensão destas fibras modificam a curvatura da mesma e também o poder refração (OFRI, 2008).

A lente é a estrutura responsável pela acomodação visual (REZENDE; REZENDE, 2000; OFRI, 2008). A interação da fisiologia entre corpo ciliar, zônula e lente, que resulta na focalização de objetos próximos sobre a retina, é conhecida como acomodação. Com a idade o poder acomodativo da lente torna-se, gradativamente, reduzido (SLATTER, 2005).

Além disso, é a única estrutura a ter apenas um tipo celular em vários estágios de citodiferenciação, retendo em seu interior todas as células formadas durante a vida. As mais antigas perdem as organelas e depositam no centro da lente, enquanto que as demais vão se acumulando perifericamente em camadas concêntricas (SLTATTER, 2005; OFRI, 2008).

Sua transparência é mantida por fatores complexos tais como: citoplasma de baixa densidade com ausência de organelas intracelulares e de núcleo celular nas fibras da lente, pequenas flutuações espaciais no índice de refração do citoplasma e principalmente pelo arranjo altamente organizado das lamelas das células das fibras lenticulares (OFRI, 2008).

Por ser avascular, seu metabolismo depende da glicose contida no humor aquoso. A glicose entra na lente por simples difusão ou transporte ativo, por isso, alterações no aquoso afetam seu metabolismo e transparência (OFRI, 2008). O metabolismo da lente é mais ativo no equador, onde há predomínio de glicólise anaeróbica. Outra fonte de energia é fornecida via sorbitol e ciclo de Krebs (MUNGER et al., 2009) .

\subsection{Catarata}

Denomina-se catarata qualquer opacidade da lente ou da sua cápsula independente desta opacidade interferir na visão e pode ser classificada de acordo 
com o estágio de desenvolvimento, localização, idade de surgimento, etiologia e consistência (GELATT, 2003).

Quanto ao estágio de desenvolvimento, a catarata pode-se dividir em 4 estágios: incipiente, imatura, madura e hipermadura. Esta classificação relaciona-se à porcentagem do reflexo tapetal bloqueado. Na catarata incipiente esta opacidade ocupa menos de 10 a $15 \%$ da lente e não interfere no reflexo tapetal. Na catarata imatura esta opacidade compromete parcialmente o reflexo tapetal, dificultando a fundoscopia e interferindo na visão. A madura apresenta opacidade total, bloqueando o reflexo de fundo e interferindo na visão e a hipermadura a opacidade é cintilante (DAVISON; NELMS, 2007; OFRI, 2008).

A opacidade é formada por um desarranjo das fibras da lente, que normalmente apresentam uma arquitetura regular (GELATT, 2003; WILLIAMS, 2006).

A catarata é, então, o resultado de um dano bioquímico resultando em perda de sua transparência, portanto sua fisiopatogenia pode estar relacionada à alterações de nutrição da lente, metabolismo energético, metabolismo protéico e no equilíbrio osmótico (ADKINS; HENDRIX, 2003; SLATTER, 2005).

A catarata de origem diabética está relacionada com as alterações das relações osmóticas da lente. Esta é permeável à glicose, que entra na mesma de forma livre a partir do humor aquoso mediante transporte facilitado. A glicose é convertida em ácido láctico pela via glicolítica anaeróbica (GLOVER; CONSTANTINESCU, 1997; GELLAT, 2003).

Contudo, com os níveis de glicose sanguínea elevados, há uma saturação das enzimas glicolíticas, como a hexoquinase (da clássica via metabólica de Embden-Myerhoff) e a glicose passa a ser metabolizada em sorbitol (pela aldoseredutase) e, parte deste, em frutose (pela sorbitol-desidrogenase), aos quais a membrana celular não é livremente permeável. Estes açúcares são agentes osmóticos potentes e provocam um aumento da pressão osmótica no interior da lente, causando edema das fibras da lente e, eventualmente, danos estruturais e celulares (RICHTER et al,. 2002; NELSON, 2004). As proteínas da lente sofrem alterações na sua conformação, se agregam e formam estruturas opacas e que dispersam a luz (CHEVILLE, 1993; HVENEGAARD et al., 2010).

No cão, a catarata pode estar associada à raça ou secundária ao DM, trauma, uveíte crônica, degeneração retiniana, alterações nutricionais dentre outras causas 
(OFRI, 2008). Nesta espécie, a catarata diabética tem surgimento agudo, com progressão rápida, bilateral e simétrica, sendo a principal causa de cegueira, diferente do homem, cuja principal causa é a retinopatia diabética (ADKINS; HENDRIX, 2005; DAVISON; NELMS, 2007).

De acordo com Beam et al. (1999), 50\% dos cães portadores do diabete desenvolvem catarata em aproximadamente 6 meses após o diagnóstico, 75\% em aproximadamente 12 meses e 80\% após 16 meses do diagnóstico, resultando, na maioria dos casos em cegueira. Schaer (2003) observou que a catarata se desenvolve em média dois anos e meio da descoberta da doença, independente da administração de insulina. Contudo com o controle diabético mais acurado, a ocorrência pode ser mais tardia.

Estudos mostram predisposição racial no cão diabético em desenvolver catarata. As raças mais predispostas são as não esportivas como braquicefálicos e Shar Peis, devido à severidade da doença ou pouca habilidade em regular os níveis séricos de glicose através da insulinoterapia (BEAM et al., 1999).

Inicialmente, a lente do animal diabético apresenta-se com vacúolos no córtex equatorial que se estende para córtex anterior e posterior. A sutura cortical se acentua e o córtex se opacifica completa e rapidamente (DAVIDSON; NELMS, 2007).

Sabe-se que o tratamento para catarata diabética ou não, é cirúrgico, apresentando a mesma taxa de sucesso entre os dois grupos (BAGLEY; LAVACH, 1994; WILLIAMS et al., 1996; BRAS et al., 2006; WILKIE et al., 2006; KLEIN et al., 2011; MOELLER et al., 2011). Reabsorção espontânea da catarata diabética é rara e quando acontece, pode resultar em iridociclite grave irresponsiva ao tratamento, evoluindo para glaucoma ou phthisis bulbi. Gonzáles-Alonso-Alegre e RodriguesAlvaro (2005) relataram um caso de reabsorção completa unilateral do material cristalino em um cão. 


\subsection{Diabete Melito}

Diabete Melito (DM) é um distúrbio endócrino, multifatorial, resultando na deficiência absoluta ou relativa de insulina. Esta deficiência leva a um controle inadequadoda glicose no sangue, ocasionando hiperglicemia e sinais clínicos comuns como poliúria, polidipsia, polifagia e perda de peso (RAND et al., 2004; FELDMAN; NELSON, 2004; CATCHPOLE et al., 2005; NELSON, 2010).

Dentre os processos envolvidos no diabete por deficiência absoluta de insulina podemos citar: hipoplasia de células $\beta$ congênitas, perda de células $\beta$, pancreatite, destruição das células $\beta$ imunemediadas e processos idiopáticos; enquanto no diabete por deficiência relativa os processos envolvidos estão relacionados ao antagonismo à ação da insulina por outros hormônios como por exemplo: diestro, diabete gestacional, hiperadrenocorticismo, acromegalia, glicocorticoides sintéticos e progestágenos sintéticos (CATCHPOLE et al., 2005; FALL el al., 2007).

A forma mais comum do DM no cão caracteriza-se por hipoinsulinemia permanente ou ausência de insulina, consequente da perda ou destruição de células beta do pâncreas, demandando de terapia insulínica exógena por toda a vida (BENETT, 2002; NELSON, 2004; NELSON, 2010).

No homem, o diabete é classificado em DM tipo I tipo que é caracterizado pela deficiência de insulina resultante da destruição ou perda das células $\beta$ das Ilhotas de Langerhans, enquanto que o DM tipo II é resultante da resistência associada ou não a produção ou secreção inadequada pelas células $\beta$ das llhotas de Langerhans (MARASCHIN et. al., 2010; ABBATE et al., 2011).

Foram identificados como fatores iniciantes do desenvolvimento do diabete melito: infecções, enfermidades antagônicas da insulina, exposição a substâncias tóxicas ou drogas que causam resistência à insulina e destruição imunomediada ou secundária à pancreatite das células das ilhotas (NELSON, 2010). Também pode ser desencadeado por obesidade, dieta, hiperfunção da hipófise anterior ou córtex adrenal e qualquer outro fator que cause degeneração das Ilhotas de Langerhans. Os diversos fatores podem estar interrelacionados (NELSON; FELDMAN, 1988; NELSON, 1992; NGUYEN et al., 1998). Fatores genéticos podem também contribuir para o desenvolvimento do diabete (GUPTILL et al., 2003). 
Catchpole et al. (2008) determinaram a susceptibilidade genética em diversas raças testadas. Esses resultados explicam a base genética para diabete em raças predispostas. No entanto, é preciso determinar quais os fatores de risco ambientais envolvidos na progressão clínica da doença em indivíduos geneticamente suscetíveis. A compreensão da fisiopatogenia e base genética da doença podem levar ao desenvolvimento de terapias (CATCHPOLE et al., 2013).

DM é uma das doenças endócrinas mais frequentes em cães e gatos. A incidência de DM no cão varia entre 1 para 100 a 1 para 500 (NELSON, 2010).

A classificação do diabete melito no cão não tem um critério aceito mundialmente. Alguns autores classificam a doença em diabete melito insulinodependente (DMID) ou não insulino-dependente (DMNID), no entanto todos os cães necessitam de terapia com insulina. Na maioria dos cães diabéticos, a causa da deficiência de insulina não é estabelecida, porém acredita-se que seja resultado de danos as células $\beta$ das llhotas de Langerhans associadas com pancreatite e/ou destruição imunomediada das células $\beta$ (FELDMAN; NELSON, 2004; CATCHPOLE et al., 2008). Alguns autores incluem como causado diabete a ação antagônica da progesterona sobre a insulina. Este tipo de diabete pode acometer fêmeas na fase do diestro ou gestação, semelhante ao diabete gestacional do humano (RAND et al., 2004), e defini-se como um grau variável de intolerância a glicose, que se inicia ou é reconhecido pela primeira vez durante a gestação (FLEEMAN; RAND, 2001).

Atualmente classifica-se o diabete canino com base na causa da hiperglicemia em diabete por deficiência primária de insulina ou diabete por resistência primária à insulina. Diabete por deficiência primária à insulina ocorre quando há uma falha na produção de insulina à partir do pâncreas (deficiência absoluta de insulina), enquanto que o diabete por resistência primária à insulina ocorre quando há uma falta de função de insulina adequada (deficiência relativa de insulina). A hiperglicemia prolongada no cão pode induzir a diabete por resistência primária à insulina (CATCHPOLE et al., 2008).

Deficiência relativa ou absoluta de insulina resulta em diminuição da utilização de glicose, aminoácidos e ácidos graxos pelos tecidos periféricos, como fígado e músculos, bem como discreto aumento na gliconeogênese hepática. A glicose proveniente da dieta ou da gliconeogênese hepática acumula-se na circulação, causando hiperglicemia. Com o aumento da concentração plasmática de glicose, a 
capacidade das células tubulares renais em absorver glicose desde o filtrado glomerular é excedida, resultando em glicosúria. Isto ocorre quando a concentração plasmática da glicose excede 180 a $220 \mathrm{mg} / \mathrm{dl}$ no cão (concentração plasmática de glicose em um cão sadio situa-se entre 65 a 110 mg/dl) (BROBST, 1997; FALL et al., 2007; NELSON, 2010).

A glicosúria cria uma diurese osmótica, causando poliúria. A polidipsia compensatória impede a desidratação. A glicosúria também representa perda calórica e, associado à diminuição do metabolismo tecidual periférico da glicose ingerida, resulta na perda de peso, pois a baixa capacidade de utilização periférica de glicose induz ao catabolismo. A gordura e a proteína do músculo são metabolizadas formando substratos para a gliconeogênese (NELSON, 1992; NGUYEN et al., 1998; NELSON, 2010).

A capacidade da glicose em penetrar nas células do centro da saciedade, localizado na região ventro medial do hipotálamo, está sob influência da insulina. No diabete melito, com ausência relativa ou absoluta de insulina, a glicose não penetra nessas células, o centro da saciedade não é inibido, e o indivíduo se torna polifágico, mesmo com hiperglicemia (NELSON, 1992; NELSON, 2001a, b; NELSON, 2010).

Assim sendo, as principais manifestações clínicas do DM são: poliúria, polidipsia, polifagia e perda de peso (KANEKO et al., 1978; NELSON, 1992; FELDMAN; NELSON, 2004; NELSON, 2010).

Estudos epidemiológicos realizados por Marmor et al. em 1982; Feldman e Nelson em 2004; Fall et al. em 2007 e Nelson em 2010 concluíram que, na maioria dos cães diabéticos, a idade variou entre 4 e 14 anos. Esses autores também observaram que as fêmeas eram mais suscetíveis que os machos. As raças mais predispostas (em ordem decrescente) foram: Keeshond, Malamute do Alasca, Puli, Cairn Terrier, Fox Terrier, Manchester Terrier, Pinscher Miniatura, Poodle Miniatura, Spitz, Schipperke, Schnauzer Miniatura, Pequinês, Pastor Alemão, Collie e Boxer (MARMOR et al., 1982; FELDMAN; NELSON, 2004). Davison et al. (2005) observaram no Reino Unido que as raças mais predispostas foram: Labrador, mestiços, Collie e Yorkshire. Outras raças caninas também consideradas de risco para o desenvolvimento do DM incluem: Norwengian Elkhound, Beagle, Border Collie, Labrador Retriever e West Highland White Terrier (FALL et al., 2007). 
Rand et al. em 2004 e Davison et al. em 2005 observaram que no alto inverno, o diagnóstico do DM tipo I nos cães era muito maior, sugerindo que fatores ambientais influenciavam na progressão desta endocrinopatia.

No mesmo estudo, Rand et al. (2004) concluíram que a obesidade não resultou em DM tipo II nos cães, porém predispunha à pancreatite, que é um frequente fator etiológico desta doença no cão.

Outras complicações relacionadas à hiperglicemia no cão podem ser citadas como: catarata, pancreatite crônica e prevalência de infecções bacterianas (trato urinário, sistema respiratório e pele) devido à reduzida aderência neutrofílica (NELSON, 1992; NICHOLS, 1992; FALL et al., 2007; NELSON, 2010). No homem as complicações observadas são: nefropatias, retinopatias, neuropatias, complicações microvasculares que resultam do espessamento das membranas basais dos capilares nos tecidos acometidos, além de doença vascular periférica que pode levar à amputação de membros (GROSS; NEHME, 1999).

O diagnóstico do DM baseia-se na presença de hiperglicemia em jejum (BENETT, 2002; GROSS; NEHME, 1999; SANTOS, 2012).

O tratamento do cão diabético visa $\mathrm{o}$ controle da glicemia $\mathrm{e}$ consequentemente das manifestações clínicas (poliúria, polidipsia, polifagia e perda de peso), uma vez que o estabelecimento de um controle glicêmico adequado é primordial para evitar complicações associadas ao DM. Para isso o tratamento deve incluir administração de insulina, instituição de dieta apropriada, exercício físico e controle de prevenção de doenças concomitantes (inflamatórias, infecciosas, hormonais e neoplásicas) e o cuidado com o uso de medicações, como glicocorticoides (HOENIG, 2002 ; NELSON, 2010).

Em relação à insulina, há diferentes tipos, as quais são classificadas de acordo com o tempo de duração e a intensidade da ação após a aplicação. Atualmente, as insulinas disponíveis para o tratamento dos cães incluem a insulina recombinante humana (como a Humulin), sendo esta a mais indicada, a combinação de origem bovina e suína (como a PZI) e a suína purificada (como a lletin II Pork). A insulina de ação intermediária (NPH) é o tipo de insulina de eleição para o início do tratamento do DM na dose de $0,5 \mathrm{U} / \mathrm{kg}$, administradas duas vezes ao dia (NELSON, 2004; NELSON, 2010). 
O controle glicêmico considerado adequado é importante para prevenir a hipoglicemia $(<80 \mathrm{mg} / \mathrm{dl})$. Caso ocorra, a dose de insulina deve ser diminuída. Assim, o controle glicêmico adequado pode ser definido pela ausência de manifestação clínica, associada a valores de glicemia na faixa de 100 a $300 \mathrm{mg} / \mathrm{dl}$ durante o dia (NELSON, 2004; FALL et al., 2007).

A instituição da dieta nos cães diabéticos tem como objetivos correção da obesidade quando presente e prevenir flutuações pós-prandiais de glicemia (NELSON, 2004; NELSON, 2010).

A monitoração do cão diabético é fundamental e deve ser embasada na ausência de manifestações clínicas, avaliação de glicemia ao longo do dia e dosagem sérica de frutosamina (HOENIG, 2002).

A frutosamina é uma proteína sanguínea que apresenta ligação nãoenzimática irreversível da glicose com a albumina. Esta ligação independe da insulina. A quantidade de frutosamina produzida é proporcional a concentração de glicose sérica. Dessa forma, a mensuração da frutosamina sérica fornece o valor médio correspondente a glicemia de 2 a 3 semanas prévias a data da coleta. Cães são considerados com excelente controle de glicemia quando a frutosamina encontra-se entre 350 e $400 \mu \mathrm{mol} / \mathrm{L}$, bom controle valores entre 400 e $450 \mu \mathrm{mol} / \mathrm{L}$, controle regular valores entre 400 e $500 \mu \mathrm{mol} / \mathrm{L}$ e controle ruim valores acima de $500 \mu \mathrm{mol} / \mathrm{L}$ (BRIGGS et al., 2000; NELSON, 2010).

A sobrevida média dos cães diabéticos após o diagnóstico é de aproximadamente 3 anos, sendo que o maior índice de mortalidade ocorre durante os seis primeiros meses após o diagnóstico (FALL et al., 2007).

\subsubsection{Retinopatia Diabética}

Retinopatia diabética (RD) é uma microangiopatia comum no homem. É uma lesão que se estende por toda a microvasculatura (arteríolas, capilares e vênulas) (ABRAMS et al., 2011).

Em pacientes com RD observam-se alterações circulatórias como perda do tônus vascular, alteração do fluxo sanguíneo, aumento da permeabilidade vascular e 
consequentemente, extravasamento e edema. Esse processo evolui para obstrução vascular que pode ocasionar em neovascularização, com vasos frágeis que se rompem, levando a hemorragias e descolamento da retina (MOTTA et al., 2008; ABRAMS et al., 2011).

Os primeiros relatos de sinais de retinopatia diabética, no homem, foram feitos em 1940, quando observaram microaneurismas em capilares retinianos (TZEKOV; ARDEN, 1999; CRAWFORD et al., 2009; ABRAMS et al., 2011).

As condições fisiológicas da retina podem ser responsáveis pelas alterações causadas pelo diabete. Dentre estas condições podemos citar primeiramente, os axônios da retina que não possuem bainha de mielina e precisam de mais energia para manterem suas funções. Segundo, a quantidade de vasos sanguíneos que podem absorver luz é relativamente baixa, ou seja, os vasos internos da retina são hipóxicos. E terceiro, a retina interna possui menos mitocôndrias que as camadas mais externas. Para obter a energia suficiente para o seu bom funcionamento a retina interna utiliza-se basicamente da glicólise, um meio menos eficiente de gerar ATP do que a fosforilação oxidativa. Estas características de alta demanda metabólica e baixo suprimento vascular podem limitar a retina interna em se adaptar ao estresse metabólico do diabete (SERRARBASSA et al., 2008).

No homem, as primeiras alterações retinianas encontradas são formações de microaneurismas originados de pequenas saculações da parede capilar que podem romper-se, resultando em pontos hemorrágicos com ou sem exsudação. A vascularização retiniana pode ter a forma de espiral e é denominada de "background" ou não proliferativa. Alterações proliferativas, incluindo neovascularização pré-retiniana e vítrea, com presença de tecido conjuntivo em vítreo, hemorragia vítrea grave e descolamento de retina não regmatogênico, são frequentes (KERN; LENGERMAN, 1995; NEHEMY et al., 2001).

A retinopatia diabética pode ser classificada de acordo com sua evolução, segundo o proposto pelo Early Treatment Diabetic Retinopathy Study (ETDRS): retinopatia diabética não proliferativa leve (RDNP) ou de fundo; retinopatia diabética não proliferativa moderada-grave ou retinopatia diabética pré-proliferativa (RDPP) e retinopatia diabética proliferativa (RDP) (CORREA; EAGLE JR, 2005).

A retinopatia diabética não proliferativa leve (RDNP) ou de fundo quase sempre é bilateral e concentra-se sobre o pólo posterior. Nesta retinopatia observa- 
se presença de micro-hemorragias puntiformes, microaneurismas e exsudatos ocasionados pela quebra da barreira hematorretiniana, a qual possui importância similar à barreira hemato-encefálica. Esta alteração é considerada uma das lesões funcionais mais precoces em olhos diabéticos (CORREA; EAGLE JR, 2005). Esta falência na barreira hematorretiniana possibilita a entrada de líquido rico em lipídeos e proteína no parênquima retiniano, causando edema e exsudação dura (coleção eosinofílica de fluido protéico) ou mole (bloqueio focal de fluxo axoplasmático) (MUÑANA, 1995, NEHEMY et al., 2001; CORRÊA; EAGLE JR., 2005).

$\mathrm{Na}$ retinopatia diabética não proliferativa moderada-grave ou retinopatia diabética pré-proliferativa (RDPP) aparecem os exsudatos algodonosos, anomalias vasculares (alças e "ensalsichamentos" venosos, fluxo arterial turbulento), anomalias microcirculatórias intraretinianas (AMIR) e zonas de não perfusão capilar (KRISTINSSON et al., 1995; KANSKI, 2005; CORRÊA; EAGLE JR., 2005).

$\mathrm{Na}$ retinopatia diabética proliferativa (RDP) observa-se surgimento de neovasos sobre disco, retina e íris que pode desencadear complicações como hemorragia vítrea e descolamento tracional da retina, resultando em cegueira (KRISTINSSON et al., 1995).

De acordo com Kern e Lengerman (1995) as lesões microvasculares dos pacientes diabéticos não são uniformemente distribuídas na retina. Microaneurismas e capilares acelulares são mais prevalentes no quadrante temporal superior que no quadrante nasal inferior (KERN; LENGERMAN, 1995). Já os pericitos fantasmas são observados de forma homogênea em todos os quadrantes (NEHEMY et al., 2001).

As hemorragias retinianas apresentam formato e aspecto diferentes em decorrêcia da localização variada do extravasamento sanguíneo. Pacientes com formas mais avançadas de retinopatia costumam apresentar hemorragia em formato escafoide ou em meia-lua. Quando o sangue se deposita no trajeto dos axônios da camada de fibras nervosas que se curvam em arcos superior e inferiormente à fóvea, paralelos à membrana limitante externa, fica com aspecto de chama de vela ou farpa. Quando a hemorragia é mais profunda, apresenta aspecto arredondado e borrado. Hemorragias maciças que se misturam ao vítreo costumam ocorrer nos estágios mais avançados da doença e são uma importante causa de baixa visual (SMALL et al., 1987; KERN; LENGERMAN, 1995; CORRÊA; EAGLE JR., 2005).

A perda dos pericitos, que ocorre principalmente nas fases iniciais da retinopatia diabética, não tem uma verdadeira explicação. Alguns autores acham 
que a causa desta perda seja o acúmulo intraocular de sorbitol produzido pela enzima aldose redutase na transformação de polióis, pois este sorbitol é incapaz de atravessar as membranas celulares, ficando represado dentro da célula (CORRÊA; EAGLE JR., 2005; PIZZOL et al., 2008).

Esta perda tem consequências importantes, pois a falta das propriedades contráteis dos pericitos desregula os capilares retinianos alterando o fluxo sanguíneo e também ocasiona proliferação das células endoteliais e neovascularização pela perda do seu efeito inibitório que é mediado pela transformação do fator de crescimento $\beta$ (CORRÊA; EAGLE JR., 2005).

$\mathrm{Na}$ retinopatia diabética proliferativa, os vasos crescem por dentro e sobre a retina e também na face posterior do vítreo descolado. Sabe-se que o estímulo para esta neovascularização vítreorretiniana é a liberação de fatores angiogênicos produzidos pela retina isquêmica e o mais importante é o fator de crescimento vascular endotelial (vascular endothelial growth factor - VEGF), cuja síntese é regulada pelos níveis de oxigênio no microambiente celular (CORRÊA; EAGLE JR., 2005). Portanto, a hiperglicemia induz a hipóxia da retina, promovendo a produção do VEFG (MATHEWS et al., 1997; CRAWFORD et al., 2009).

Outro fator de crescimento responsável pela neovascularização retiniana é o fator básico de crescimento de fibroblasto (bFGF) cuja liberação é devida à lesão celular induzida pela isquemia prolongada (CORRÊA; EAGLE JR., 2005).

Estudos sugerem que a hiperglicemia no diabete leva a um aumento da proteína quinase $\mathrm{C}(\mathrm{PKC})$, especialmente nas formas beta e delta, responsáveis por disfunções vasculares associadas à doença (NEHEMY et al., 2001).

O tratamento da retinopatia diabética é feito com bom controle clínico, fotocoagulação com laser e vitrectomia (NEHEMY et al., 2001; ABATTE et al., 2011). Como a aplicação de laser não melhora a visão, o melhor momento para iniciar-se o tratamento é antes que o paciente apresente baixa acuidade visual. Baixa acuidade visual é um sintoma tardio da RD e muitos pacientes permanecem sem diagnóstico, mesmo quando a doença se encontra em fase avançada. Desta forma, todo paciente deve ser submetido à oftalmoscopia tão logo DM tenha sido diagnosticado (GROSS, NEHME, 1999; NEHEMY et al., 2001; ABBATE et al., 2011). 


\subsubsection{Retinopatia diabética no cão}

Retinopatia diabética no cão (espontânea ou induzida) é caracterizada por aumento da espessura da membrana basal vascular, perda de pericitos, formação de microaneurismas, obstrução de capilares e lesão das células da musculatura lisa das arteríolas retinianas (BARNETT, 1981; MUÑANA, 1995; LANDRY et al., 2004).

As primeiras lesões microvasculares só se tornam visíveis, tanto no paciente humano como no cão diabético, após alguns anos do início da doença (KERN; LENGERMAN, 1995; CULLEN; WEBB, 2007a), independentemente de o paciente estar ou não sendo tratado (CULLEN; WEBB, 2007a; LI et al., 1992). Nos cães, portadores de DM espontânea, a RD demora de 3 a 5 anos para se desenvolver, enquanto nos cães com DM induzida demora aproximadamente 2 anos (CULLEN; WEBB, 2007b).

Os achados oftalmoscópicos incluem microaneurismas, hemorragia retiniana, dilatação e tortuosidade das vênulas retinianas, hiperrefletividade da área tapetal e exsudatos coriorretinianos, capilares acelulares são mais prevalentes no quadrante temporal superior que no quadrante nasal inferior, enquanto que a distribuição dos pericitos fantasmas é igual em todos os quadrantes ou seja, alterações vasculares similares as que ocorrem na retinopatia diabética humana em sua fase inicial (MONTI et al., 1976; MUÑANA, 1995; GUPTILL et al., 2003).

Histologicamente, a retinopatia diabética no cão assemelha-se a forma não proliferativa do homem, com microaneurismas, perda das células murais, células murais fantasmas e dilatação dos capilares retinianos (ENGERMAN; KERN, 1995; LANDRY et al., 2004).

Como a maioria dos casos de retinopatia diabética em cães é sub-clínica não há relatos de cegueira oriundos destas complicações (MUÑANA, 1995; GUPTILL et al., 2003).

Os fatores de risco para o desenvolvimento da RD no DM espontâneo no cão não foram bem estudados (LANDRY et al., 2004).

Estudo realizado por Landry et al. (2004) concluiram que a duração do DM não foi responsável pela RD. Os autores sugerem que o tempo de seguimento dos pacientes, que foi de 2,1 anos fo insuficiente para comprovar tal afirmação. Sibay (1967) sugeriu que o diabete precisa estar presente por pelo menos cinco anos no 
cão, antes da manifestação da retinopatia. Existem vários casos reportados de retinopatia em cães com diabete melito espontânea (PATZ, 1962; SIBAY, 1967; MONTI, 1976; BARNETT, 1981; ONO, 1986).

As pesquisas mostram que ao comparar cães com controle glicêmico adequado com cães com controle glicêmico inadequado, este último apresentou progressão da RD após 2,5 anos (LANDRY et al., 2004).

A progressão da $\mathrm{RD}$ após remoção da catarata por facoemulsificação não foi perfeitamente estudada nos cães, mas estudos recentes mostram que esta não ocorre, como ocorre no homem (BAGLEY; LAVACH, 1994; LANDRY et al., 2004).

Recentemente, o fator de crescimento vascular endotelial (VEGF) foi determinado no humor aquoso de cães diabéticos e não diabéticos, demonstrando que não há diferença significante, o que pode explicar a baixa prevalência e gravidade da RD em cães (ABRAMS et al., 2011).

Cães diabéticos não desenvolvem grau grave da RD comparado a pacientes humanos em razão da menor expectativa de vida, portanto, não há tempo suficiente para as lesões retinianas desenvolverem e progredirem como em humanos diabéticos com maior expectativa de vida (ABRAMS et al., 2011).

\subsection{Facoemulsificação}

A facoemulsificação foi idealizada por Kelman em 1967 e introduzida no Brasil em 1990, resultando numa mudança radical na maneira de se tratar cirurgicamente a catarata (GLOVER; CONSTANTINESCU, 1997; MONTENEGRO; REZENDE, 2000; REZENDE; REZENDE, 2000; WILKIE; COLITZ, 2009).

A cirurgia consiste em remover a lente opacificada por pequena incisão, fragmentando-a, emulsificando-a e aspirando-a. A técnica necessita de poucas suturas e permite a cicatrização mais precoce com menor período de recuperação (MONTENEGRO; REZENDE, 2000; LAUS, 2009; SHAH; CHEN, 2010).

Para emulsificar a lente, a energia é gerada por um transdutor localizado na caneta do facoemulsificador que vibra numa frequência ultrassônica. A lente é 
aspirada posteriormente e todo material cortical é removido (MONTENEGRO; REZENDE, 2000; OFRI, 2008; LAUS, 2009).

A cirurgia é realizada em sistema fechado de irrigação e aspiração, impedindo o colapso da câmara anterior, mantendo seu volume constante (OFRI, 2008).

No cão e no homem esta técnica cirúrgica é mais utilizada para a remoção da lente devido à pequena incisão, menor tempo cirúrgico e baixa lesão nas estruturas intraoculares, resultando em menores complicações, principalmente quanto inflamação (BAGLEY; LAVACH, 1994; BRAS et al., 2006; HONG et al., 2009; CHIURCIU et al., 2010; CRASTA et al., 2010; KLEIN et al., 2011; MOELLER et al., 2011).

\subsection{Anti-inflamatórios}

A medicina veterinária e humana disponibilizade 2 grupos de antiinflamatórios: anti-inflamatórios esteroidais e não esteroidais (AINES), ambos interferindo na via cicloxigenase/lipoxigenase. Os AINES diminuem a inflamação por inibir a atividade da enzima cicloxigenase e consequentemente inibir a síntese de prostaglandinas. Os corticóides agem inibindo a síntese do ácido aracdônico e são muito utilizados no tratamento de pós-operatório em cirurgias de catarata (MUNGER et al., 2009). São comumente utilizados duas a seis semanas após a cirurgia. Entretanto, estudos no homem mostram que este grupo de fármacos pode ocasionar efeitos adversos como aumento da pressão intraocular, retardo da cicatrização e aumento de possibilidade de infecção (EL-HAZARI et al., 2000).

DM no cão pode ser induzida por terapêuticas crônicas ou exageradas com corticosteróides e progestágenos. Contudo, uma vez que a grande maioria dos cães não desenvolve diabete clínica apenas com terapêutica crônica de corticosteróides ou com Cushing espontâneo, pode-se afirmar que é necessário haver uma diminuição na capacidade funcional das células- $\beta$, resultante de processos imunológicos oude pancreatite crônica, para o aparecimento da doença. A administração destes fármacos antagonizam a ação da insulina e causam exaustão da função pancreática (NELSON, 2010). 
Alguns estudos sugerem que a dexametasona tem melhor potência antiinflamatória e maior capacidade de ligação a receptores de glicocorticóides do que a prednisolona, porém a capacidade de proteger a barreira hemato-aquosa é semelhante (DIESTELHORST et al., 1992). No entanto, quando comparadas entre $\mathrm{si}$, fosfato de dexametasona $0,1 \%$ e acetato de prednisolona $1 \%$ apresentaram eficácia similar no tratamento pós cirúrgico de facoemulsificação no homem, além de apresentarem boa tolerância e controle dos efeitos de inflamação (STRUCK; BARISLOVICH, 2001).

Em substituição aos corticóides, alguns estudos envolvendo uso de AINES no tratamento pós-operatório de catarata foram realizados em humanos, principalmente com cetorolaco de trometamina $0,5 \%$. Pesquisadores concluíram que este fármaco mostrou-se eficaz, pois apenas $28 \%$ do total de pacientes descontinuaram a terapia pelo tratamento não apresentar resultado (HEIER et al., 2009). Quando comparado à anti-inflamatórios esteroidais como dexametasona e prednisolona o cetorolaco de trometamina 0,5\% obteve desempenho similiar (OSTROV et al., 1997).

A uveíte pós-operatória é considerada o maior problema da cirurgia para extração de catarata no cão (MOORE et al., 2003). O desenvolvimento de iridociclite ou inflamação do segmento anterior é uma das complicações mais comuns resultantes da facoemulsificação (BRIKSHAVANA, 2005). Com a manipulação das estruturas intraoculares, é possível que ocorram alterações na barreira hematoaquosa resultanto em liberação de mediadores inflamatórios. Esta situação é, no entanto, geralmente controlável com administração tópica e sistêmica de antiinflamatórios esteróides ou não esteróides no período pré e pós-operatório, sendo geralmente reversível ao fim de poucos dias (TUNTIVANICH; TUNTIVANICH, 2007).

\subsection{Eletrorretinograma}

A maioria dos organismos tem, de alguma forma, capacidade de responder à luz. O fenomeno de fototransdução visual consiste na absorção de um sinal luminoso por uma proteína fotossensível e na sua conversão e ampliação num sinal 
eletrofisiológico, transmíssivel ao sistema nervoso central (SNC) (CHAUDIEU; MOLON-NOBLOT, 2004). Apesar da morfologia do olho variar entre as diferentes espécies, o fenômeno de fototransdução é comum entre elas e baseia-se no funcionamento de proteínas altamente seletivas que se localizam na superfície da membrana celular fotorreceptora e são responsáveis pela captação de fótons de luz e transmissão de um estímulo luminoso à respectiva célula fotorreceptora (SLATTER, 2008).

A retina dos mamíferos possuem células responsáveis pela captação dos estímulos luminosos e consequente transmissão dessa informação ao SNC (CHAUDIEU; MOLON-NOBLOT, 2004).

Todos os neurônios que compõem a retina, bem como as células do epitélio pigmentado da retina, contribuem para a resposta aos estímulos luminosos. Uma vez no córtex visual, estes impulsos recriam a cena visual e com o envolvimento de áreas visuais de associação selecionadas, resultando na percepção consciente, ou seja, visão (MENDONÇA; TAKAHASHI, 2010).

As células da retina geram corrente elétrica, que é capturada pelo eletrorretinograma. Quando uma parte da retina é iluminada, as células da retina são ativadas simultaneamente (HONSHO et al., 2004). A resistência que a corrente passa é formada pela córnea, vítreo e retina (KOMAROMY et al., 2002).

Os fotorreceptores têm conexão sináptica direta com os interneurônios bipolares, que conectam os fotorreceptores com as células ganglionares. Tais células formam o nervo óptico e transmitem o potencial de ação que chega ao cérebro (WEICHSLER; HERRERA, 2007).

Distinguem-se nos canídeos e em outras espécies mamíferas, dois tipos de células fotorreceptoras: os cones e os bastonetes. Esta distinção é feita com base nas caraterísticas morfológicas e eletrofisiológicas destas células (SLATTER, 2005).

Como citado anteriormente, os cones são mais sensíveis a luz intensa (visão fotópica) permitem uma melhor resolução da imagem e a visão de cores. Os bastonetes são mais sensíveis no crepúsculo (visão escotópica) sendo responsáveis pela visão acromática (RANDALL et al., 1998).

O eletrorretinograma é baseado na estimulação da retina pela luz e no registro de sua resposta. Luz de intensidade, comprimentos de onda e duração de flashes variáveis são direcionados a córnea (KOMAROMY et al., 2002). Estudos revelam que estas alterações elétricas propagam-se através de várias camadas da 
retina e atingem o córtex visual via nervo óptico, trato óptico e tálamo (MENDONÇA; TAKAHASHI, 2010).

Com o eletrorretinograma (ERG) de campo total, é possível avaliar a função retiniana pela análise dos potenciais de ação da retina. Esses potenciais foram descobertos em 1849 por Du Bois Reymond (WEICHSLER; HERRERA, 2007).

Em 1865 o eletrofisiologista sueco Frutiof Holmgren foi o primeiro a mensurar a soma dos potenciais de ação da retina em resposta ao estímulo luminoso. O trabalho foi feito em olhos de rãs (DANTAS, 1995; MENDONÇA; TAKAHASHI, 2010).

Alguns anos depois, removendo o segmento anterior e colocando o eletrodo diretamente na superfície retiniana, a resposta teve origem da própria retina (DANTAS, 1995; MENDONÇA; TAKAHASHI, 2010).

Dewar mostrou que os potenciais elétricos podiam ser registrados colocando um eletrodo na córnea e aplicando o eletrodo de referência na pele. Esta atividade bioelétrica observada no olho e desencadeada pela estimulação luminosa, denomina-se corrente retiniana, corrente de iluminação ou potencial de ação (DANTAS, 1995; MENDONÇA; TAKAHASHI, 2010).

Dewar relatou o primeiro eletrorretinograma humano em 1877, mas só em 1920 o equipamento ficou sensível o suficiente para caracterizar o registro das ondas (DANTAS, 1995; MENDONÇA; TAKAHASHI, 2010).

Riggs em 1941, com eletrodos em lentes de contato, conseguiu quantificar os resultados obtidos pelo ERG (DANTAS, 1995; MENDONÇA; TAKAHASHI, 2010).

Karpe (1945) introduziu o eletrorretinograma como um teste diagnóstico de rotina a ser utilizado na clínica oftalmológica com a lente de contato corneal. Além disso, foi um dos primeiros a enfatizar a importância do ERG como registro objetivo da função retiniana. Desde então, houve considerável desenvolvimento da eletrofisiologia clínica (NARFSTRÖM, 2002).

Atualmente há quatro tipos de eletrorretinograma: eletrorretinograma de campo total (Full Field ERG); eletrorretinograma focal (Focal ERG); eletrorretinograma por padrão reverso (Pattern ERG) e eletrorretinograma multifocal (Multifocal ERG) (MENDONÇA; TAKAHASHI, 2010).

Os aparelhos utilizados para a realização do ERG apresentam dois componentes principais: o sistema de estimulação e o de gravação. O sistema de 
estimulação é variável, podendo ser produzido porflash de luz difusa, por estimulação padrão ou por estimulação focal (TZECOV; ARDEN, 1999).

Para registrar a resposta ao estímulo luminoso, necessitam-se de três eletrodos: ativo, referência e terra. Eletrodos bipolares possuem 0 ativo e 0 referência juntos. Existem diversos modelos que podem ser utilizados tanto na medicina humana como na medicina veterinária, tais como: ERG-jet, Burian Allen, Goldlens, bipolar com fonte luminosa acoplada e DTL (HÉRBERT et al., 1996; MAHEHARA et al., 2005; BELLER et al., 2007). Ao comparar os eletrodos, podemos observar que as respostas dos testes eletrofisiológicos diferem entre si (GUM, 1980; DANTAS, 1995; KUZE; UJI, 2000; ITOH et al., 2013; PEREIRA et al., 2013).

Para avaliar isoladamente cones e bastonetes, podem-se utilizar estímulos repetitivos ou variáveis, de maior ou menor intensidade, frequências de luzes oscilatórias (flickers), além da adaptação à luz ou ao escuro (DANTAS, 1995).

Por definição, eletrorretinograma (ERG) é a onda polifásica retiniana obtida em resposta ao estímulo luminoso (GUM, 1980). É um meio de diagnóstico importante por ser objetivo, não invasivo e capaz de avaliar a função retiniana, detectando precocemente lesões nas suas camadas mais externas (KOMAROMY et al., 1998a, b; TZEKOV; ARDEN, 1999; SAFATLE et al., 2005).

O ERG tem uma representação gráfica que consiste na rápida onda negativa " $a$ ", seguida pela positividade da onda " $b$ ", terminando em um potencial positivo lento a onda "c" (WEICHSLER; HERRERA, 2007). O eletrorretinograma de campo total é uma resposta em massa, que representa a atividade de todas as unidades envolvidas em gerar a resposta (BIRCH; ANDERSON, 1992; GONÇALVES et al., 2000).

Os fotorreceptores geram a onda- $a$. A onda- $b$ é resultante da ativação das células de Müller e, em menor significância, das células bipolares, além disso, indiretamente, avalia as camadas médias da retina (HECKENLIVELY; ARDEN, 2006). A onda- $c$ tem sua origem no epitélio pigmentado da retina, entretanto, devido às condições usadas na Medicina Veterinária, a onda- $C$ é raramente detectada (WEICHSLER; HERRERA, 2007).

A onda-c pode ser observada quando é feito um tipo especial de ERG, o ERG de longos flashes. Enquanto as ondas- $a$ e $b$ aparecem na escala de milisegundos, $a$ onda- $c$ aparece na escala de segundos. O aparecimento da onda- $c$ no epitélio pigmentado da retina depende do fluxo de potássio das outras camadas da retina. 
Só que o fluxo extracelular de potássio depende da fototransdução. Portanto, a onda- $c$ pode nos dar um panorama da fototransdução como um todo, da integridade do epitélio pigmentado da retina e da interação do EPR e do resto da retina. A pesquisa da onda- $c$ não é rotineira, geralmente só é pesquisada quando já se sabe que há algo errado com o ERG e consequentemente, com a retina (WEICHSLER; HERRERA, 2007).

Há também os potenciais oscilatórios, que são pequenas ondas rítmicas da fase ascendente da onda- $b$, vindas da camada nuclear interna. $O$ aumento repentino na pressão intraocular muda a latência e a amplitude desses potenciais (OFRI et al., 1993).

Antes do surgimento da eletrorretinografia, o clínico ou oftalmologista se baseava na presença dos reflexos pupilares direto e consensual, teste de ofuscamento e, quando possível na fundoscopia direta e indireta para avaliar a retina (NARFSTRÖM, 2002).

ERG na medicina humana é usado em várias instituições para diagnosticar e avaliar a progressão de degenerações retinianas hereditárias, enfermidades tóxicas e nutricionais além de detectar e acompanhar, em pacientes diabéticos, a retinopatia proliferativa e não proliferativa, avaliar a retina quando há opacidade de meio e perda inexplicável da visão (RUBIN, 1971; OFRI, 2002; ORIÁ et al., 2004; CATALA; CASTANY, 2005; SAFATLE et al., 2005; PETERSEN-JONES et al., 2006; NARFSTRÖM; PETERSEN-JONES, 2007).

$\mathrm{Na}$ medicina veterinária, ERG tem grande importância na clínica de pequenos animais, como meio de diagnosticar condições que possam resultar em cegueira; podendo ser realizado também em grandes animais e animais exóticos. Em cães, a maior utilidade desse exame é avaliação pré-operatória de pacientes com catarata, nos quais não é possível avaliar o fundo do olho (GRANITZ, 1994; OFRI, 2002; ORIÁ et al., 2004; CHEN et al., 2006; SAFATLE, 2008; SAFATLE et al., 2010b, c, d).

As principais indicações do eletrorretinograma são com a intenção de avaliar a função retiniana. O exame é empregado quando se suspeita de lesão retiniana e outros meios de diagnóstico não foram eficazes para detectá-la, monitorar o grau de comprometimento retiniano após diagnóstico por exame oftalmoscópico das lesões retinianas, avaliar a função da retina em pacientes candidatos a cirurgia para remoção da catarata, diagnosticar precocemente, degenerações retinianas 
hereditárias, principalmente nos cães, algumas vezes nos gatos e mais raramente nos equinos (KOMAROMY et al., 2003; NEGRETTO et al., 2008). Este exame é também importante nos casos em que o oftalmologista, mesmo após boa anamnese e exame clínico, não consegue chegar a um diagnóstico correto, podendo assim, orientá-lo, se é de etiologia neurológica ou oftalmológica (KOMAROMY et al., 1998a, b).

O exame permite avaliar as camadas externas da retina, por meio de um estímulo luminoso, com controle de intensidade, frequência e cor (HONSHO et al., 2004).

ERG possibilita diagnosticar alterações iniciais, mesmo em retinas aparentemente normais à oftalmoscopia (AGUIRRE; RUBIN, 1971; KOMAROMY et al., 1998b; HONSHO et al., 2004; SAFATLE et al., 2007).

Testes eletrofisiológicos utilizados com objetivo de pesquisa foram feitos em várias espécies tais como: rato, camundongo, pombo, esquilo, galinha, coelho, gato, cão, ovelha, macaco. Espécies de maior porte como suíno, bovino e equino são raramente usados para este fim, pois anestesia geral é um procedimento dispendioso, demorado e mais arriscado (KOMAROMY et al., 2003; HENDRIX; SIMS, 1999; NUSINOWITZ; HECKENLIVELY, 2006; PETERSEN-JONES et al., 2006). Em gatos, ERG pode ser utilizado para diagnosticar doenças retinianas como degeneração retiniana hereditária, retinopatia não inflamatória e degeneração retiniana central causada por dieta deficiente em taurina (SIMS, 1999).

Nos equinos, alterações retinianas também são frequentes. Várias são as doenças que necessitam de eletrorretinograma para auxiliar na avaliação da função retiniana, principalmente quando há opacidade de meios, como catarata que é frequente em potros (KOMAROMY et al., 2003; NARFSTRÖM, 2006).

Animais portadores de uveíte recorrente equina (URE), cegueira noturna congênita estacionária (CNCE), retinites e coriorretinites não relacionadas a URE, descolamento de retina, trauma ocular e glaucoma, necessitam do exame para auxiliar no diagnóstico e prognóstico (KOMAROMY et al., 2003; NARFSTRÖM, 2006).

O diagnóstico de acromatopsia também é feito com auxílio do ERG revelando ausência da resposta retiniana a estimulação luminosa com alta frequência e intensidade, caracterizando disfunção de cones. Hurn et al. (2003) diagnosticaram acromatopsia em cães da raça Chihuahua, Pastor de Shetland e mestiço de 
Rhodesian Ridgeback, além do Poodle Miniatura e Malamute já descritos anteriormente por Rubin (1971).

Alguns fatores podem influenciar o ERG, como iluminação ambiental, estado de adaptação da retina, intensidade do flash, idade do paciente, estágio da catarata, técnica anestésica, espécie, raça do animal, qualidade do equipamento que registra e principalmente as condições da retina (TANSKANEN et al., 1996; YANASE; OGAWA, 1997; CHAUDHARY et al., 2003; HONSHO et al., 2004; ITOH et al., 2004; KOMMONEN et al., 2007; MAEHARA et al., 2007; WOODWARD et al., 2007; YU et al., 2007; LEE et al., 2009; LIN et al., 2009). Mentzer et al. (2005) observaram que o tipo do eletrodo e a distância do eletrodo referência também influenciam os traçados do ERG.

Como o paciente deve permanecer imóvel durante o exame, na medicina veterinária há a necessidade de contenção química promovida por sedação ou anestesia (HONSHO et al., 2004; HECKENLIVELY; ARDEN, 2006).

O estabelecimento de um protocolo de sedação para cada espécie, que associe segurança, praticidade, acinesia palpebral e ocular e pouca alteração na amplitude e tempo das ondas do traçado do ERG é desejável tanto para procedimentos de rotina como para pesquisas comparativas (WOODWARD et al., 2007; GIULIANO, 2008; LIN et al., 2009; SAFATLE et al., 2010a).

Alguns estudos sugerem que a anestesia pode interferir nos resultados do ERG (TANSKANEN et al., 1996; YANASE et al., 1997; CHAUDHARY et al., 2003; KOMMONEN et al., 2007; WOODWARD et al., 2007; LIN et al., 2009).

A cetamina é um anestésico dissociativo, porém está associado a movimentos palpebrais involuntários e reflexo corneano (NOWROUZIAN et al., 1981). Em cães, a associação de cetamina com xilazina ou detomidina não deprime a resposta elétrica da retina como halotano ou sevoflurano (YANASE; OGAWA, 1997), porém pode promover rotação do bulbo ocular, necessitando assim de pontos de reparo para seu posicionamento (KOMMONEN; RAITTA, 1987).

Com o objetivo de evitar interferências no registro pelo reflexo de constrição pupilar e estimular a maior área da retina, é necessário dilatar a pupila com um midriático de curta duração (KOMMONEN; RAITTA, 1987).

AInternational Society for Clinical Electrophysiology of Vision (ISCEV) em 1989 juntamente com a Foundation Fighting Blindness, recomendaram um protocolo 
padrão internacional para o uso clínico do ERG de campo total (full-field ERG) no homem. Esse protocolo foi atualizado em 1999 por Marmor e Zrenner e, em 2009 por Marmor et al. com o objetivo de que todo o registro eletrorretinograma feito em diferentes locais pudesse ser interpretado e analisado de forma uniforme.

Os parâmetros a serem usados neste protocolo se referem à amplitude (altura da onda em relação à linha de base ou isoelétrica) pico-a-pico, que é definida em microvolts $(\mu \mathrm{V})$ como o tamanho da resposta entre o pico da onda-a e o pico da onda- $b$, e o tempo de culminação da onda- $b$, que é definido em milisegundos (ms) como o tempo entre o estímulo luminoso e o pico da resposta da onda- $b$. A amplitude da onda-a é mensurada desde a linha isoelétrica até o ponto mais deprimido da onda- $a$. A amplitude da onda- $b$ é medida desde ponto mais baixo da onda- $a$ até o ponto mais elevado da deflexão da onda- $b$. A relação das ondas $b / a$ é importante para correlacionar a função entre camadas internas e externas da retina (Figura 6) (MENDONÇA; TAKAHASHI, 2010).

Figura 6 - Representação esquemática da mensuração da amplitude das onda- $a$ e $b$ no eletrorretinograma de campo total

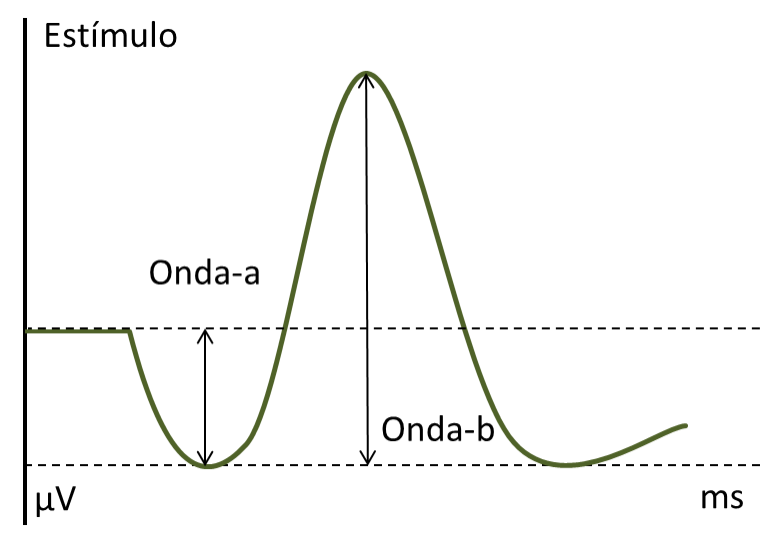

De acordo com ISCEV as cinco respostas obtidas pelo exame são: resposta escotópica obtida pelos bastonetes (com adaptação ao escuro), resposta escotópica máxima (com adaptação ao escuro), potencial oscilatório, resposta fotópica obtida pelos cones (com adaptação ao claro), resposta a estímulos repetitivos rápidos Flicker a 30Hz (MARMOR; ZRENNER, 1999; MARMOR et al., 2004; SAFATLE et al., 
2007) (Figuras 7 e 8). As respostas são registradas após 20 minutos de adaptação do olho ao escuro (NARFSTRÖM, 2002; MARMOR et al., 2009).

Resposta de bastonetes é a primeira resposta a ser registrada, após adaptação ao escuro, com estímulo de flash de luz branca com sua intensidade máxima atenuada em 2,5 unidades logarítmicas, com intervalo de 2 segundos, utilizando-se filtros de densidade neutra. A intensidade de iluminação, abaixo do limiar de resposta dos cones, produz apenas resposta de bastonetes (MARMOR et al., 2004).

Resposta escotópica máxima é obtida com estímulos de alta intensidade e contém tanto as respostas de cones como a de bastonetes. A estimulação é feita no estado adaptado ao escuro e sem a presença de luz de fundo, com intervalo de no mínimo 10 segundos entre cada estimulação, devido à alta intensidade do estímulo (MARMOR et al., 2004).

Os potenciais oscilatórios (POs) são 4 a 10 ondas de baixa amplitude e alta frequência sobrepostas na onda- $a$ ou no ramo ascendente da onda- $b$ do ERG, que são registradas em várias espécies animais, incluindo cão e gato (SIMS, 1999). Estas ondas são fortemente dependentes de uma circulação retiniana intacta, sendo então, indicadores sensíveis de isquemia retiniana (SIMONSEN, 1975; SEVERNS et al., 1994; NEGRETTO et al., 2008). Todos os pacientes devem estar com os olhos adaptados ao escuro e utiliza-se o mesmo standard flash (SF) branco, com um filtro passa-alto de 75 a $100 \mathrm{~Hz}$ e com intervalo interestímulo de 15 segundos. Os potenciais aparecem na porção ascendente da máxima resposta (MARMOR et al., 2004; NEGRETTO et al., 2008).

Acredita-se que os POs sejam resultados do feedback entre as células amácrinas e células bipolares e/ou feedback entre células bipolares e células amácrinas (WACHTMEISTER, 1987; TZEKOV; ARDEN 1999). Para Heckenlively e Arden (2006), a origem dos POs estaria nas células amácrinas, possivelmente células horizontais e células interplexiformes, refletindo a atividade das camadas internas da retina. São mais vulneráveis à distúrbios de circulação retiniana que a onda-b (TZEKOV; ARDEN, 1999; MARMOR; ZRENNER, 1999; NEGRETTO et al., 2008).

Vários estudos foram feitos para descrever alterações de POs em pacientes diabéticos, nos quais se detectaram ausência ou diminuição dos POs nos casos que 
apresentavam retinopatia diabética em grau avançado (NEGRETTO et al., 2008; MARMOR; ZRENNER, 1999). Os POs podem ser utilizados como uma ferramenta muito importante na identificação de pacientes diabéticos com risco de desenvolverem retinopatia proliferativa e assim indicar com urgência, o tratamento com laser (TZEKOV; ARDEN, 1999; NEGRETTO et al., 2008). Podem, também, ser utilizados para mensurar quantitativamente, toda a isquemia retiniana interna em outras doenças vasculares, degenerações retinianas pigmentárias, glaucoma, doença de Alzheimer e outras doenças coriorretinianas difusas (SIMS, 1999).

A resposta fotópica de cones a flash isolado reflete somente a atividade dos cones. É obtida, saturando-se os bastonetes por meio de uma luz branca de fundo com luminância da luz de 17 a $34 \mathrm{~cd} / \mathrm{m}^{2}$ (candelas por metro quadrado). Para obtenção desta resposta é necessário período de adaptação à luz de 10 minutos, pois as respostas dos cones tendem a crescer nos primeiros minutos. A intensidade do estímulo luminoso é máxima (MARMOR et al., 2004).

Flicker a $30 \mathrm{~Hz}$ é a resposta à estimulação intermitente em uma frequência de $30 \mathrm{~Hz}$ (60 reversões entre claro e escuro/segundo). É registrada na presença de luz de fundo $34 \mathrm{~cd} / \mathrm{m}^{2}$ (MARMOR et al., 2004). 
Figura 7 - Eletrorretinograma de campo total utilizando Eletrorretinógrafo Veris 2000, realizado em cão da raça Poodle, fêmea, com 9 anos de idade portadora de diabete melito pré cirurgia de catarata

\section{Ganzfeld Summary}

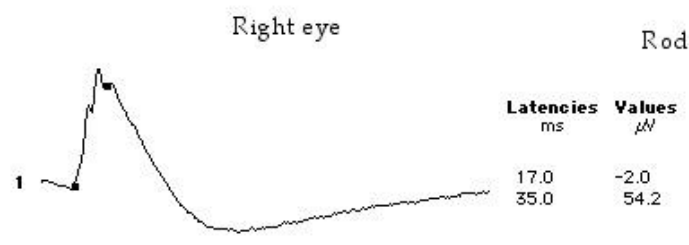

Left eye
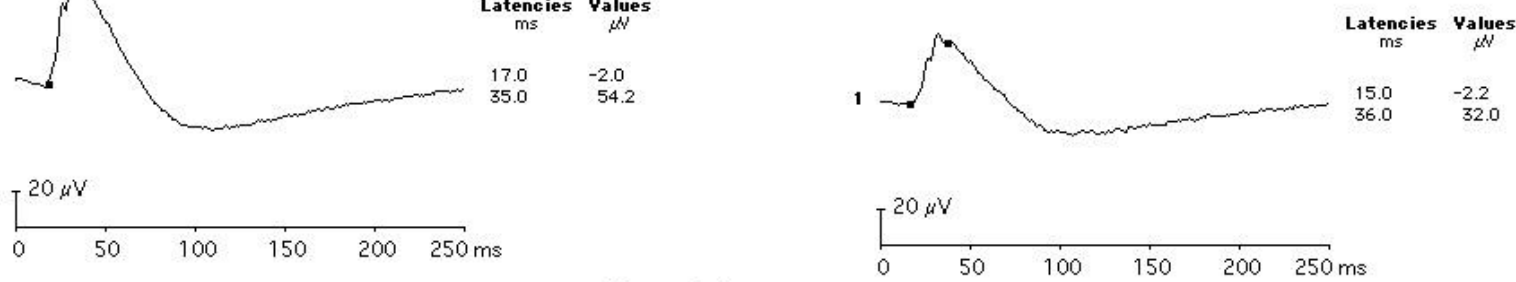

Maximal Response
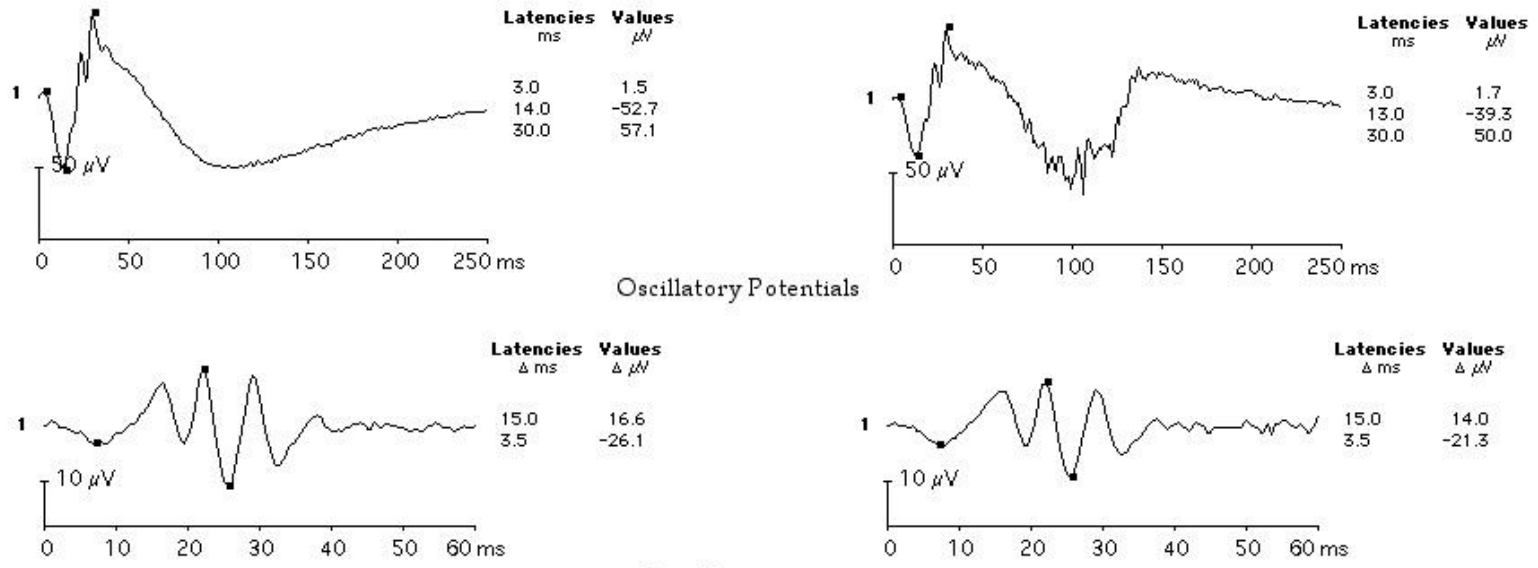

Cone Response
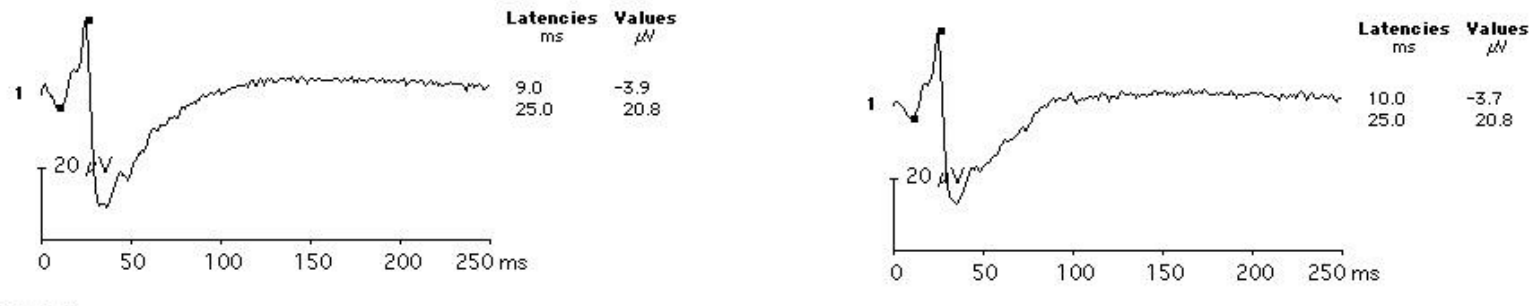

Field View

Field Viev

$30 \mathrm{~Hz}$ Flicker
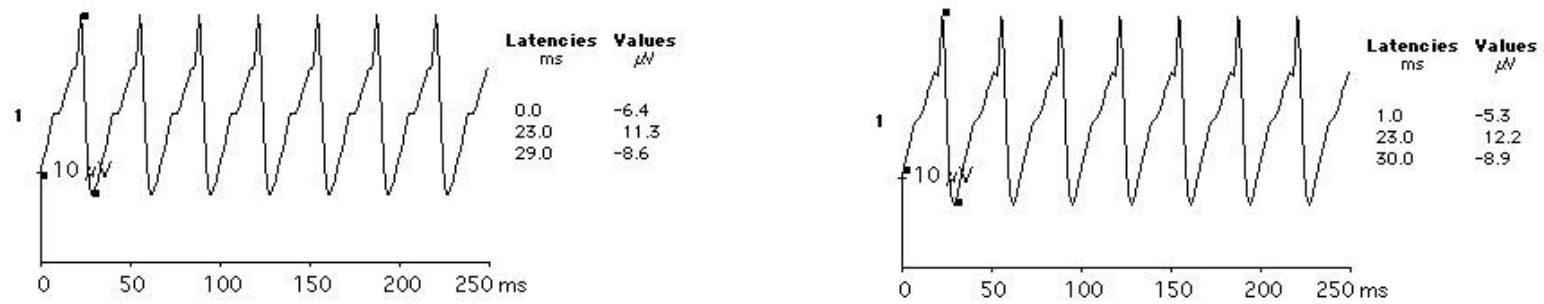

Fonte: LIOC - FMVZ/USP (2012) 
Figura 8 - Eletrorretinograma de Campo Total utilizando Eletrorretinógrafo Veris 2000 realizado em cão da raça Poodle,fêmea, com 9 anos de idade portadora de diabete melito 6 meses pós facoemulsificação

\section{Ganzfeld Summary}

Right eye

Rod response

Left eye
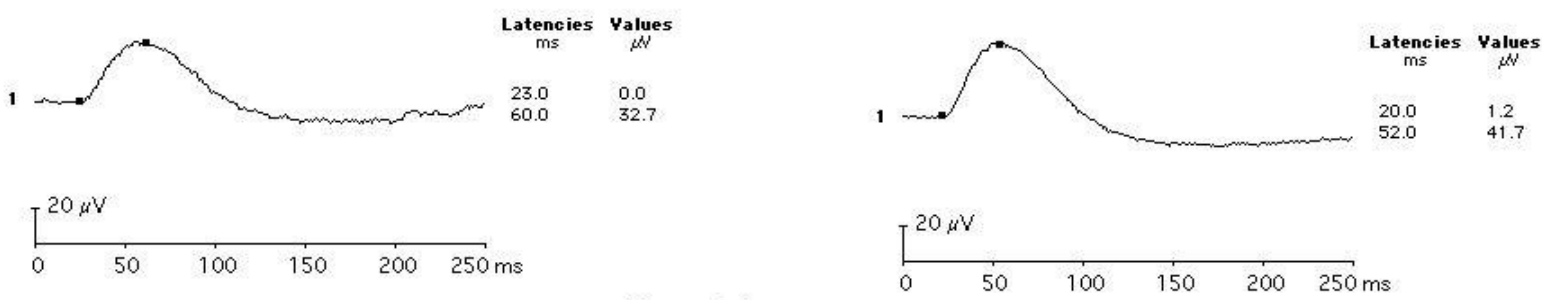

Maximal Response
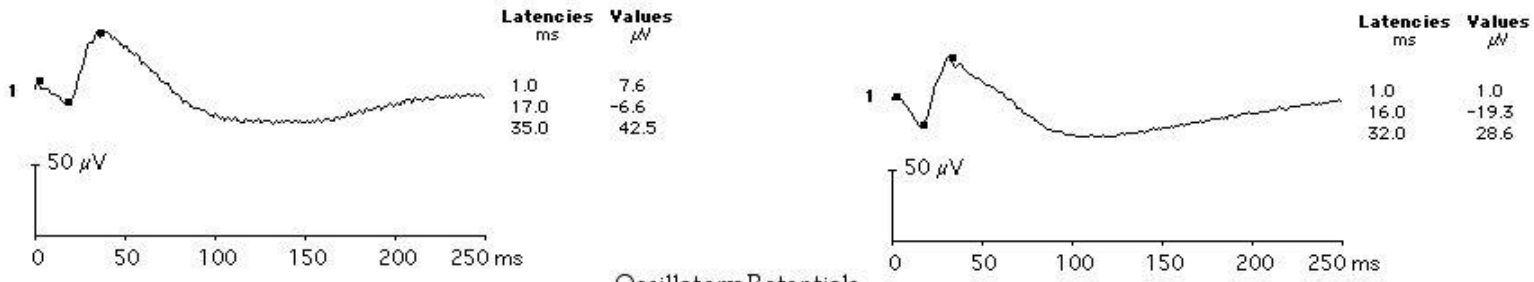

\section{$\underset{\Delta \mathrm{ms}}{\text { Latencies }} \underset{\substack{\Delta, W \\ \Delta N}}{\text { Values }}$}

$\underset{\Delta \mathrm{ms}}{\text { Latencies }} \underset{\Delta \mu \mathrm{N}}{\text { Values }}$

1 (N)
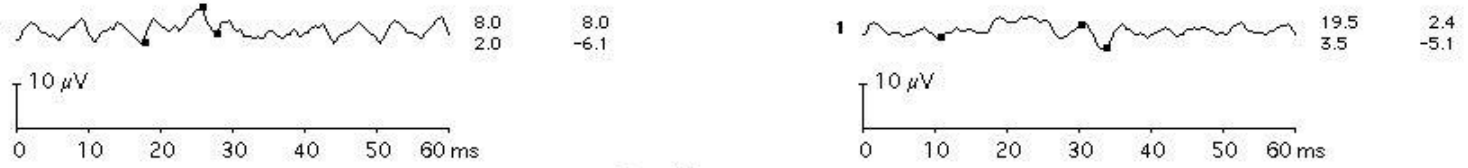

Cone Response

\section{Latencies Values}
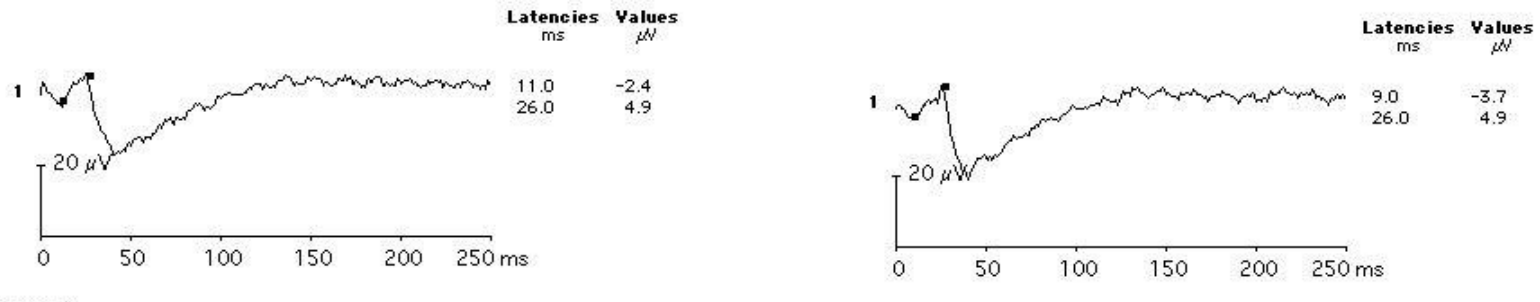

Field Yie*

Field Viev

$30 \mathrm{~Hz}$ Flicker
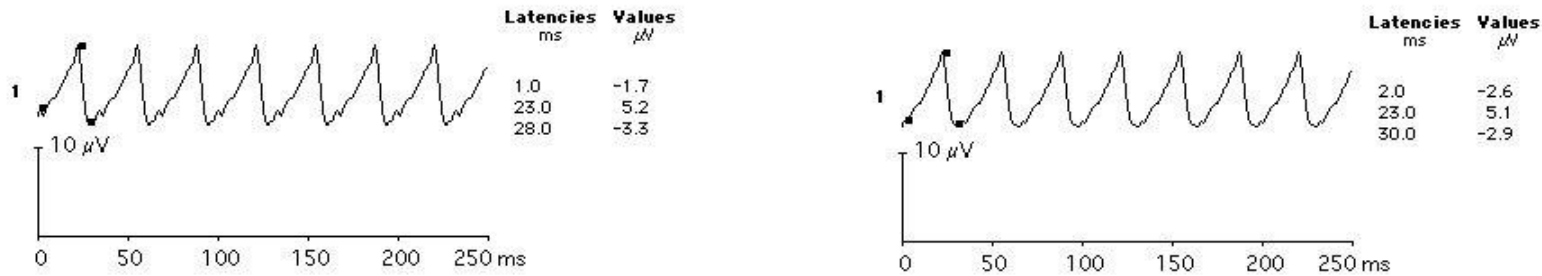

Fonte: LIOC - FMVZ/USP (2012) 


\subsubsection{Alterações eletrorretinográficas}

$\mathrm{Na}$ avaliação das alterações eletrorretinográficas deve-se observar a amplitude $(\mu \mathrm{v})$ e tempo de culminação $(\mathrm{ms})$. Como o eletrorretinograma de campo total registra as respostas da retina como um todo, alterações focais podem não ser detectadas. As alterações relacionadas à retinopatia diabética têm características de comprometimento difuso (PARISI et al., 1997). Assim sendo, podem ser observadas diminuição das amplitudes e aumento do tempo de culminação nas respostas registradas. Onda- $b$ com baixa amplitude representa diminuição funcional de fotorreceptores (KOMAROMY et al., 1998b). As amplitudes das ondas-a e $c$ também podem ser utilizadas para avaliar a função retiniana (SALOMÃO, 2002). O tempo de culminação, que corresponde ao tempo que leva do início do estímulo até o máximo da resposta em cada onda, pode ser mensurado nas 3 ondas, principalmente na onda-b, e também serve para identificar alterações retinianas (KOMAROMY et al., 1998b).

Nos processos isquêmicos de doenças vasculares, como por exemplo nos casos de diabete e consequentemente obstrução venosa, um dos parâmetros importantes na avaliação de alterações vasculares da retina é a relação b/a (DANTAS et al., 2010).

Em doenças vasculares da retina ocorre diminuição na amplitude da onda-a (fotorreceptores) e onda- $b$ (gerada na camada nuclear interna, provavelmente pelas células de Müller, e indiretamente pela atividade da célula bipolar). O processo de diminuição da amplitude da onda- $a$ e $b$ foi descrito primeiramente por Henkes em 1953, porém com uma diminuição maior na amplitude da onda- $b$.

No início da retinopatia diabética, quando à oftalmoscopia ainda não se observa alterações fundoscópias, pode ser identificadas alterações no eletrorretinograma de campo total (estágio 0) (TORREN; MULDER, 1993). A principal alteração é um aumento significativo no tempo de culminação do potencial oscilatório 1 (OP1) (TZEKOV; ARDEN, 1999). Total diminuição das corcovas (ou oscilações) de POs também pode ser observada tanto para a luz branca como luz azul, além atraso no tempo de culminação da onda-b (TZEKOV; ARDEN, 1999). 
A amplitude do potencial oscilatório pode ser correlacionada com a gravidade da retinopatia diabética. A diminuição seletiva ou predominante da amplitude da onda- $b$ pode ser indicativa de oclusões vasculares. Pacientes com grau grave de RDNP têm diminuição acentuada ou até ausência de POs (TZEKOV; ARDEN, 1999). O restante do exame pode apresentar-se dentro da normalidade (MENDONÇA; TAKAHASHI, 2010). Pode haver redução significativa da amplitude da onda- $b$ na fase escotópica em crianças com diabete melito insulino-dependentes onde não se detecta retinopatia diabética na angiografia fluoresceínica (TZEKOV; ARDEN, 1999).

Vários outros parâmetros de ERG podem estar alterados em pacientes humanos com retinopatia diabética não proliferativa (RDNP) grau leve, como: tempo de culminação de onda-b escotópica, tempo de culminação e amplitude do flicker a $30 \mathrm{~Hz}$, e tempo de culminação de ERG fotópico. A maioria dos estudos utilizando eletrorretinograma por padrão reverso (PERG) relata diminuição e retardo no tempo de culminação em casos de DRNP (TZEKOV; ARDEN, 1999).

Estudos feito por Chen et al. (2008) em humanos portadores de retinopatia diabética não proliferativa concluíram que tanto os POs como a amplitude da onda-a são indicadores da função das camadas internas da retina, onde observaram redução da amplitude das respostas além do aumento do tempo de culminação. A pesquisa utilizou estímulo com luz vermelha e luz de fundo azul. Neste estudo afirmaram que esta diminuição foi estatisticamente significante na retinopatia leve, moderada e grave, enquanto que para os POs esta diminuição foi estatisticamente significante nos grupos moderado e grave.

Estudos feitos em ratos diabéticos demonstraram habilidade reduzida nestes animais em sintetizar glutamina do glutamato, aumentando, consequentemente, sua concentração no vítreo. O glutamato, que é neurotransmissor excitatório, quando presente em altas concentrações no vítreo é tóxico para os neurônios retinianos, resultando em função retiniana reduzida no $D M$, o que pode ser observado no $E R G$, com diminuição das respostas logo no início da doença, com exceção dos potenciais oscilatórios (POs), onde esta diminuição ocorre mais tardiamente (HANCOK; KRAFT, 2004).

Diminuição da amplitude da onda-a na fase fotópica, pode ter origem na camada de células ganglionares da retina e axônios, o que confirma a hipótese de que a neuropatia retiniana seja um fator precoce e importante da retinopatia diabética (BRESNICK; PALTA, 1987; CHEN et al., 2008). 
Pacientes com retinopatia diabética proliferativa (RDP) também apresentam alterações no ERG como diminuição da amplitude de POs, retardo no tempo de culminação dos POs, diminuição das ondas-a e b escotópica e fotópica e atraso no $30 \mathrm{~Hz}$ flicker. Yoshida et al. (1991) observaram que anormalidade seletiva nos POs é decorrente de uma disfunção da neurorretina que pode ocorrer antes das alterações vasculares retinianas detectáveis em pacientes diabéticos. Esta neuropatia retiniana pode preceder o aumento da permeabilidade da barreira hematorretiniana, que representa a primeira alteração funcional da retina em pacientes diabéticos não insulino-dependentes (SERRARBASSA et al., 2008).

De acordo com Bresnick e Palta (1987); Kristinssson et al. (1995) e Abbate et al. (2011) pacientes humanos que apresentam baixa amplitude de POs, com moderada a grave retinopatia diabética não proliferativa e discreta retinopatia diabética proliferativa, possuem grandes possibilidades de progressão da retinopatia diabética, quando comparado com olhos que apresentam a mesma lesão, porém com amplitudes normais ou levemente diminuídas dos POs.

ERG é um exame útil na avaliação da retinopatia diabética, porque permite determinar pacientes que tenham ou não propensão a desenvolver DRP, além de mensurar objetivamente, de forma não invasiva a progressão da doença e definir o estado funcional da retina quando o paciente apresenta complicações como a presença de catarata (TZEKOV; ARDEN, 1999).

Segundo Kristinsson et al. (1995), baseados nas diretrizes estabelecidas pela Retinopathy Working Party em 1991 na Europa, o acompanhamento oftalmológico deve ser realizado bianualmente em todos os pacientes diabéticos que não apresentam retinopatia, e anualmente naqueles pacientes portadores de retinopatia diabética, ressaltando a importância do eletrorretinograma nos pacientes diabéticos, objetivando melhorar a qualidade de vida destes pacientes, diminuindo a chance de apresentarem baixa de visão (POLLACK et al., 1991; MUÑANA, 1995; NEHEMY et al., 2001; SQUIRELL et al., 2002; SAFATLE et al., 2008; CHEEMA et al., 2009; SAFATLE et al., 2010d). 


\section{OBJETIVO}

Objetiva-se avaliar a progressão da retinopatia diabética pelo eletrorretinograma de campo total em cães portadores de catarata madura e hipermadura. 


\section{MATERIAL E MÉTODO}

Eletrorretinograma de campo total foi realizado no Serviço de Oftalmologia do Departamento de Cirurgia da Faculdade de Medicina Veterinária e Zootecnia da Universidade de São Paulo no período de julho de 2009 a novembro de 2012 após aprovação pela Comissão de Bioética da Faculdade de Medicina Veterinária e Zootecnia da Universidade de São Paulo - Protocolo nº 1675/2009.

\subsection{Pacientes}

O projeto avaliou 24 cães com catarata (12 cães não diabéticos e 12 diabéticos), 9 machos e 15 fêmeas, das raças Cocker Spaniel Inglês (1), Labrador (1), Lhasa Apso (2), Maltês (3), Poodle Miniatura (4), Schnauzer Miniatura (1), SRD (10) e Yorkshire Terrier (2) encaminhados ao Serviço de Oftalmologia do Hospital Veterinário da Faculdade de Medicina Veterinária e Zootecnia da Universidade de São Paulo. No atendimento oftalmológico foram coletadas informações referentes aos pacientes, como raça, idade, sexo e tempo de desenvolvimento do diabete. Todos os pacientes passaram por exame oftalmológico completo que incluiu: teste de lágrima de Schirmer; tingimento pela fluoresceína; mensuração da pressão intraocular; utilização da lâmpada de fenda para exame do segmento anterior e dilatação pupilar, utilizando colírio de tropicamida 1\%, para avaliar a catarata quanto ao seu estágio e posicionamento.

Previamente ao ERG, os pacientes foram submetidos ao ultrassom ocular, para que fossem excluídos animais com descolamento de retina e hemorragia vítrea.

Dentre os pacientes selecionados, não houve critério de exclusão relacionado à idade.

Todos os animais deste estudo foram submetidos ao ERG de campo total antes da realização da facoemulsificação e 180 dias após a cirurgia. No momento do exame, mensuraram-se os valores séricos de glicose em jejum, com o uso de sensor 
portátil Optium Xceed®, em todos os pacientes e de frutosamina apenas nos diabéticos.

Foram excluídos do projeto animais que apresentaram eletrorretinograma extinto ou respostas atenuadas compatíveis com degeneração retiniana e animais que foram submetidos à facectomia extracapsular pelo método convencional. Selecionou-se para a cirurgia o olho com melhor reposta ao exame do ERG.

O exame foi realizado em sala escura, com o paciente sedado. Administrouse atropina $(0,044 \mathrm{mg} / \mathrm{Kg})$ por via subcutânea. Instilou-se colírio de tropicamida $1 \%$, seguido de colírio de fenilefrina $10 \%$ com intervalo de 5 minutos entre eles em ambos os olhos. A adaptação ao escuro por 30 minutos foi feita com uso de bandagem. Para a sedação administrou-se, por via intramuscular, xilazina $(0,5$ $\mathrm{mg} / \mathrm{Kg})$ e butorfanol $(0,2 \mathrm{mg} / \mathrm{Kg})$. Com o intuito de provocar acinesia palpebral e evitar interferências, injetou-se lidocaína $2 \%(4 \mathrm{mg} / \mathrm{Kg})$ no canto temporal ao bulbo ocular em ambos os lados. Para a obtenção dos registros utilizou-se eletrodo bipolar - Burian Allen que foi colocado sobre a córnea após preenchê-lo com metilcelulose $2 \%$ a fim de oferecer melhor contato elétrico e proteger a superfície corneal. $O$ formato especular de ambos os eletrodos impossibilitou o fechamento palpebral durante o exame. O eletrodo-terra, tipo ear-clip foi colocado no bordo auricular esquerdo tricotomizado após preenchê-lo com creme eletrolítico (Figura 9). Com os eletrodos devidamente colocados, o animal foi posicionado em decúbito ventral com a cabeça inteiramente colocada no interior da cúpula de estimulação (Ganzfeld). Este estimulador formado por uma cúpula com diodos emissores de luz (LEDS Light-emitting diodes) integrados em seu interior, emitiu flashes em diferentes intensidades luminosas, forneceu iluminação de fundo difusa e permitiu a estimulação de todo o campo visual de uma maneira uniforme. Todos os animais foram posicionados sob mesa cirúrgica coberta com tapete de borracha para minimizar a interferência elétrica.

Para a realização do ERG de campo total utilizou-se sistema eletro diagnóstico Veris 2000 , onde um programa de computador comandou o número de apresentações e a duração dos estímulos luminosos. O intervalo interestímulos variou de 1 a 15 segundos. As amplitudes das respostas foram medidas do pico da onda- $a$ ao pico da onda- $b$ em microvolts $(\mu \mathrm{V})$, nas 5 respostas, e o tempo de culminação da onda- $b$ em milisegundos (ms) na resposta de bastonetes, máxima resposta, cones e flicker. 


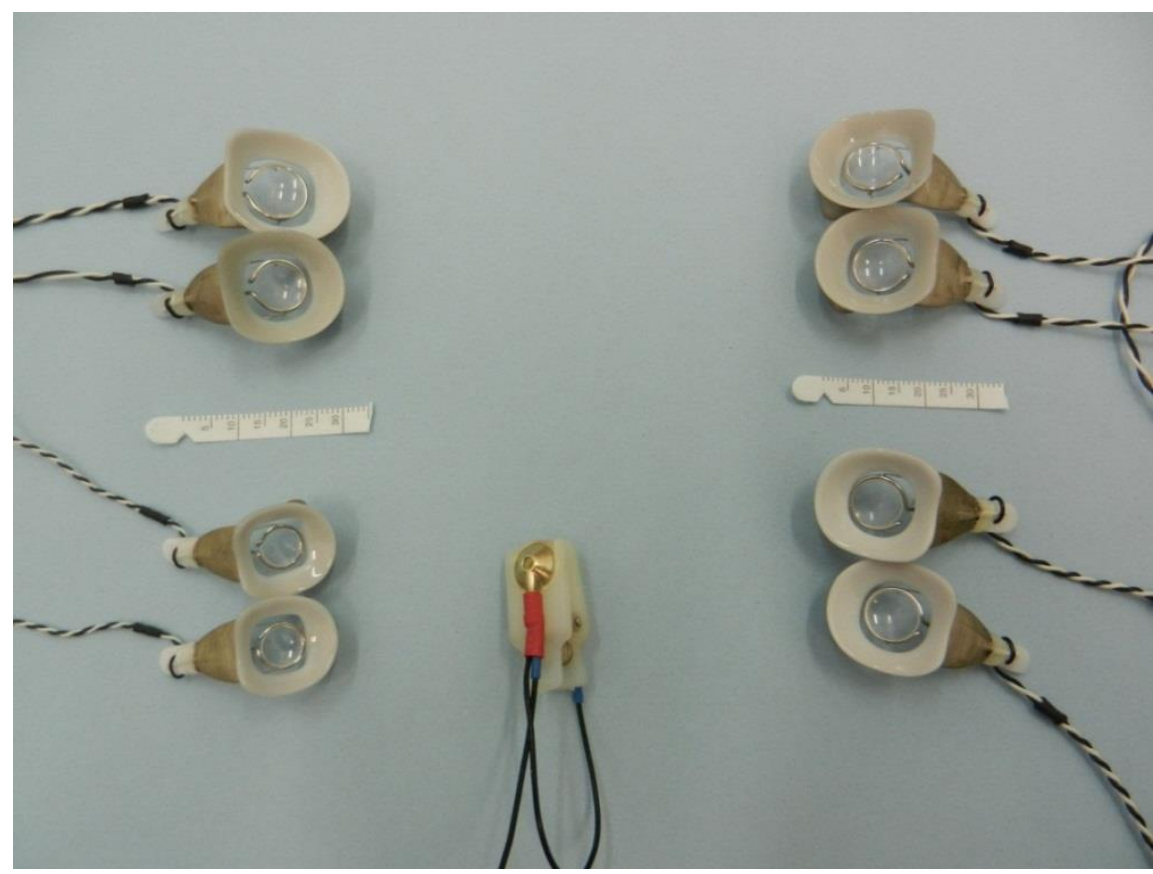

Fonte: LIOC - FMVZ/USP (2013)

O protocolo utlizado foi o mesmo do padrão humano (ISCEV). Primeiramente testou a resposta escotópica de bastonetes: obtida com estímulo de flash de luz branca com intensidade máxima atenuada em 2,5 unidades logarítmicas por filtro de densidade neutra $\left(0,0098 \mathrm{~cd} / \mathrm{m}^{2}\right)$. O intervalo interestímulos foi de 2 segundos. Este estímulo fica abaixo do limiar de resposta dos cones, produzindo apenas respostas de bastonetes.

A segunda resposta obtida foi a resposta escotópica máxima. Para esta resposta há participação tanto dos cones como dos bastonetes e foi obtida com estímulos de alta intensidade $\left(2,467 \mathrm{~cd} / \mathrm{m}^{2}\right)$. Esta resposta é gerada com os olhos ainda adaptados ao escuro e sem a presença de luz de fundo (removeu-se o filtro de 2.5 unidades logarítmicas). O intervalo interestímulos foi de 10 segundos, devido à alta intensidade dos mesmos.

A terceira resposta obtida foram os potenciais oscilatórios: a intensidade dos estímulos foi a mesma da resposta escotópica máxima, porém colhida com filtro passa-alto de $75 \mathrm{~Hz}$, com intervalo interestímulos de 15 segundos. 
A mensuração dos POs foi feita de maneira padronizada, colocando o cursor na primeira deflexão negativa ao redor de $10 \mathrm{~ms}$ e medindo-se o delta da segunda onda que se localiza ao redor de 20 a $30 \mathrm{~ms}$. Assim, padronizou-se a mensuração dos POs deste estudo, uma vez que esta análise pode ser feita de diversas formas.

Depois de adaptação por 10 minutos com luz de fundo azul, realizou-se a fase fotópica. A quarta resposta representa a resposta fotópica de cones registrada por flash único: revela apenas as respostas dos cones. Foi obtida com luminância de $30 \mathrm{~cd} / \mathrm{m}^{2}$ e com intervalo interestímulos de 1 segundo.

A quinta resposta obtida foi o estímulo flicker: resposta isolada dos cones com estimulação intermitente à frequência de $30 \mathrm{~Hz}$, registrada na presença de luz de fundo com luminância de $30 \mathrm{~cd} / \mathrm{m}^{2}$.

Em cada uma das cinco respostas do protocolo padrão da ISCEV, foram feitas 20 apresentações dos estímulos luminosos, sendo considerada a resposta final, a média destes registros, exceto a resposta de flicker que foi resultado de uma média de 50 apresentações dos estímulos luminosos.

A amplitude da onda-a foi medida da linha de base até o pico negativo e a onda- $b$ foi medida do pico negativo da onda- $a$ até o pico positivo da onda- $b$. $O$ tempo de culminação da onda- $b$ foi medido a partir do início do estímulo até o pico da respectiva onda.

Todas as cirurgias de facoemulsificação foram realizadas pelo mesmo cirurgião sob anestesia geral. Para a cirurgia utilizaram-se dois aparelhos de facoemulsificação - Universal II e Laureate, ambos da Alcon. Dos 24 animais 12 cães ( 6 não diabéticos e 6 diabéticos) foram operados pelo Universal II, os outros 12 cães (6 não diabéticos e 6 diabéticos) a cirurgia foi realizada pelo Laureate. A incisão principal e a side-port foram realizadas em córnea clara. A cápsula anterior da lente foi corada com azul de tripano e a câmara anterior preenchida com substância viscoelástica (Metilcelulose $2 \%($ ). Em seguida realizou-se capsulorrexe circular contínua, o núcleo foi hidrodissecado e emulsificado e o material cortical removido por aspiração. Viscoelástico foi removido e a ferida cirúrgica reparada com fio de seda 8-0 (Ethicon).

O grupo dos diabéticos teve todos os olhos tratados com moxifloxacino (Vigamox®) e ceterolaco de trometamina $0,5 \%$ (Cetrolac $\left.{ }^{\circledR}\right) 6$ vezes ao dia, enquanto o grupo não diabético foi tratado com moxifloxacino, dexametasona (Vigadexa®) 6 vezes ao dia. Ambos os grupos foram tratados com tropicamida 1\% (Mydriacy|®) e 
cloridrato de dorzolamida 2\% (Trusopt巴) 3 vezes ao dia nos primeiros 2 dias e depois diminuiu-se a administração dos colírios gradativamente, com exceção do antibiótico tópico que foram mantidos a administração de no mínimo quatro vezes ao dia por 30 dias.

Administrou-se ainda no pós operatório, por via oral, antibiótico a cada 12 horas e anti-inflamatório a cada 24 horas para os 2 grupos. O grupo DM foi tratado com anti-inflamatório não esteroidal (meloxican, Maxican®) e o grupo NDM com esteroidal (prednisona, Meticorten®).

As análises estatísticas foram realizadas pelo programa estatístico SPSS for Windows 7 IBM. Foram calculadas mínima, máxima, média, desvio-padrão (DP), mediana e 2,5 e 97,5 percentis da amplitude pico a pico, do tempo de culminação da onda- $b$ e a relação $b / a$ - amplitude da onda-b/amplitude da onda-a na máxima resposta (condição escotópica) dos 24 animais que fizeram parte deste estudo. $O$ nível de significância de $5 \%(p<0,05)$ foi usado para todos os testes.

Ao compararmos as variações nas respostas do eletrorretinograma de campo total utilizando o teste de Mann-Whitney, ou seja, as diferenças entre as medidas pré e pós cirurgia entre os animais operados pelo aparelho Universal ou pelo aparelho Laureate, observou-se diferença significativa apenas no grupo DM em b/a do olho operado e no tempo de culminação da onda-b de cones do olho controle (Quadro 1). Assim, decidiu-se pela não distinção entre os animais tratados pelo aparelho Universal e Laureate, de modo a se trabalhar com dois grupos de doze animais cada, um de diabéticos e outro de não diabéticos (Quadros 2 e 3).

Considerando os dois grupos de animais operados, diabéticos e não diabéticos, com os resultados dos exames pré e pós-cirurgias, foi verificado pelos testes de Kolmogorov-Smirnov e de Shapiro-Wilk que as variáveis rejeitaram a hipotese nula de normalidade. Sendo assim, optou-se por aplicar testes nãoparamétricos onde foram realizados dois tipos de testes - o teste de Wilcoxon (para dados pareados) e o teste de Mann-Whitney (para dados não pareados). Estes testes objetivaram observar se havia diferença significativa entre as medidas pré e pós-cirúrgicas dentro do mesmo grupo e entre os grupos (Quadro 3).

O efeito da cirurgia e do tempo de DM foi ainda avaliado por meio do cálculo das diferenças entre as respostas no momento pré e pós 6 meses de cada olho (delta OP e delta OC). 
Os gráficos em "boxplot" ou diagrama em caixas representam a distribuição dos dados da amostra. A linha horizontal dentro da caixa é o valor da mediana e os limites inferior e superior da caixa mostram respectivamente o percentil 25 e o percentil 75. Os limites inferior e superior, simbolizados pelas linhas verticais, representam o valor mínimo ou máximo não "outliers". Valores "outliers" são os pontos localizados fora do intervalo formado pelo percentil 75 mais 1,5 vez o intervalo interquartílico e pelo percentil 25 menos 1,5 vez o intervalo interquartílico. 


\section{RESULTADOS}

Foram realizados 48 exames eletrorretinográficos em 24 cães (12 em cães diabéticos e 12 em cães não diabéticos) pré e pós-cirurgia de catarata. Destes animais, 12 (6 diabéticos e 6 não diabéticos) foram operados com o aparelho Universal II e os outros 12 cães (6 diabéticos e 6 não diabéticos) foram operados com facoemulsificador Laureate.

A idade dos pacientes que fizeram parte do estudo variou de 4 a 13 anos no grupo dos diabéticos e 5 a 12 anos no grupo dos não diabéticos. Foram acompanhados cães de raças diversas, dentre elas incluem-se SRD (10), Poodle Miniatura (4), Maltês (3), Lhasa Apso (2), Yorkshire Terrier (2), Cocker Spaniel Inglês (1), Labrador (1) e Schnauzer Miniatura (1).

O tempo de duração do diabete melito na ocasião do exame pré cirurgia de catarata variou entre 4 e 24 meses (média de 10 meses). No exame realizado 6 meses após a facoemulsificação, o tempo de evolução da doença variou 11 a 32 meses (média de 18 meses). Os valores de frutosamina obtidos dos animais diabéticos neste estudo no primeiro exame variaram de 386,0 $\mu \mathrm{mol} / \mathrm{l}$ a $656,0 \mu \mathrm{mol} / \mathrm{l}$ (média 522,5 $\mu \mathrm{mol} / \mathrm{l}$ ), no segundo exame variou de $386,0 \mu \mathrm{mol} / \mathrm{l}$ a $739,4 \mu \mathrm{mol} / \mathrm{l}$ (média 537,0 $\mu \mathrm{mol} / \mathrm{l}$ ). A glicemia do grupo diabético no primeiro exame variou de 80,0 a $377,0 \mathrm{mg} / \mathrm{dl}$ (média $240,3 \mathrm{mg} / \mathrm{dl}$ ) e no segundo exame de 97,0 a $385,0 \mathrm{mg} / \mathrm{dl}$ (média 199,6 mg/dl) (Tabela 1). No grupo não diabético a glicemia no primeiro exame variou de 55,0 a 101,0 mg/dl (média $79,0 \mathrm{mg} / \mathrm{dl}$ ) e no segundo exame de 65,0 a $97,0 \mathrm{mg} / \mathrm{dl}$ (média $84,1 \mathrm{mg} / \mathrm{dl}$ ) (Tabela 2).

Os resultados obtidos dos 24 animais do estudo, comparando o eletrorretinograma de campo total pré e pós-operatórios e entre os animais normais e diabéticos, estão representados nas tabelas 3 a 6 , nos quadros 1 a 3 e nos gráficos 1 a 6 .

O tempo de US utlizado durante a cirurgia de facoemulsifacação no grupo diabético variou de 0,40 a 5,60 (média 2,78, mediana 2,90, DP 1,47) e no grupo não diabético variou de 1,24 a 5,50 (média 3,36, mediana 3,52, DP 1,27) (Tabelas 4 e 6). 
Observou-se diferenças no grupo DM entre OP e OC, no momento pré, nas respostas dos bastonetes e da máxima resposta (amplitude e tempo de culminação onda-b). No momento pós, foram observados diferenças entre OP e OC no tempo de culminação dos bastonetes e flicker, e nas amplitudes do potencial oscilatório, cones e flicker. No grupo NDM, não foram observados diferenças entre os momentos pré e pós assim como entre OP e OC (Quadro 2).

Ao compararmos a amplitude dos bastonetes pré e pós-cirurgia nos dois grupos, observamos diminuição estatisticamente não significante no olho operado e olho não operado do grupo diabético e grupo não diabético (Quadro 3).

Quanto ao tempo de culminação da onda- $b$, observamos diminuição estatisticamente não significante do tempo de culminação nos olhos operados dos dois grupos e aumento nos olhos não operados (Quadro 3).

A diminuição estatisticamente não significante da amplitude da máxima resposta foi observada no grupo dos diabéticos no olho afácico e fácico e no grupo dos não diabéticos no olho fácico. Quanto ao tempo de culminação da onda-b da máxima resposta, observou-se aumento estatisticamente não significante no tempo de culminação do grupo diabético e diminuição estatisticamente não significante no grupo não diabético, tanto em olhos fácicos e afácicos (Quadro 3).

Os potenciais oscilatórios diminuíram de forma não estatisticamente significante ao se compararem os valores pré e pós-cirurgia no grupo dos diabéticos e não diabéticos em olhos afácicos e fácicos ( Quadro 3).

Ao compararmos a amplitude dos cones pré e pós-cirúrgia nos dois grupos, observou-se aumento não estatisticamente significante da amplitude do olho fácico não diabético e afácico do grupo diabético e não diabético. No olho fácico do grupo diabético, houve diminuição não estatisticamente significante da amplitude de cones (Quadro 3).

No tempo de culminação da onda- $b$ dos cones, em olhos operados e não operados, foi observada diminuição não estatisticamete significante nos dois grupos (Quadro 3).

$\mathrm{Na}$ amplitude do flicker a $30 \mathrm{~Hz}$ observou-se aumento não estatisticamente significante nos olhos afácicos dos dois grupos e nos olhos fácicos do grupo não diabético. No olho fácico do grupo diabético houve diminuição não estatisticamente significante da amplitude (Quadro 3). 
O tempo de culminação da onda-b do flicker, houve diminuição não estatisticamente significante no olho afácico dos animais diabéticos e não diabéticos e aumento não estatisticamente significante do tempo de culminação nos olhos fácicos (controle) (Quadro 3).

Quanto à relação das amplitudes das ondas b/a dos olhos fácicos não diabéticos e afácicos diabéticos e não diabéticos observou-se diminuição não estatisticamente significante. O olho fácico do grupo diabético observou-se aumento não estatisticamente significante da amplitude (Quadro 3).

Com a análise estatística, foi possível observar que não houve diferença significativa nos grupos estudados (diabéticos e não diabéticos) entre os valores obtidos do ERG antes e 6 meses após a facoemulsificação, tanto no olho selecionado para a cirurgia (OP) quanto no olho contra-lateral (OC) (Quadro 3).

Quando comparou-se as respostas obtidas entre os grupos (DM e NDM), os valores médios nos momentos pré OP, pós OP, pré OC e pós OC observou-se diferença significativa no tempo de culminação da onda- $b$ na máxima resposta do OP no momento pós, no tempo de culminação da onda- $b$ na máxima resposta OC no momento pós e tempo de culminação da onda- $b$ da resposta de cones no momento pré cirurgia. As diferenças obtidas entre as respostas do ERG entre OP e OC (entre os grupos) observou-se diferença estatisticamente significantes na amplitude da máxima resposta no momento prévio a cirurgia, a diferença entre o olho operado e olho controle no momento pré foi maior no grupo DM (Quadro 3). 
Tabela 1 - Raça, peso, sexo, idade, duraçãodo DM, valores de glicemia e frutosamina dos cães diabéticos durante o ERG

\begin{tabular}{|c|c|c|c|c|c|c|c|c|c|c|}
\hline Animal & Raça & $\begin{array}{c}\text { Peso } \\
(\mathbf{k g})\end{array}$ & Sexo & $\begin{array}{l}\text { Idade } \\
\text { anos }\end{array}$ & $\begin{array}{c}\text { Tempo } \\
\text { DM } \\
\text { (meses) } \\
\text { Pré } \\
\end{array}$ & $\begin{array}{c}\text { Tempo } \\
\text { DM } \\
\text { (meses) } \\
\text { Pós }\end{array}$ & $\begin{array}{c}\text { Glicemia } \\
\text { (mg/dl) } \\
\text { Pré }\end{array}$ & $\begin{array}{c}\text { Glicemia } \\
\text { (mg/dl) } \\
\text { Pós }\end{array}$ & $\begin{array}{c}\text { Frutosamina } \\
(\mu \mathrm{mol} / \mathrm{l}) \text { Pré }\end{array}$ & $\begin{array}{c}\text { Frutosamina } \\
\text { ( } \mu \mathrm{mol} / \mathrm{l}) \text { Pós }\end{array}$ \\
\hline $1 U$ & SRD & 21,0 & $M$ & 4 & 12 & 20 & 178,0 & 224,0 & 423,0 & 423,0 \\
\hline $2 U$ & Cocker & 12,0 & $\mathrm{~F}$ & 10 & 24 & 32 & 376,0 & 123,0 & 499,3 & 423,1 \\
\hline $3 U$ & SRD & 30,0 & $\mathrm{~F}$ & 11 & 8 & 16 & 116,0 & 241,0 & 386,0 & 386,0 \\
\hline $4 U$ & Labrador & 42,0 & $M$ & 6 & 13 & 20 & 96,0 & 373,0 & 579,3 & 739,4 \\
\hline $5 U$ & Lhasa & 6,0 & $M$ & 8 & 8 & 21 & 80,0 & 114,0 & 584,1 & 484,0 \\
\hline $6 U$ & SRD & 8,0 & $\mathrm{~F}$ & 7 & 4 & 12 & 377,0 & 385,0 & 471,9 & 578,0 \\
\hline 7L & SRD & 7,0 & $\mathrm{~F}$ & 7 & 10 & 22 & 185,0 & 124,0 & 460,2 & 622,0 \\
\hline $8 \mathrm{~L}$ & Poodle & 5,0 & $\mathrm{~F}$ & 8 & 12 & 18 & 292,0 & 138,0 & 656,0 & 696,0 \\
\hline $9 \mathrm{~L}$ & Poodle & 4,0 & $\mathrm{~F}$ & 9 & 6 & 12 & 240,0 & 97,0 & 575,0 & 415,0 \\
\hline $10 \mathrm{~L}$ & Maltês & 6,0 & $M$ & 10 & 7 & 13 & 276,0 & 217,0 & 598,0 & 542,0 \\
\hline $11 \mathrm{~L}$ & SRD & 8,0 & $\mathrm{~F}$ & 13 & 5 & 11 & 293,0 & 137,0 & 517,0 & 542,0 \\
\hline \multirow[t]{5}{*}{$12 \mathrm{~L}$} & SRD & 14,0 & $\mathrm{~F}$ & 12 & 8 & 14 & 374,0 & 222,0 & 520,0 & 593,0 \\
\hline & Minima & 4,0 & & 4 & 4 & 11 & 80,0 & 97,0 & 386,0 & 386,0 \\
\hline & Máxima & 42,0 & & 13 & 24 & 32 & 377,0 & 385,0 & 656,0 & 739,4 \\
\hline & Mediana & 8,0 & & 9 & 8 & 17 & 258,0 & 177,5 & 518,5 & 542,0 \\
\hline & Média & 13,6 & & 9 & 10 & 18 & 240,3 & 199,6 & 522,5 & 537,0 \\
\hline
\end{tabular}

U= Universal; L= Laureate; SRD= Sem Raça Definida; $\mathbf{M}=$ macho, $\mathbf{F}=$ fêmea, $\mathbf{K g}=$ Kilograma; $\mathbf{m g} / \mathbf{d l}=$ miligramas por decilitro; $\mu \mathrm{mol} / \mathrm{l}=$ micromolaridade por litro

Tabela 2 - Raça, sexo, peso, idade e valores de glicemia dos cães não diabéticos durante o ERG

\begin{tabular}{ccccccc}
\hline Animal & Raça & Sexo & $\begin{array}{c}\text { Peso } \\
(\mathbf{K g})\end{array}$ & $\begin{array}{c}\text { Idade } \\
\text { anos }\end{array}$ & $\begin{array}{c}\text { Glicemia } \\
(\mathbf{m g} / \mathbf{d l})\end{array}$ & $\begin{array}{c}\text { Glicemia } \\
(\mathbf{m g} / \mathbf{d l})\end{array}$ \\
\hline $1 \mathrm{U}$ & Yorkshire & $\mathrm{M}$ & 5,0 & 5 & 95,0 & 85,0 \\
$2 \mathrm{U}$ & Lhasa & $\mathrm{F}$ & 9,0 & 7 & 76,0 & 97,0 \\
3U & SRD & $\mathrm{F}$ & 6,0 & 6 & 78,0 & 80,0 \\
4U & SRD & $\mathrm{F}$ & 12,0 & 3 & 82,0 & 81,0 \\
5U & Poodle & $\mathrm{F}$ & 8,0 & 8 & 76,0 & 80,0 \\
6U & SRD & $\mathrm{M}$ & 6,0 & 5 & 101,0 & 91,0 \\
7L & Poodle & $\mathrm{M}$ & 6,0 & 8 & 73,0 & 94,0 \\
$8 \mathrm{~L}$ & Schnauzer & $\mathrm{M}$ & 11,0 & 6 & 55,0 & 67,0 \\
9L & Maltês & $\mathrm{M}$ & 6,0 & 8 & 61,0 & 92,0 \\
10L & Yorkshire & $\mathrm{F}$ & 7,0 & 8 & 71,0 & 93,0 \\
11L & SRD & $\mathrm{F}$ & 10,0 & 8 & 92,0 & 65,0 \\
12L & Maltês & $\mathrm{F}$ & 8,0 & 6 & 88,0 & 84,0 \\
\hline & Minima & & 5,0 & 3 & 55,0 & 65,0 \\
& Máxima & & 12,0 & 8 & 101,0 & 97,0 \\
& Mediana & & 7,5 & 7 & 77,0 & 84,5 \\
& Média & & 7,8 & 7 & 79,0 & 84,1 \\
\hline
\end{tabular}

$\mathbf{U}=$ Universal; $\mathbf{L}=$ Laureate; $\mathbf{S}=$ Sem Raça Defininda; $\mathbf{F}=$ fêmea; $\mathbf{M}=$ macho;

$\mathbf{K g}=$ Kilograma $; \mathbf{m g} / \mathbf{d l}=$ miligrama por decilitro 
Tabela 3 - Valores obtidos do eletrorretinograma de campo total dos cães diabéticos

\begin{tabular}{|c|c|c|c|c|c|c|c|c|}
\hline \multirow[t]{2}{*}{ Animal } & \multicolumn{2}{|c|}{ Bastonete OP pré } & \multicolumn{2}{|c|}{ Bastonete OP pós } & \multicolumn{2}{|c|}{ Bastonete OC pré } & \multicolumn{2}{|c|}{ Bastonete OC pós } \\
\hline & amp. $(\mu \mathrm{V})$ & Tcb. (ms) & amp. $(\mu \mathrm{V})$ & Tcb. (ms) & amp. $(\mu \mathrm{V})$ & Tcb. (ms) & amp. $(\mu \mathrm{V})$ & Tcb. (ms) \\
\hline $1 U$ & 92,80 & 44,00 & 61,70 & 51,50 & 56,80 & 48,50 & 34,90 & 56,00 \\
\hline $2 U$ & 30,00 & 64,00 & 26,90 & 65,50 & 31,20 & 64,00 & 28,80 & 64,00 \\
\hline $3 U$ & 60,30 & 66,00 & 51,30 & 49,00 & 42,00 & 67,00 & 27,10 & 63,00 \\
\hline $4 U$ & 74,20 & 63,00 & 34,20 & 66,00 & 50,60 & 66,00 & 25,30 & 81,00 \\
\hline $5 U$ & 63,00 & 53,00 & 54,50 & 44,00 & 25,80 & 58,00 & 53,00 & 55,00 \\
\hline $6 U$ & 39,80 & 54,00 & 35,90 & 49,50 & 33,60 & 57,50 & 31,70 & 55,00 \\
\hline 7L & 41,70 & 41,70 & 85,50 & 42,00 & 55,60 & 44,00 & 33,90 & 40,00 \\
\hline $8 \mathrm{~L}$ & 56,20 & 35,00 & 32,70 & 60,00 & 34,20 & 36,00 & 40,50 & 52,00 \\
\hline 9L & 29,30 & 34,00 & 21,70 & 35,00 & 23,70 & 39,00 & 33,70 & 44,00 \\
\hline $10 \mathrm{~L}$ & 27,60 & 47,00 & 15,40 & 35,00 & 22,00 & 42,00 & 33,50 & 41,00 \\
\hline $11 \mathrm{~L}$ & 36,60 & 54,00 & 28,30 & 36,00 & 25,40 & 56,00 & 37,10 & 46,00 \\
\hline $12 \mathrm{~L}$ & 28,80 & 41,00 & 34,20 & 40,00 & 29,30 & 43,00 & 49,30 & 48,00 \\
\hline \multirow[t]{2}{*}{ Animal } & \multicolumn{2}{|c|}{ Máx. resposta OP pré } & \multicolumn{2}{|c|}{ Máx. resposta OP pós } & \multicolumn{2}{|c|}{ Máx. resposta OC pré } & \multicolumn{2}{|c|}{ Máx. resposta OC pós } \\
\hline & amp. $(\mu \mathrm{V})$ & Tcb. (ms) & amp. $(\mu \mathrm{V})$ & Tcb. (ms) & amp. $(\mu \mathrm{V})$ & Tcb. (ms) & amp. $(\mu \mathrm{V})$ & Tcb. (ms) \\
\hline $1 \mathrm{U}$ & 66,90 & 33,50 & 44,20 & 32,50 & 57,60 & 34,50 & 29,30 & 33,00 \\
\hline $2 U$ & 57,20 & 30,50 & 30,00 & 32,00 & 47,00 & 31,00 & 38,00 & 31,50 \\
\hline $3 U$ & 58,90 & 34,00 & 47,40 & 32,00 & 40,80 & 34,00 & 53,40 & 33,00 \\
\hline $4 U$ & 78,90 & 35,00 & 36,20 & 41,00 & 47,80 & 35,00 & 32,20 & 57,00 \\
\hline $5 U$ & 72,20 & 34,40 & 77,90 & 31,00 & 36,60 & 35,50 & 72,50 & 33,00 \\
\hline $6 U$ & 70,00 & 30,50 & 54,70 & 29,50 & 50,80 & 31,50 & 42,70 & 30,50 \\
\hline 7L & 90,00 & 29,00 & 127,20 & 33,00 & 82,20 & 30,00 & 59,30 & 31,00 \\
\hline $8 \mathrm{~L}$ & 109,80 & 30,00 & 55,70 & 35,00 & 89,30 & 30,00 & 47,90 & 32,00 \\
\hline $9 \mathrm{~L}$ & 59,60 & 30,00 & 52,50 & 30,00 & 55,90 & 32,00 & 54,70 & 31,00 \\
\hline $10 \mathrm{~L}$ & 22,90 & 30,00 & 38,30 & 32,00 & 41,70 & 34,00 & 49,30 & 33,00 \\
\hline $11 \mathrm{~L}$ & 40,60 & 30,00 & 53,80 & 29,00 & 22,90 & 31,00 & 44,20 & 31,00 \\
\hline $12 \mathrm{~L}$ & 39,80 & 32,00 & 63,00 & 30,00 & 45,90 & 31,00 & 69,30 & 33,00 \\
\hline Animal & b/a OP & b/a OP & b/a OC & b/a OC & POs OP pré & POs OP pós & POs OC pré & POs OC pós \\
\hline & pré & pós & pré & pós & $(\mu \mathrm{V})$ & $(\mu \mathrm{V})$ & $(\mu \mathrm{V})$ & $(\mu \mathrm{V})$ \\
\hline $1 \mathrm{U}$ & 1,94 & 1,40 & 2,03 & 1,14 & 12,10 & 4,60 & 8,30 & 4,6 \\
\hline $2 U$ & 3,97 & 2,36 & 5,43 & 4,75 & 8,60 & 3,30 & 5,60 & 6,7 \\
\hline $3 U$ & 3,08 & 1,64 & 2,61 & 2,84 & 6,40 & 6,20 & 7,30 & 5,4 \\
\hline $4 U$ & 5,47 & 2,08 & 5,13 & 16,99 & 5,00 & 2,70 & 5,20 & 0,0 \\
\hline $5 U$ & 2,32 & 2,11 & 3,73 & 2,62 & 9,30 & 8,70 & 8,60 & 8,1 \\
\hline $6 U$ & 3,38 & 2,83 & 4,00 & 4,14 & 7,20 & 8,90 & 6,20 & 8,5 \\
\hline 7L & 2,71 & 3,26 & 2,65 & 2,89 & 10,40 & 9,90 & 16,10 & 8,3 \\
\hline $8 \mathrm{~L}$ & 2,02 & 3,92 & 2,17 & 2,35 & 16,60 & 8,00 & 14,40 & 2,4 \\
\hline 9L & 1,29 & 1,34 & 1,39 & 1,45 & 11,00 & 10,80 & 8,20 & 9,5 \\
\hline $10 \mathrm{~L}$ & 1,59 & 1,09 & 1,70 & 1,44 & 6,70 & 11,40 & 6,60 & 9,1 \\
\hline $11 \mathrm{~L}$ & 1,57 & 1,58 & 1,54 & 1,45 & 9,20 & 11,60 & 8,00 & 9,5 \\
\hline $12 \mathrm{~L}$ & 1,59 & 1,51 & 1,63 & 1,75 & 4,60 & 7,10 & 5,20 & 5,9 \\
\hline Animal & Cone & JP pré & Cone & pós & Cone & C pré & Cones & C pós \\
\hline & amp. $(\mu \mathrm{V})$ & Tcb. (ms) & amp. $(\mu \mathrm{V})$ & Tcb. (ms) & amp. $(\mu \mathrm{V})$ & Tcb. (ms) & amp. $(\mu \mathrm{V})$ & Tcb. (ms) \\
\hline $1 \mathrm{U}$ & 15,6 & 28,0 & 10,8 & 23,0 & 7,6 & 28,5 & 3,7 & 21 \\
\hline $2 U$ & 0,8 & 31,5 & 4,9 & 21,0 & 1,0 & 31,5 & 4,1 & 22 \\
\hline $3 U$ & 1,9 & 22,0 & 1,4 & 26,0 & 3,0 & 34,0 & 8,5 & 33 \\
\hline $4 U$ & 3,7 & 26,0 & 1,5 & 21,0 & 0,8 & 27,0 & 0,7 & 21 \\
\hline $5 U$ & 3,9 & 23,0 & 7,3 & 24,0 & 1,0 & 22,0 & 1,9 & 23 \\
\hline $6 U$ & 1,5 & 31,0 & 6,1 & 24,0 & 0,5 & 27,5 & 2,7 & 23 \\
\hline 7L & 18,0 & 25,0 & 30,5 & 26,0 & 23,4 & 25,0 & 13,7 & 26 \\
\hline $8 \mathrm{~L}$ & 24,7 & 25,0 & 7,3 & 26,0 & 24,5 & 25,0 & 8,6 & 26 \\
\hline 9L & 23,4 & 26,0 & 25,7 & 26,0 & 18,3 & 26,0 & 14,2 & 27 \\
\hline $10 \mathrm{~L}$ & 17,6 & 26,0 & 19,5 & 26,0 & 16,3 & 26,0 & 14,7 & 27 \\
\hline $11 \mathrm{~L}$ & 4,6 & 24,0 & 8,3 & 26,0 & 4,2 & 20,0 & 6,6 & 25 \\
\hline $12 \mathrm{~L}$ & 4,7 & 27,0 & 9,8 & 26,0 & 10,3 & 26,0 & 9,7 & 26 \\
\hline Animal & Flick & OP pré & Flick & pós & Flicke & C pré & Flicke & C pós \\
\hline & amp. $(\mu \mathrm{V})$ & Tcb.(ms) & amp. $(\mu \mathrm{V})$ & $\mathrm{Tcb}(\mathrm{ms})$ & amp. $(\mu \mathrm{V})$ & Tcb. (ms) & amp. $(\mu \mathrm{V})$ & Tcb. (ms) \\
\hline $1 \mathrm{U}$ & 19,0 & 20,0 & 11,8 & 19,0 & 10,8 & 21,5 & 7,8 & 20,0 \\
\hline $2 U$ & 1,7 & 23,5 & 2,3 & 21,0 & 1,0 & 23,5 & 1,4 & 21,5 \\
\hline $3 U$ & 3,3 & 20,0 & 4,3 & 20,0 & 2,0 & 22,0 & 0,8 & 25,0 \\
\hline $4 U$ & 4,9 & 24,0 & 0,6 & 22,0 & 0,3 & 26,0 & 0,4 & 34,0 \\
\hline $5 U$ & 3,2 & 20,0 & 7,1 & 21,0 & 1,1 & 22,0 & 3,7 & 21,0 \\
\hline $6 U$ & 1,1 & 22,0 & 6,6 & 20,5 & 2,0 & 20,5 & 5,1 & 21,0 \\
\hline 7L & 8,6 & 23,0 & 18,5 & 23,0 & 12,2 & 22,0 & 8,9 & 23,0 \\
\hline $8 \mathrm{~L}$ & 17,7 & 23,0 & 6,9 & 23,0 & 17,5 & 23,0 & 7,7 & 23,0 \\
\hline $9 \mathrm{~L}$ & 14,3 & 23,0 & 12,6 & 23,0 & 8,9 & 23,0 & 7,6 & 23,0 \\
\hline $10 \mathrm{~L}$ & 9,0 & 23,0 & 10,6 & 23,0 & 8,3 & 22,0 & 9,3 & 24,0 \\
\hline $11 \mathrm{~L}$ & 2,9 & 22,0 & 4,1 & 22,0 & 1,4 & 21,0 & 4,7 & 22,0 \\
\hline $12 \mathrm{~L}$ & 3,7 & 22,0 & 4,8 & 22,0 & 4,8 & 22,0 & 7,9 & 22,0 \\
\hline
\end{tabular}

$\mathbf{a m p}=$ amplitude; $\mathbf{T c b}=$ tempo de culminação da onda- $b ; \mathbf{M a ́ x}=$ máxima; $\mathbf{O P}=$ olho operado; $\mathbf{O C}=$ olho controle;

POs=potenciais oscilatórios; $\mathbf{U}=$ Universal; $\mathbf{L}=$ Laureaute; $\mathbf{m s}=$ milisegundos; $\mu \mathbf{V}=$ microvolts 
Tabela 4 - Tempo de US gerado durante a facoemulsificação e valores mínimo, máximo, média, mediana e desvio padrão dos resultados obtidos no eletrorretinograma de campo total dos cães diabéticos

\begin{tabular}{|c|c|c|c|c|c|c|c|c|c|}
\hline & \multirow{2}{*}{ Tempo US } & \multicolumn{2}{|c|}{ Bastonete OP pré } & \multicolumn{2}{|c|}{ Bastonete OP pós } & \multicolumn{2}{|c|}{ Bastonete OC pré } & \multicolumn{2}{|c|}{ Bastonete OC pós } \\
\hline & & amp. $(\mu \mathrm{V})$ & $\operatorname{Tcb}(\mathrm{ms})$ & amp. $(\mu \mathrm{V})$ & $\operatorname{Tcb}(\mathrm{ms})$ & amp. $(\mu \mathrm{V})$ & $\mathrm{Tcb}(\mathrm{ms})$ & amp. $(\mu \mathrm{V})$ & $\mathrm{Tcb}(\mathrm{ms})$ \\
\hline Mínimo & 0,40 & 27,60 & 34,00 & 15,40 & 35,00 & 22,00 & 36,00 & 25,30 & 40,00 \\
\hline Máximo & 5,60 & 92,80 & 66,00 & 85,50 & 66,00 & 56,80 & 67,00 & 53,00 & 81,00 \\
\hline Mediana & 2,90 & 48,95 & 50,00 & 34,20 & 46,50 & 32,40 & 52,25 & 33,80 & 53,50 \\
\hline Média & 2,78 & 53,69 & 49,73 & 40,19 & 47,79 & 35,85 & 51,75 & 35,73 & 53,75 \\
\hline \multirow[t]{3}{*}{ DP } & 1,47 & 23,51 & 11,02 & 19,69 & 11,23 & 12,45 & 10,99 & 8,35 & 11,62 \\
\hline & & \multicolumn{2}{|c|}{$\begin{array}{l}\text { Máx.resposta OP } \\
\text { Pré }\end{array}$} & \multicolumn{2}{|c|}{$\begin{array}{c}\text { Máx. resposta OP } \\
\text { Pós }\end{array}$} & \multicolumn{2}{|c|}{$\begin{array}{c}\text { Máx. resposta OC } \\
\text { pré }\end{array}$} & \multicolumn{2}{|c|}{$\begin{array}{l}\text { Máx. resposta OC } \\
\text { pós }\end{array}$} \\
\hline & & amp. $(\mu \mathrm{V})$ & $\operatorname{Tcb}(\mathrm{ms})$ & amp. $(\mu \mathrm{V})$ & $\operatorname{Tcb}(\mathrm{ms})$ & amp. $(\mu \mathrm{V})$ & $\mathrm{Tcb}(\mathrm{ms})$ & amp. $(\mu \mathrm{V})$ & $\mathrm{Tcb}(\mathrm{ms})$ \\
\hline & Mínimo & 22,90 & 29,00 & 30,00 & 29,00 & 22,90 & 30,00 & 29,30 & 30,50 \\
\hline & Máximo & 109,80 & 35,00 & 127,20 & 41,00 & 89,30 & 35,50 & 72,50 & 57,00 \\
\hline & Mediana & 63,25 & 30,50 & 53,15 & 32,00 & 47,40 & 31,75 & 48,60 & 32,50 \\
\hline & Média & 63,90 & 31,58 & 56,74 & 32,25 & 51,54 & 32,46 & 49,40 & 34,08 \\
\hline \multirow{2}{*}{\multicolumn{2}{|c|}{ DP }} & 23,40 & 2,10 & 25,59 & 3,23 & 18,45 & 2,01 & 13,40 & 7,28 \\
\hline & & $\begin{array}{l}\text { b/a OP } \\
\text { pré }\end{array}$ & $\begin{array}{l}\text { b/a OP } \\
\text { pós }\end{array}$ & $\begin{array}{l}\text { b/a OC } \\
\text { pré }\end{array}$ & $\begin{array}{l}\text { b/a OC } \\
\text { pós }\end{array}$ & $\begin{array}{l}\text { POs OP } \\
\text { pré }(\mu \mathrm{V})\end{array}$ & $\begin{array}{l}\text { POs OP } \\
\text { pós }(\mu \mathrm{V})\end{array}$ & $\begin{array}{l}\text { POs OC } \\
\text { pré }(\mu \mathrm{V})\end{array}$ & $\begin{array}{l}\text { POs OC } \\
\text { pós }(\mu \mathrm{V})\end{array}$ \\
\hline \multicolumn{2}{|r|}{ Mínimo } & 1,29 & 1,09 & 1,39 & 1,14 & 4,60 & 2,70 & 5,20 & 0,00 \\
\hline & Máximo & 5,47 & 3,92 & 5,43 & 16,99 & 16,60 & 11,60 & 16,10 & 9,50 \\
\hline \multicolumn{2}{|r|}{ mediana } & 2,17 & 1,86 & 2,39 & 2,49 & 8,90 & 8,35 & 7,65 & 7,40 \\
\hline \multicolumn{2}{|r|}{ Média } & 2,58 & 2,09 & 2,83 & 3,65 & 8,93 & 7,77 & 8,31 & 6,50 \\
\hline \multicolumn{2}{|r|}{ DP } & 1,23 & 0,86 & 1,41 & 4,35 & 3,36 & 3,05 & 3,48 & 3,00 \\
\hline & & \multicolumn{2}{|c|}{ Cones OP pré } & \multicolumn{2}{|c|}{ Cones OP pós } & \multicolumn{2}{|c|}{ Cones OC pré } & \multicolumn{2}{|c|}{ Cones OC pós } \\
\hline & & amp. $(\mu \mathrm{V})$ & $\operatorname{Tcb}(\mathrm{ms})$ & amp. $(\mu \mathrm{V})$ & $\operatorname{Tcb}(\mathrm{ms})$ & amp. $(\mu \mathrm{V})$ & $\mathrm{Tcb}(\mathrm{ms})$ & amp. $(\mu \mathrm{V})$ & $\mathrm{Tcb}(\mathrm{ms})$ \\
\hline & Mínimo & 0,80 & 22,00 & 1,40 & 21,00 & 0,50 & 20,00 & 0,70 & 21,00 \\
\hline & Máximo & 24,70 & 31,50 & 30,50 & 26,00 & 24,50 & 34,00 & 14,70 & 33,00 \\
\hline & mediana & 4,65 & 26,00 & 7,80 & 26,00 & 5,90 & 26,00 & 7,55 & 25,50 \\
\hline & Média & 10,03 & 26,21 & 11,09 & 24,58 & 9,24 & 26,54 & 7,43 & 25,00 \\
\hline \multirow{3}{*}{\multicolumn{2}{|c|}{ DP }} & 9,07 & 2,87 & 9,28 & 1,98 & 9,13 & 3,74 & 4,95 & 3,36 \\
\hline & & \multicolumn{2}{|c|}{ Flicker OP pré } & \multicolumn{2}{|c|}{ Flicker OP pós } & \multicolumn{2}{|c|}{ Flicker OC pré } & \multicolumn{2}{|c|}{ Flicker OC pós } \\
\hline & & amp. $(\mu \mathrm{V})$ & $\operatorname{Tcb}(\mathrm{ms})$ & amp. $(\mu \mathrm{V})$ & $\operatorname{Tcb}(\mathrm{ms})$ & amp. $(\mu \mathrm{V})$ & $\mathrm{Tcb}(\mathrm{ms})$ & amp. $(\mu \mathrm{V})$ & $\mathrm{Tcb}(\mathrm{ms})$ \\
\hline & Mínimo & 1,10 & 20,00 & 0,60 & 19,00 & 0,30 & 20,50 & 0,40 & 20,00 \\
\hline & Máximo & 19,00 & 24,00 & 18,50 & 23,00 & 17,50 & 26,00 & 9,30 & 34,00 \\
\hline & mediana & 4,30 & 22,50 & 6,75 & 22,00 & 3,40 & 22,00 & 6,35 & 22,50 \\
\hline & Média & 7,45 & 22,13 & 7,52 & 21,63 & 5,86 & 22,38 & 5,44 & 23,29 \\
\hline & DP & 6,32 & 1,42 & 5,05 & 1,33 & 5,59 & 1,42 & 3,24 & 3,65 \\
\hline
\end{tabular}

US= ultrassom; $\mathbf{D P}=$ desvio padrão; $\mathbf{a m p =}$ amplitude; Máx= máxima; $\mathbf{O P}=$ olho operado; $\mathbf{P O s}=$ potenciais oscilatórios; $\mathbf{O C}=$ olho controle; $\mathbf{T c b}=$ tempo de culminação da onda $-b ; \mu \mathbf{V}=$ microvolts; $\mathbf{m s = m i l i s e g u n d o s}$ 
Tabela 5 - Valores obtidos do eletrorretinograma de campo total dos cães não diabéticos

\begin{tabular}{|c|c|c|c|c|c|c|c|c|}
\hline \multirow[t]{2}{*}{ Animal } & \multicolumn{2}{|c|}{ Bastonete OP pré } & \multicolumn{2}{|c|}{ Bastonete OP pós } & \multicolumn{2}{|c|}{ Bastonete OC pré } & \multicolumn{2}{|c|}{ Bastonete OC pós } \\
\hline & amp. $(\mu \mathrm{V})$ & $\operatorname{Tcb}(\mathrm{ms})$ & amp. $(\mu \mathrm{V})$ & $\operatorname{Tcb}(\mathrm{ms})$ & amp. $(\mu \mathrm{V})$ & Tcb. (ms) & amp. $(\mu \mathrm{V})$ & Tcb. (ms) \\
\hline $1 U$ & 57,10 & 50,00 & 23,40 & 55,00 & 33,40 & 47,50 & 30,50 & 58,00 \\
\hline $2 U$ & 38,80 & 48,00 & 46,20 & 46,00 & 51,50 & 52,00 & 47,60 & 57,00 \\
\hline $3 U$ & 19,80 & 67,00 & 46,40 & 52,50 & 32,70 & 66,00 & 35,20 & 59,00 \\
\hline $4 U$ & 76,70 & 52,00 & 94,30 & 50,00 & 90,60 & 54,00 & 85,50 & 52,00 \\
\hline $5 U$ & 31,70 & 55,00 & 24,00 & 55,00 & 43,00 & 52,00 & 33,20 & 58,00 \\
\hline $6 U$ & 42,20 & 52,00 & 28,80 & 41,00 & 29,10 & 53,00 & 24,90 & 56,00 \\
\hline 7L & 51,20 & 51,00 & 40,30 & 59,00 & 25,90 & 47,00 & 23,90 & 65,00 \\
\hline $8 \mathrm{~L}$ & 40,50 & 42,00 & 48,60 & 42,00 & 29,70 & 50,00 & 50,00 & 55,00 \\
\hline 9L & 37,30 & 31,00 & 42,70 & 33,00 & 32,20 & 33,00 & 36,60 & 31,00 \\
\hline $10 \mathrm{~L}$ & 35,00 & 48,00 & 31,00 & 45,00 & 41,70 & 49,00 & 36,90 & 40,00 \\
\hline $11 \mathrm{~L}$ & 42,50 & 38,00 & 41,30 & 33,00 & 57,40 & 35,00 & 46,90 & 33,00 \\
\hline $12 \mathrm{~L}$ & 33,70 & 43,00 & 33,70 & 50,50 & 52,30 & 47,00 & 28,80 & 45,00 \\
\hline \multirow[t]{2}{*}{ Animal } & \multicolumn{2}{|c|}{ Máx. resposta OP pré } & \multicolumn{2}{|c|}{ Máx. resposta OP pós } & \multicolumn{2}{|c|}{ Máx. resposta OC pré } & \multicolumn{2}{|c|}{ Máx. resposta Ocpós } \\
\hline & amp. $(\mu \mathrm{V})$ & Tcb. (ms) & amp. $(\mu \mathrm{V})$ & Tcb. (ms) & amp. $(\mu \mathrm{V})$ & Tcb. (ms) & amp. $(\mu \mathrm{V})$ & Tcb. (ms) \\
\hline $1 \mathrm{U}$ & 68,40 & 29,00 & 26,60 & 30,00 & 49,60 & 30,50 & 34,00 & 30,00 \\
\hline $2 U$ & 41,50 & 32,00 & 62,00 & 31,00 & 53,90 & 35,00 & 52,80 & 32,00 \\
\hline $3 \mathrm{U}$ & 47,60 & 33,50 & 85,00 & 30,50 & 60,50 & 31,50 & 72,70 & 31,00 \\
\hline $4 U$ & 100,60 & 35,00 & 131,10 & 30,00 & 91,00 & 35,00 & 100,80 & 29,00 \\
\hline $5 U$ & 43,00 & 33,00 & 34,90 & 32,00 & 56,10 & 33,00 & 37,90 & 33,00 \\
\hline $6 U$ & 33,70 & 30,00 & 39,30 & 29,00 & 38,10 & 31,00 & 60,60 & 30,00 \\
\hline 7L & 77,40 & 29,00 & 67,80 & 30,00 & 38,50 & 28,00 & 51,30 & 31,00 \\
\hline $8 \mathrm{~L}$ & 48,30 & 29,00 & 85,50 & 29,00 & 39,80 & 31,00 & 58,10 & 31,00 \\
\hline 9L & 62,50 & 28,00 & 79,30 & 28,00 & 63,70 & 29,00 & 51,00 & 28,00 \\
\hline $10 \mathrm{~L}$ & 43,00 & 31,00 & 46,60 & 29,00 & 64,90 & 31,00 & 64,00 & 29,00 \\
\hline $11 \mathrm{~L}$ & 56,40 & 30,00 & 63,40 & 29,00 & 90,00 & 30,00 & 79,10 & 30,00 \\
\hline $12 \mathrm{~L}$ & 43,50 & 29,00 & 30,50 & 31,50 & 78,60 & 30,00 & 54,70 & 28,50 \\
\hline Animal & b/a OP & b/a OP & b/a OC & b/a OC & POs OP & POs OP & POs OC & POs OC \\
\hline & pré & pós & pré & pós & pré $(\mu \mathrm{V})$ & pós $(\mu \mathrm{V})$ & pré$(\mu \mathrm{V})$ & pós $(\mu \mathrm{V})$ \\
\hline $1 \mathrm{U}$ & 2,59 & 2,35 & 4,72 & 2,44 & 10,30 & 5,00 & 6,20 & 10,80 \\
\hline $2 U$ & 2,07 & 1,61 & 2,48 & 2,02 & 3,40 & 5,60 & 5,80 & 6,70 \\
\hline $3 U$ & 4,06 & 2,57 & 2,95 & 2,76 & 6,40 & 3,10 & 7,30 & 2,70 \\
\hline $4 U$ & 2,10 & 3,15 & 3,15 & 2,20 & 11,50 & 10,80 & 10,50 & 15,20 \\
\hline $5 U$ & 2,59 & 2,64 & 3,18 & 2,80 & 6,90 & 2,60 & 5,80 & 3,40 \\
\hline $6 U$ & 1,86 & 1,59 & 2,55 & 2,52 & 4,80 & 7,10 & 5,80 & 9,70 \\
\hline 7L & 2,04 & 2,89 & 1,90 & 3,37 & 13,40 & 4,10 & 8,30 & 7,80 \\
\hline 8L & 2,02 & 1,74 & 2,39 & 1,98 & 7,60 & 14,70 & 5,80 & 7,50 \\
\hline 9L & 1,60 & 1,49 & 1,52 & 1,40 & 9,40 & 19,00 & 14,00 & 15,60 \\
\hline $10 \mathrm{~L}$ & 2,79 & 1,85 & 2,88 & 2,00 & 6,90 & 8,10 & 12,60 & 6,80 \\
\hline $11 \mathrm{~L}$ & 1,67 & 1,55 & 1,58 & 1,61 & 12,50 & 9,20 & 14,40 & 8,50 \\
\hline $12 \mathrm{~L}$ & 2,27 & 3,50 & 2,72 & 2,01 & 5,20 & 7,60 & 8,70 & 10,60 \\
\hline Animal & Cone & P pré & Cone & P pós & Cones & C pré & Cone & C pós \\
\hline & amp. $(\mu \mathrm{V})$ & Tcb. (ms) & amp. $(\mu \mathrm{V})$ & Tcb. (ms) & amp. $(\mu \mathrm{V})$ & Tcb. (ms) & amp. $(\mu \mathrm{V})$ & Tcb. (ms) \\
\hline $1 \mathrm{U}$ & 1,70 & 25,50 & 1,20 & 21,00 & 1,70 & 26,00 & 1,90 & 22,00 \\
\hline $2 U$ & 2,20 & 23,00 & 10,00 & 24,00 & 3,90 & 23,00 & 2,70 & 24,00 \\
\hline $3 U$ & 5,10 & 25,00 & 16,10 & 24,00 & 14,60 & 24,00 & 20,30 & 24,00 \\
\hline $4 U$ & 11,00 & 24,00 & 7,30 & 24,00 & 6,60 & 24,00 & 7,10 & 23,00 \\
\hline $5 U$ & 4,40 & 26,00 & 5,60 & 23,00 & 2,40 & 24,00 & 2,40 & 23,00 \\
\hline $6 U$ & 1,70 & 23,00 & 8,00 & 24,00 & 2,70 & 20,00 & 2,20 & 23,00 \\
\hline 7L & 4,20 & 21,00 & 9,00 & 25,00 & 7,10 & 25,00 & 10,50 & 25,00 \\
\hline $8 \mathrm{~L}$ & 6,30 & 26,00 & 8,80 & 20,00 & 2,40 & 26,00 & 3,70 & 25,00 \\
\hline $9 \mathrm{~L}$ & 9,00 & 26,00 & 20,70 & 25,00 & 17,60 & 26,00 & 17,30 & 25,00 \\
\hline $10 \mathrm{~L}$ & 10,50 & 24,00 & 13,00 & 25,00 & 14,40 & 24,00 & 19,00 & 25,00 \\
\hline $11 \mathrm{~L}$ & 15,20 & 26,00 & 15,60 & 24,00 & 14,90 & 26,00 & 16,30 & 24,00 \\
\hline $12 \mathrm{~L}$ & 10,00 & 23,00 & 6,80 & 24,00 & 12,20 & 23,00 & 9,30 & 23,00 \\
\hline Animal & Flick & P pré & Flicke & P pós & Flicke & DC pré & Flicke & C pós \\
\hline & amp. $(\mu \mathrm{V})$ & Tcb. (ms) & amp. $(\mu \mathrm{V})$ & Tcb. (ms) & amp. $(\mu \mathrm{V})$ & Tcb. (ms) & amp. $(\mu \mathrm{V})$ & Tcb. (ms) \\
\hline $1 \mathrm{U}$ & 2,50 & 21,50 & 1,10 & 20,00 & 2,70 & 22,50 & 1,20 & 21,00 \\
\hline $2 U$ & 4,60 & 21,00 & 10,20 & 22,00 & 5,40 & 22,00 & 4,00 & 24,00 \\
\hline $3 U$ & 4,20 & 22,00 & 7,00 & 20,50 & 6,60 & 21,00 & 7,60 & 20,00 \\
\hline $4 U$ & 9,80 & 21,00 & 5,10 & 20,00 & 7,50 & 21,00 & 4,70 & 21,00 \\
\hline $5 U$ & 3,70 & 22,00 & 5,00 & 21,00 & 3,60 & 22,00 & 3,20 & 22,00 \\
\hline $6 U$ & 3,60 & 18,00 & 5,30 & 19,00 & 2,60 & 20,00 & 5,90 & 22,00 \\
\hline 7L & 4,80 & 23,00 & 5,00 & 22,00 & 4,80 & 22,00 & 6,50 & 23,00 \\
\hline 8L & 6,60 & 22,00 & 3,80 & 22,00 & 2,80 & 23,00 & 3,00 & 23,00 \\
\hline $9 \mathrm{~L}$ & 4,50 & 23,00 & 11,50 & 23,00 & 6,30 & 22,00 & 9,60 & 23,00 \\
\hline $10 \mathrm{~L}$ & 8,10 & 22,00 & 9,00 & 22,00 & 8,60 & 22,00 & 13,10 & 23,00 \\
\hline $11 \mathrm{~L}$ & 11,50 & 22,00 & 12,60 & 23,00 & 11,20 & 24,00 & 12,40 & 23,00 \\
\hline $12 \mathrm{~L}$ & 9,80 & 19,00 & 4,60 & 21,00 & 10,20 & 19,00 & 10,10 & 19,00 \\
\hline
\end{tabular}

$\operatorname{amp}(\mu \mathrm{V})=$ amplitude; $\mathbf{T c b}(\mu \mathbf{s})=$ tempo de culminação da onda $b ; \mathbf{M a ́ x}=$ máxima; $\mathbf{O P}=$ olho operado; $\mathbf{O C}=$ olho controle; POs= potenciais oscilatórios; $\mathbf{U}=$ Universal; $\mathbf{L}=$ Laureaute; $\mu \mathbf{V}=$ microvolts; $\mathbf{m s}=$ milisegundos 
Tabela 6 - Tempo de US gerado durante a facoemulsificação e valores mínimo, máximo, média, mediana e desvio padrão dos resultados obtidos no eletrorretinograma de campo total dos cães não diabéticos

\begin{tabular}{|c|c|c|c|c|c|c|c|c|c|}
\hline & \multirow{2}{*}{$\begin{array}{c}\text { Tempo } \\
\text { US }\end{array}$} & \multicolumn{2}{|c|}{ Bastonete OP pré } & \multicolumn{2}{|c|}{ Bastonete OP pós } & \multicolumn{2}{|c|}{ Bastonete OC pré } & \multicolumn{2}{|c|}{ Bastonete OC pós } \\
\hline & & amp.(mV) & $\mathrm{Tcb}(\mathrm{ms})$ & amp. $(\mathrm{mV})$ & $\mathrm{Tcb}(\mathrm{ms})$ & amp.(mV) & $\mathrm{Tcb}(\mathrm{ms})$ & amp.(mV) & $\mathrm{Tcb}(\mathrm{ms})$ \\
\hline mínimo & 1,24 & 19,80 & 31,00 & 23,40 & 33,00 & 25,90 & 33,00 & 23,00 & 31,00 \\
\hline máximo & 5,50 & 76,70 & 67,00 & 94,20 & 59,00 & 90,60 & 66,00 & 85,50 & 65,00 \\
\hline mediana & 3,52 & 26,75 & 49,00 & 40,80 & 48,00 & 37,55 & 49,50 & 35,90 & 55,50 \\
\hline média & 3,36 & 26,75 & 48,08 & 41,73 & 46,83 & 43,29 & 48,79 & 40,00 & 50,75 \\
\hline \multirow[t]{3}{*}{ DP } & 1,27 & 9,83 & 9,07 & 18,72 & 8,43 & 18,12 & 8,59 & 16,70 & 10,94 \\
\hline & & \multicolumn{2}{|c|}{ Máx. resposta OP pré } & \multicolumn{2}{|c|}{ Máx. resposta OP pós } & \multicolumn{2}{|c|}{ Máx. resposta OC pré } & \multicolumn{2}{|c|}{ Máx. resposta OC pós } \\
\hline & & amp.(mV) & Tcb.(ms) & amp. (mV) & $\mathrm{Tcb}(\mathrm{ms})$ & amp.(mV) & $\mathrm{Tcb}(\mathrm{ms})$ & amp.(mV) & $\mathrm{Tcb}(\mathrm{ms})$ \\
\hline \multicolumn{2}{|c|}{ mínimo } & 33,70 & 28,00 & 26,00 & 28,00 & 38,10 & 28,00 & 34,00 & 28,00 \\
\hline \multicolumn{2}{|c|}{ máximo } & 100,60 & 35,00 & 131,30 & 32,00 & 91,00 & 35,00 & 100,80 & 33,00 \\
\hline \multicolumn{2}{|c|}{ mediana } & 47,95 & 30,00 & 62,70 & 30,00 & 58,30 & 31,00 & 56,40 & 30,00 \\
\hline \multicolumn{2}{|c|}{ média } & 55,49 & 30,71 & 62,67 & 20,92 & 60,39 & 31,25 & 59,75 & 30,21 \\
\hline \multicolumn{2}{|c|}{ DP } & 9,12 & 2,20 & 30,03 & 1,97 & 18,47 & 2,15 & 18,12 & 1,47 \\
\hline & & $\begin{array}{c}\text { b/a OP } \\
\text { pré }\end{array}$ & $\begin{array}{c}\text { b/a OP } \\
\text { pós }\end{array}$ & $\begin{array}{c}\text { b/a OC } \\
\text { pré }\end{array}$ & $\begin{array}{c}\text { b/a OC } \\
\text { pós }\end{array}$ & $\begin{array}{l}\text { POs OP } \\
\text { pré (mV) }\end{array}$ & $\begin{array}{l}\text { POs OP } \\
\text { pós(mV) }\end{array}$ & $\begin{array}{c}\text { POs OC } \\
\text { pré }(\mathrm{mV})\end{array}$ & $\begin{array}{l}\text { POs OC } \\
\text { pós(mV) }\end{array}$ \\
\hline \multicolumn{2}{|c|}{ mínimo } & 1,60 & 1,49 & 1,52 & 1,40 & 3,40 & 2,60 & 5,80 & 2,70 \\
\hline \multicolumn{2}{|c|}{ máximo } & 4,06 & 3,50 & 4,72 & 3,37 & 13,40 & 19,00 & 14,40 & 15,60 \\
\hline \multicolumn{2}{|c|}{ mediana } & 2,09 & 2,10 & 2,64 & 2,11 & 7,25 & 7,35 & 7,80 & 8,15 \\
\hline \multicolumn{2}{|c|}{ média } & 2,31 & 2,24 & 2,15 & 2,26 & 8,19 & 8,08 & 8,77 & 8,78 \\
\hline \multicolumn{2}{|c|}{ DP } & 0,66 & 0,70 & 0,86 & 0,55 & 3,20 & 4,85 & 3,32 & 3,96 \\
\hline & & \multicolumn{2}{|c|}{ Cones OP pré } & \multicolumn{2}{|c|}{ Cones OP pós } & \multicolumn{2}{|c|}{ Cones OC pré } & \multicolumn{2}{|c|}{ Cones OC pós } \\
\hline & & amp.(mV) & Tcb (ms) & amp. $(\mathrm{mV})$ & $\operatorname{Tcb}(\mathrm{ms})$ & amp.(mV) & $\mathrm{Tcb}(\mathrm{ms})$ & amp.(mV) & $\operatorname{Tcb}(\mathrm{ms})$ \\
\hline mín & & 1,70 & 21,00 & 1,20 & 20,00 & 1,70 & 20,00 & 1,90 & 22,00 \\
\hline máx & & 15,20 & 26,00 & 20,70 & 25,00 & 17,60 & 26,00 & 20,30 & 25,00 \\
\hline med & & 5,70 & 24,50 & 8,90 & 24,00 & 6,85 & 24,00 & 8,20 & 24,00 \\
\hline mé & & 6,78 & 24,38 & 10,18 & 23,58 & 8,38 & 24,25 & 9,39 & 24,83 \\
\hline \multirow{3}{*}{\multicolumn{2}{|c|}{ DP }} & 4,33 & 1,64 & 5,33 & 1,56 & 5,96 & 1,76 & 7,15 & 1,03 \\
\hline & & \multicolumn{2}{|c|}{ Flicker OP pré } & \multicolumn{2}{|c|}{ Flicker OP pós } & Flicker & C pré & Flicker & C pós \\
\hline & & amp.(mV) & Tcb (ms) & amp. $(\mathrm{mV})$ & $\operatorname{Tcb}(\mathrm{ms})$ & amp.(mV) & $\mathrm{Tcb}(\mathrm{ms})$ & $\mathrm{amp}(\mathrm{mV})$ & $\operatorname{Tcb}(\mathrm{ms})$ \\
\hline Mín & & 2,50 & 18,00 & 1,10 & 19,00 & 2,60 & 19,00 & 1,20 & 19,00 \\
\hline Máx & & 11,50 & 23,00 & 12,60 & 23,00 & 11,20 & 24,00 & 13,10 & 24,00 \\
\hline Med & & 4,70 & 22,00 & 5,20 & 21,50 & 5,85 & 22,00 & 6,20 & 22,50 \\
\hline Mé & & 6,14 & 21,38 & 6,68 & 21,29 & 6,03 & 21,71 & 6,78 & 22,00 \\
\hline D & & 2,95 & 1,49 & 3,44 & 1,25 & 2,93 & 1,32 & 1,20 & 1,48 \\
\hline
\end{tabular}

US=ultrassom; $\mathbf{D P}=$ desvio padrão; $\mathbf{a m p}=$ amplitude; Máx= máxima; $\mathbf{O P}=$ olho operado; $\mathbf{P O s}=$ potenciais oscilatórios; $\mathbf{O C}=$ olho controle; $\mathbf{T c b}=$ tempo de culminação da onda $-b ; \mu \mathbf{V}=$ microvolts; $\mathbf{m s = m i l i s e g u n d o s}$ 
Quadro 1 - Análise estatística, utilizando o teste Mann-Whitney, comparando os resultados obtidos dos animais operados com o aparelho Universal e Laureate nos 2 grupos estudados

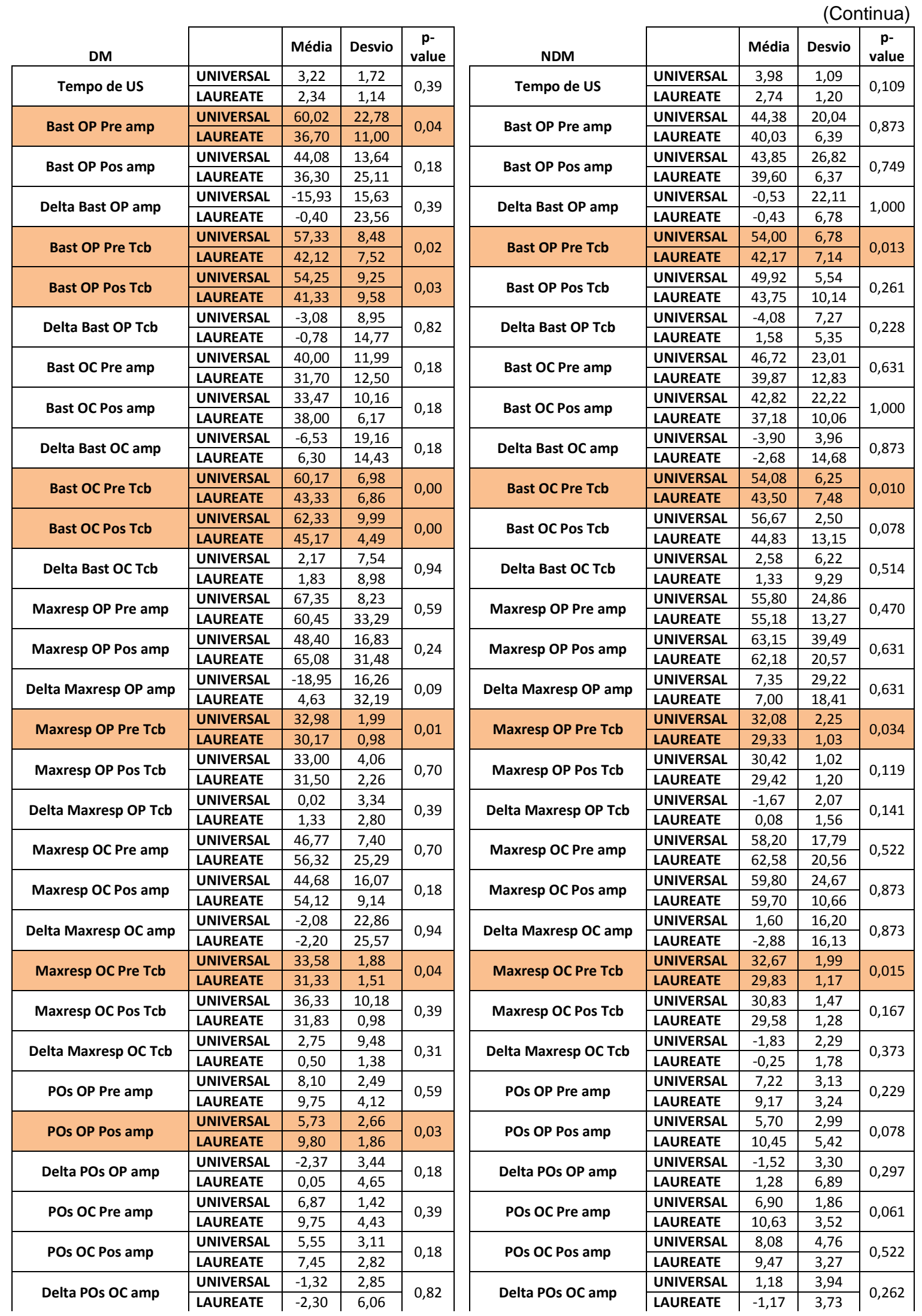

$\mathbf{a m p}=$ amplitude; $\mathbf{T c b}=$ tempo culminação onda- $b ; \mathbf{O P}=$ olho operado; $\mathbf{O C}=$ olho controle; $\mathbf{P O s}=$ potenciais oscilatórios; Máx= maxima resposta; $p<0,05=$ Universal versus Laureate; $p<0,05$ Universal versus Laureate 
Quadro 1 - Análise estatística, utilizando o teste Mann-Whitney, comparando os resultados obtidos dos animais operados com o aparelho Universal e Laureate nos 2 grupos estudados

\begin{tabular}{|c|c|c|c|c|}
\hline \multirow{2}{*}{ Cones OP Pre amp } & UNIVERSAL & 4,57 & 5,54 & \multirow{2}{*}{0,01} \\
\hline & LAUREATE & 15,50 & 8,87 & \\
\hline \multirow{2}{*}{ Cones OP Pos amp } & UNIVERSAL & 5,33 & 3,60 & \multirow{2}{*}{0,02} \\
\hline & LAUREATE & 16,85 & 9,86 & \\
\hline \multirow{2}{*}{ Delta Cones OP amp } & UNIVERSAL & 0,77 & 3,85 & \multirow{2}{*}{0,59} \\
\hline & LAUREATE & 1,35 & 9,97 & \\
\hline \multirow{2}{*}{ Cones OP Pre Tcb } & UNIVERSAL & 26,92 & 3,98 & \multirow{2}{*}{0,59} \\
\hline & LAUREATE & 25,50 & 1,05 & \\
\hline \multirow{2}{*}{ Cones OP Pos Tcb } & UNIVERSAL & 23,17 & 1,94 & \multirow{2}{*}{0,02} \\
\hline & LAUREATE & 26,00 & 0,00 & \\
\hline \multirow{2}{*}{ Delta Cones OP Tcb } & UNIVERSAL & $-3,75$ & 5,33 & \multirow{2}{*}{0,24} \\
\hline & LAUREATE & 0,50 & 1,05 & \\
\hline \multirow{2}{*}{ Cones OC Pre amp } & UNIVERSAL & 2,32 & 2,74 & \multirow{2}{*}{0,00} \\
\hline & LAUREATE & 16,17 & 7,80 & \\
\hline \multirow{2}{*}{ Cones OC Pos amp } & UNIVERSAL & 3,60 & 2,70 & \multirow{2}{*}{0,00} \\
\hline & LAUREATE & 11,25 & 3,40 & \\
\hline \multirow{2}{*}{ Delta Cones OC amp } & UNIVERSAL & 1,28 & 3,19 & \\
\hline & LAUREATE & $-4,92$ & 6,74 & 0,07 \\
\hline & UNIVERSAL & 28,42 & 4,12 & \\
\hline Cones OC Pre Icb & LAUREATE & 24,67 & 2,34 & 0,04 \\
\hline & UNIVERSAL & 23,83 & 4,58 & \\
\hline Cones OC Pos Icb & LAUREATE & 26,17 & 0,75 & $0,0 /$ \\
\hline & UNIVERSAL & $-4,58$ & 3,97 & \\
\hline Delta Cones OC Tcb & LAUREATE & 1,50 & 1,76 & 0,02 \\
\hline & UNIVERSAL & 5,53 & 6,73 & \\
\hline Fllcker UP pre amp & LAUREATE & 9,37 & 5,80 & $0, \angle 4$ \\
\hline & UNIVERSAL & 5,45 & 3,98 & \\
\hline Flicker UP Pos amp & LAUREATE & 9,58 & 5,47 & 0,24 \\
\hline & UNIVERSAL & $-0,08$ & 4,84 & \\
\hline Delta FIIcker UP amp & LAUREATE & 0,22 & 6,67 & 0,82 \\
\hline & UNIVERSAL & 21,58 & 1,86 & \\
\hline Flicker OP Pre Icb & LAUREATE & 22,67 & 0,52 & 0,49 \\
\hline Flicker OP Pos Tcb & UNIVERSAL & 20,58 & 1,02 & O \\
\hline FIICKer UP Pos IcD & LAUREATE & 22,67 & 0,52 & 0,00 \\
\hline Delta Flicker OP Tch & UNIVERSAL & $-1,00$ & 1,30 & 0.18 \\
\hline DeIta FIIcker UP I cD & LAUREATE & 0,00 & 0,00 & 0,18 \\
\hline Flicker $O C$ Pre amn & UNIVERSAL & 2,87 & 3,94 & 007 \\
\hline Flicker UC Pre amp & LAUREATE & 8,85 & 5,63 & 0,01 \\
\hline Flicker OC Pos amn & UNIVERSAL & 3,20 & 2,89 & 003 \\
\hline Flicker UC pos amp & LAUREATE & 7,68 & 1,62 & 0,03 \\
\hline Delta Flicker OC amn & UNIVERSAL & 0,33 & 2,29 & 0.82 \\
\hline Delta Flicker UC amp & LAUREATE & $-1,17$ & 4,94 & 0,82 \\
\hline Flicker OC Pre Tcb & UNIVERSAL & 22,58 & 1,93 & 1.00 \\
\hline FIIcker OC Pre IcD & LAUREATE & 22,17 & 0,75 & 1,00 \\
\hline Flicker OC Pos Tch & UNIVERSAL & 23,75 & 5,31 & 0,39 \\
\hline Flicker OC Pos Icb & LAUREATE & 22,83 & 0,75 & 0,39 \\
\hline & UNIVERSAL & 1,17 & 3,80 & 070 \\
\hline Delta Flicker OC Tcb & LAUREATE & 0,67 & 0,82 & \\
\hline & UNIVERSAL & 3,36 & 1,26 & בח \\
\hline BA OP Pre amp & LAUREATE & 1,80 & 0,51 & 0,02 \\
\hline & UNIVERSAL & 2,07 & 0,51 & 059 \\
\hline BA OP Pos amp & LAUREATE & 2,12 & 1,17 & 0,59 \\
\hline Delta RA PP amn & UNIVERSAL & $-1,29$ & 1,17 & ח \\
\hline Delta BA OP amp & LAUREATE & 0,32 & 0,84 & 0,00 \\
\hline BA OCPre amn & UNIVERSAL & 3,82 & 1,34 & 200 \\
\hline BA UC pre amp & LAUREATE & 1,85 & 0,47 & 0,02 \\
\hline BA OC Pos amn & UNIVERSAL & 5,41 & 5,81 & 013 \\
\hline BA UC Pos amp & LAUREATE & 1,89 & 0,60 & 0,13 \\
\hline Delta BA OC amn & UNIVERSAL & 1,59 & 5,06 & 070 \\
\hline Delta BA OC amp & LAUREATE & 0,04 & 0,19 & 0,10 \\
\hline
\end{tabular}

\begin{tabular}{|c|c|c|c|c|}
\hline \multirow{2}{*}{ Cones OP Pre amp } & UNIVERSAL & 4,35 & 3,56 & \multirow{2}{*}{0,078} \\
\hline & LAUREATE & 9,20 & 3,79 & \\
\hline \multirow{2}{*}{ Cones OP Pos amp } & UNIVERSAL & 8,03 & 4,94 & \multirow{2}{*}{0,200} \\
\hline & LAUREATE & 12,32 & 5,20 & \\
\hline \multirow{2}{*}{ Delta Cones OP amp } & UNIVERSAL & 3,68 & 5,58 & \multirow{2}{*}{1,000} \\
\hline & LAUREATE & 3,12 & 4,99 & \\
\hline \multirow{2}{*}{ Cones OP Pre Tcb } & UNIVERSAL & 24,42 & 1,28 & \multirow{2}{*}{0,742} \\
\hline & LAUREATE & 24,33 & 2,07 & \\
\hline \multirow{2}{*}{ Cones OP Pos Tcb } & UNIVERSAL & 23,33 & 1,21 & \multirow{2}{*}{0,168} \\
\hline & LAUREATE & 23,83 & 1,94 & \\
\hline \multirow{2}{*}{ Delta Cones OP Tcb } & UNIVERSAL & $-1,08$ & 2,25 & \multirow{2}{*}{0,683} \\
\hline & LAUREATE & $-0,50$ & 3,39 & \\
\hline \multirow{2}{*}{ Cones OC Pre amp } & UNIVERSAL & 5,32 & 4,86 & \multirow{2}{*}{0,092} \\
\hline & LAUREATE & 11,43 & 5,65 & \\
\hline \multirow{2}{*}{ Cones OC Pos amp } & UNIVERSAL & 6,10 & 7,22 & \multirow{2}{*}{0,078} \\
\hline & LAUREATE & 12,68 & 5,85 & \\
\hline \multirow{2}{*}{ Delta Cones OC amp } & UNIVERSAL & 0,78 & 2,48 & 0522 \\
\hline & LAUREATE & 1,25 & 2,66 & 0,522 \\
\hline & UNIVERSAL & 23,50 & 1,97 & 0157 \\
\hline Cones OC Pre Tcb & LAUREATE & 25,00 & 1,26 & $0,15 /$ \\
\hline Cones OC Pos Tch & UNIVERSAL & 23,17 & 0,75 & \\
\hline Cones OC Pos Icb & LAUREATE & 24,50 & 0,84 & 0,024 \\
\hline Dolta Conoc OC Tch & UNIVERSAL & $-0,33$ & 2,34 & 0805 \\
\hline Delta Cones OC Icb & LAUREATE & $-0,50$ & 1,05 & 0,805 \\
\hline Flicker OP Pre amn & UNIVERSAL & 4,73 & 2,58 & 0045 \\
\hline Flicker OP Pre amp & LAUREATE & 7,55 & 2,78 & 0,045 \\
\hline Flicker OP Pos amn & UNIVERSAL & 5,62 & 2,97 & 0688 \\
\hline HIIcker UP Pos amp & LAUREATE & 7,75 & 3,80 & 0,688 \\
\hline Delta Flicker OP amn & UNIVERSAL & 0,88 & 3,55 & 0423 \\
\hline Delta FIIcker UP amp & LAUREATE & 0,20 & 4,14 & 0,423 \\
\hline Flicker OP Pre Tch & UNIVERSAL & 20,92 & 1,50 & 0096 \\
\hline FIlcker UP Pre IсD & LAUREATE & 21,83 & 1,47 & 0,096 \\
\hline Flicker OP Pos Tch & UNIVERSAL & 20,42 & 1,02 & 001 \\
\hline FIICKer UP POS ICD & LAUREATE & 22,17 & 0,75 & 0,014 \\
\hline Delta Flicker OP Tch & UNIVERSAL & $-0,50$ & 1,18 & 016 \\
\hline Deita FIIcker UP I cD & LAUREATE & 0,33 & 1,03 & 0,1 \\
\hline & UNIVERSAL & 4,73 & 2,08 & 01 \\
\hline Flicker OC Pre amp & LAUREATE & 7,32 & 3,25 & 0,1 \\
\hline & UNIVERSAL & 4,43 & 2,21 & 00 \\
\hline Flicker OC Pos amp & LAUREATE & 9,12 & 3,80 & \\
\hline & UNIVERSAL & $-0,30$ & 2,17 & \\
\hline Delta Flicker OC amp & LAUREATE & 1,80 & 1,79 & \\
\hline & UNIVERSAL & 21,42 & 0,92 & \\
\hline Flicker OC Pre Tcb & LAUREATE & 22,00 & 1,67 & \\
\hline & UNIVERSAL & 21,67 & 1,37 & \\
\hline Flicker OC Pos Tcb & LAUREATE & 22,33 & 1,63 & \\
\hline & UNIVERSAL & 0,25 & 1,47 & \\
\hline Delta Flicker OC Tcb & LAUREATE & 0,33 & 0,82 & \\
\hline & UNIVERSAL & 2,55 & 0,80 & \\
\hline BA OP Pre amp & LAUREATE & 2,07 & 0,43 & 0,199 \\
\hline RA OP Posamn & UNIVERSAL & 2,32 & 0,62 & $06:-3$ \\
\hline BA UP POS amp & LAUREATE & 2,17 & 0,83 & 0,6 \\
\hline Delta $\mathrm{R}, 2$ & UNIVERSAL & $-0,23$ & 0,82 & ב25 52 \\
\hline Delta BA OP amp & LAUREATE & 0,11 & 0,79 & 0,522 \\
\hline BA OC Pre amn & UNIVERSAL & 3,17 & 0,81 & (2025 \\
\hline BA OC Pre amp & LAUREATE & 2,17 & 0,58 & 0,025 \\
\hline & UNIVERSAL & 2,46 & 0,31 & \\
\hline BA OC Pos amp & LAUREATE & 2,06 & 0,69 & 0,055 \\
\hline & UNIVERSAL & $-0,72$ & 0,83 & \\
\hline & LAUREATE & $-0,10$ & 0,84 & \\
\hline
\end{tabular}

$\mathbf{a m p}=$ amplitude; $\mathbf{T c b}=$ tempo culminação onda $-b ; \mathbf{O P}=0$ lho operado; $\mathbf{O C}=$ olho controle; $\mathbf{P O}=$ potenciais oscilatórios; Máx = maxima resposta; $p<0,05=$ Universal versus Laureate; $p<0,05$ Universal versus Laureate 
Quadro 2 - $\quad$ Análise estatística realizada pelos métodos Wilcoxon dos resultados obtidos no ERG pré OP versus pré OC e pós OP versus pós OC dos 24 animais avaliados neste estudo em cada grupo

\begin{tabular}{|c|c|c|c|c|c|c|}
\hline & \multicolumn{3}{|c|}{ DM } & \multicolumn{3}{|c|}{ NDM } \\
\hline & \multirow{2}{*}{ Médi } & \multirow{2}{*}{ Desvio } & Wilcoxon & \multirow{2}{*}{ Média } & \multirow{2}{*}{ Desvio } & Wilcoxon \\
\hline & & & p-vlue & & & p-vlue \\
\hline Bast OP Pre amp & 48,36 & 20,96 & \multirow{2}{*}{0,02} & 42,21 & 14,36 & \multirow{2}{*}{0,69} \\
\hline Bast OC Pre amp & 35,85 & 12,45 & & 43,29 & 18,12 & \\
\hline Bast OP Pre Tcb & 49,73 & 11,02 & \multirow{2}{*}{0,04} & 48,08 & 9,07 & \multirow{2}{*}{0,64} \\
\hline Bast OC Pre Tcb & 51,75 & 10,99 & & 48,79 & 8,59 & \\
\hline Bast OP Pos amp & 40,19 & 19,69 & \multirow{2}{*}{0,75} & 41,73 & 18,72 & \multirow{2}{*}{0,58} \\
\hline Bast OC Pos amp & 35,73 & 8,35 & & 40,00 & 16,70 & \\
\hline Bast OP Pos Tcb & 47,79 & 11,23 & \multirow{2}{*}{0,02} & 46,83 & 8,43 & \multirow{2}{*}{0,07} \\
\hline Bast OC Pos Tcb & 53,75 & 11,62 & & 50,75 & 10,94 & \\
\hline Maxresp OP Pre amp & 63,90 & 23,40 & \multirow{2}{*}{0,02} & 55,49 & 19,00 & \multirow{2}{*}{0,35} \\
\hline Maxresp OC Pre amp & 51,54 & 18,45 & & 60,39 & 18,47 & \\
\hline Maxresp OP Pre Tcb & 31,58 & 2,10 & \multirow{2}{*}{0,03} & 30,71 & 2,20 & \multirow{2}{*}{0,20} \\
\hline Maxresp OC Pre Tcb & 32,46 & 2,01 & & 31,25 & 2,15 & \\
\hline Maxresp OP Pos amp & 56,74 & 25,59 & \multirow{2}{*}{0,31} & 62,67 & 30,03 & \multirow{2}{*}{0,58} \\
\hline Maxresp OC Pos_amp & 49,40 & 13,40 & & 59,75 & 18,12 & \\
\hline Maxresp OP Pos Tcb & 32,25 & 3,23 & \multirow{2}{*}{0,13} & 29,92 & 1,18 & \multirow{2}{*}{0,27} \\
\hline Maxresp OC Pos Tcb & 34,08 & 7,28 & & 30,21 & 1,47 & \\
\hline POs OP Pre amp & 8,93 & 3,36 & \multirow{2}{*}{0,18} & 8,19 & 3,20 & \multirow{2}{*}{0,56} \\
\hline POs OC Pre amp & 8,31 & 3,48 & & 8,77 & 3,32 & \\
\hline POs OP Pos amp & 7,77 & 3,05 & م & 8,08 & 4,85 & 30 \\
\hline POs OC Pos amp & 6,50 & 3,00 & & 8,78 & 3,96 & \\
\hline Cones OP Pre amp & 10,03 & 9,07 & 037 & 6,78 & 4,33 & 031 \\
\hline Cones OC Pre amp & 9,24 & 9,13 & & 8,38 & 5,96 & \\
\hline Cones OP Pre Tcb & 26,21 & 2,87 & $0<1$ & 24,38 & 1,64 & $0 \in 0$ \\
\hline Cones OC Pre Tcb & 26,54 & 3,74 & & 24,25 & 1,76 & \\
\hline Cones OP Pos amp & 11,09 & 9,28 & 00 & 10,18 & 5,33 & 0,0 \\
\hline Cones OC Pos amp & 7,43 & 4,95 & & 9,39 & 7,15 & \\
\hline Cones OP Pos Tcb & 24,58 & 1,98 & 9 & 23,58 & 1,56 & 10 \\
\hline Cones OC Pos lat & 25,00 & 3,36 & & 23,83 & 1,03 & \\
\hline Flicker OP Pre amp & 7,45 & 6,32 & 10 & 6,14 & 2,95 & 00 \\
\hline Flicker OC Pre amp & 5,86 & 5,59 & & 6,03 & 2,93 & \\
\hline Flicker OP Pre lat & 22,13 & 1,42 & م & 21,38 & 1,49 & 7 \\
\hline Flicker OC Pre lat & 22,38 & 1,42 & & 21,71 & 1,32 & \\
\hline Flicker OP Pos amp & 7,52 & 5,05 & בחת & 6,68 & 3,44 & ه \\
\hline Flicker OC Pos amp & 5,44 & 3,24 & & 6,78 & 3,84 & \\
\hline Flicker OP Pos lat & 21,63 & 1,33 & 0 & 21,29 & 1,25 & 006 \\
\hline Flicker OC Pos lat & 23,29 & 3,65 & & 22,00 & 1,48 & \\
\hline BA OP Pre amp & 2,58 & 1,23 & 16 & 2,31 & 0,66 & 11 \\
\hline BA OC Pre amp & 2,83 & 1,41 & & 2,67 & 0,86 & \\
\hline BA OP Pos amp & 2,09 & 0,86 & 10 & 2,24 & 0,70 & م20 \\
\hline BA OC Pos amp & 3,65 & 4,35 & & 2,26 & 0,55 & \\
\hline
\end{tabular}

$\mathbf{a m p}=$ amplitude; $\mathbf{T c b}=$ tempo culminação onda- $b ; \mathbf{O P}=$ olho operado; $\mathbf{O C}=$ olho controle;

$\mathbf{P O s}=$ potenciais oscilatórios; $\mathbf{M a ́ x}=$ maxima resposta; $\mathrm{p}<0,05$ 
Quadro 3 - $\quad$ Análise estatística realizada pelos métodos Wilcoxon e Mann-Whitney dos resultados obtidos no eletrorretinograma de campo total pré e pós facoemulsificação dos 24 animais avaliados neste estudo em cada grupo e entre os grupos

\begin{tabular}{|c|c|c|c|c|c|c|c|}
\hline & \multicolumn{3}{|c|}{ DM } & \multicolumn{3}{|c|}{ NDM } & \multirow{2}{*}{$\begin{array}{c}\text { Mann-Whitney } \\
\text { p-value }\end{array}$} \\
\hline & Média & Desvio & $\begin{array}{c}\text { Wilcoxon } \\
\text { p-value }\end{array}$ & Média & Desvio & $\begin{array}{c}\text { Wilcoxon } \\
\text { p-value }\end{array}$ & \\
\hline Tempo de US & 2,776 & 1,467 & - & 3,360 & 1,274 & - & 0,319 \\
\hline Bast OP Pre amp & 48,358 & 20,956 & \multirow{3}{*}{0,060} & 42,208 & 14,359 & \multirow{3}{*}{0,929} & 0,843 \\
\hline Bast OP Pos amp & 40,192 & 19,690 & & 41,725 & 18,715 & & 0,799 \\
\hline Delta Bast OP amp & $-8,167$ & 20,715 & & $-0,483$ & 15,594 & & 0,143 \\
\hline Bast OP Pre $\mathrm{Tcb}$ & 49,725 & 11,025 & \multirow{3}{*}{0,556} & 48,083 & 9,070 & \multirow{3}{*}{0,609} & 0,799 \\
\hline Bast OP Pos Tcb & 47,792 & 11,230 & & 46,833 & 8,427 & & 0,977 \\
\hline Delta Bast OP lat & $-1,933$ & 11,709 & & $-1,250$ & 6,767 & & 0,799 \\
\hline Bast OC Pre amp & 35,850 & 12,455 & \multirow{3}{*}{0,937} & 43,292 & 18,116 & \multirow{3}{*}{0,117} & 0,266 \\
\hline Bast OC Pos amp & 35,733 & 8,354 & & 40,000 & 16,703 & & 0,799 \\
\hline Delta Bast OC amp & $-0,117$ & 17,504 & & $-3,292$ & 10,271 & & 0,410 \\
\hline Bast OC PreTcb & 51,750 & 10,991 & \multirow{3}{*}{0,423} & 48,792 & 8,585 & \multirow{3}{*}{0,431} & 0,551 \\
\hline Bast OC PosTcb & 53,750 & 11,616 & & 50,750 & 10,939 & & 0,977 \\
\hline Delta Bast OC Tcb & 2,000 & 7,906 & & 1,958 & 7,563 & & 0,843 \\
\hline Delta Bast Pre amp & 12,51 & 15,37 & \multirow{2}{*}{0,064} & $-1,083$ & 15,85 & \multirow{2}{*}{0,470} & 0,073 \\
\hline Delta Bast Pos amp & 4,458 & 20,6 & & 1,725 & 8,077 & & 0,708 \\
\hline Delta Bast Pre Tcb & $-2,025$ & 2,74 & \multirow{2}{*}{0,083} & $-0,7083$ & 3,583 & \multirow{2}{*}{0,155} & 0,234 \\
\hline Delta Bast Pos Tcb & $-5,958$ & 6,86 & & $-3,917$ & 6,677 & & 0,435 \\
\hline Maxresp OP Pre amp & 63,900 & 23,396 & \multirow{3}{*}{0,433} & 55,492 & 19,002 & \multirow{3}{*}{0,347} & 0,347 \\
\hline Maxresp OP Pos amp & 56,742 & 25,593 & & 62,667 & 30,027 & & 0,551 \\
\hline Delta Maxresp OP amp & $-7,158$ & 27,258 & & 7,175 & 23,287 & & 0,178 \\
\hline Maxresp OP Pre Tcb & 31,575 & 2,096 & \multirow{3}{*}{0,532} & 30,708 & 2,200 & \multirow{3}{*}{0,192} & 0,219 \\
\hline Maxresp OP Pos Tcb & 32,250 & 3,230 & & 29,917 & 1,184 & & 0,017 \\
\hline Delta Maxresp OP Tcb & 0,675 & 3,020 & & $-0,792$ & 1,971 & & 0,410 \\
\hline Maxresp OC Pre amp & 51,542 & 18,449 & \multirow{3}{*}{0,695} & 60,392 & 18,472 & \multirow{3}{*}{0,814} & 0,219 \\
\hline Maxresp OC Pos amp & 49,400 & 13,402 & & 59,750 & 18,118 & & 0,128 \\
\hline Delta Maxresp OC amp & $-2,142$ & 23,125 & & $-0,642$ & 15,588 & & 0,887 \\
\hline Maxresp OC Pre Tcb & 32,458 & 2,005 & \multirow{3}{*}{1,000} & 31,250 & 2,148 & \multirow{3}{*}{0,075} & 0,178 \\
\hline Maxresp OC Pos Tcb & 34,083 & 7,283 & & 30,208 & 1,469 & & 0,002 \\
\hline Delta Maxresp OC Tcb & 1,625 & 6,565 & & $-1,042$ & 2,126 & & 0,291 \\
\hline Delta Maxresp Pre amp & 12,36 & 15,04 & \multirow{2}{*}{0,129} & $-4,9$ & 21,52 & 0266 & 0,040 \\
\hline Delta Maxresp Pos amp & 7,342 & 20,87 & & 2,917 & 20,29 & & 0,840 \\
\hline Delta Maxresp PreTcb & $-0,8833$ & 1,247 & 0.964 & $-0,5417$ & 1,339 & 0.765 & 0,615 \\
\hline Delta Maxresp Pos Tcb & $-1,833$ & 4,769 & & $-0,2917$ & 1,287 & & 0,299 \\
\hline POs OP Pre amp & 8,925 & 3,360 & & 8,192 & 3,203 & & 0,755 \\
\hline POs OP Pos amp & 7,767 & 3,051 & 0,433 & 8,075 & 4,854 & 0,814 & 0,755 \\
\hline Delta POs OP amp & $-1,158$ & 4,103 & & $-0,117$ & 5,352 & & 0,887 \\
\hline POs OC Pre amp & 8,308 & 3,478 & & 8,767 & 3,316 & & 0,671 \\
\hline POs OC Pos amp & 6,500 & 2,998 & 0,433 & 8,775 & 3,963 & 0,969 & 0,178 \\
\hline Delta POs OC amp & $-1,808$ & 4,546 & & 0,008 & 3,861 & & 0,319 \\
\hline Delta POs Pre amp & 0,6167 & 2,49 & 0,424 & $-0,575$ & 3,322 & 1,000 & 0,272 \\
\hline Delta POs Pos amp & 1,267 & 2,078 & & $-0,7$ & 3,62 & & 0,069 \\
\hline
\end{tabular}

amp= amplitude; Bast $=$ bastonete; $\mathbf{D M}=$ diabete melito; $\mathbf{N D M}=$ não diabético melito; $\mathbf{T c b}=$ tempo culminação onda- $b ; \mathbf{O P}=$ olho operado; $\mathbf{O C}=$ olho controle; $\mathbf{P O s}=$ potenciais oscilatórios; Pre= antes cirurgia, Pos= após a cirurgia; US= ultrassom 
Quadro 3 - $\quad$ Análise estatística realizada pelos métodos Wilcoxon e Mann-Whitney dos resultados obtidos no eletrorretinograma de campo total pré e pós facoemulsificação dos 24 animais avaliados neste estudo em cada grupo e entre os grupos

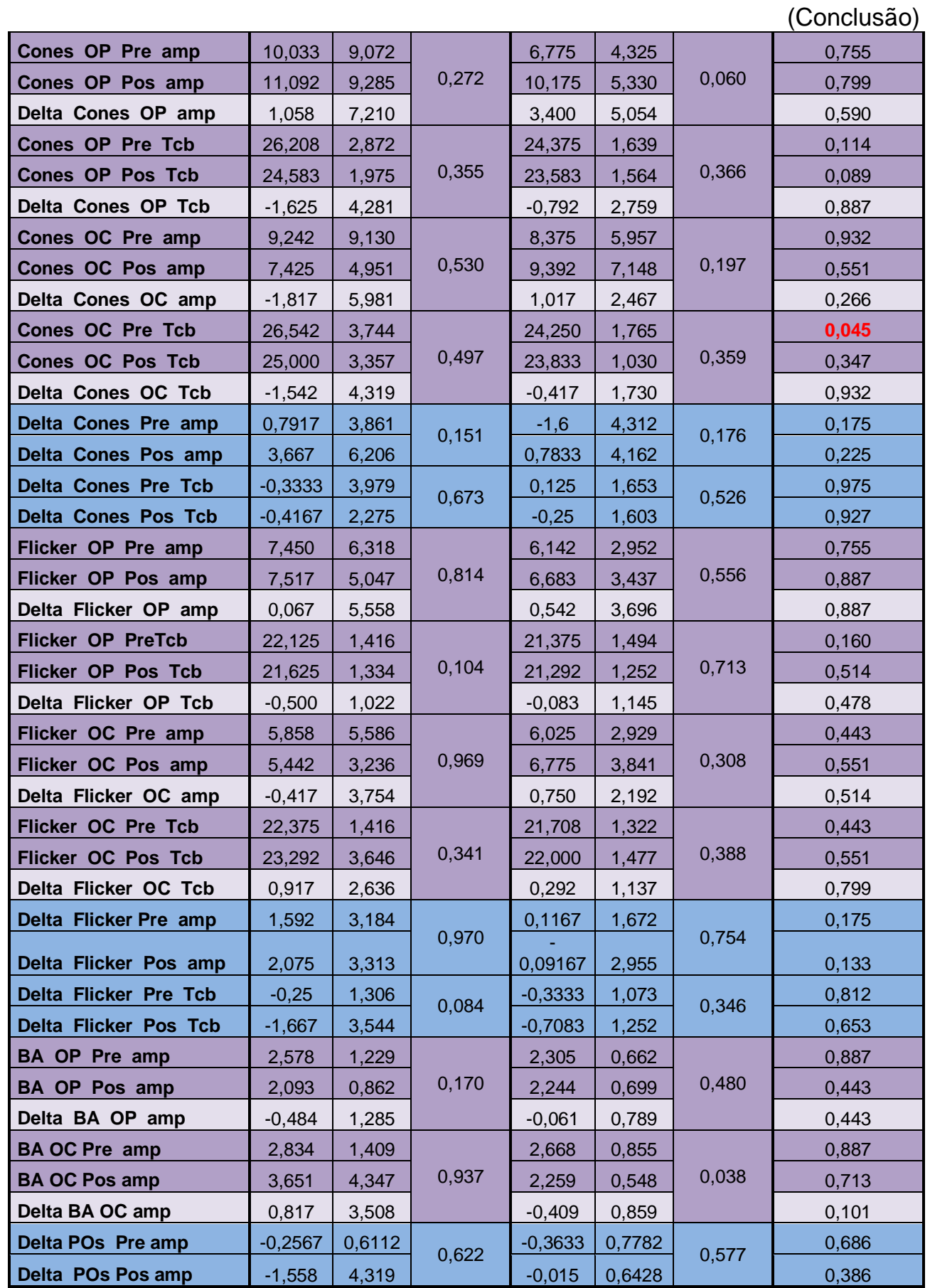

amp= amplitude; Bast= bastonete; $\mathbf{D M}=$ diabete melito; $\mathbf{N D M}=$ não diabético melito; $\mathbf{T c b}=$ tempo culminação onda- $b ; \mathbf{O P}=$ olho operado; $\mathbf{O C}=$ olho controle; $\mathbf{P O} \mathbf{s}=$ potenciais oscilatórios; Pre= antes cirurgia, Pos= após a cirurgia; US= ultrassom 
Gráfico 1 - Representação gráfica em box plot das médias das amplitudes $(\mu \mathrm{V})$, tempo de culminação da onda- $b$ (ms) na resposta de bastonetes e desvio padrão nos 2 grupos (DM e NDM)

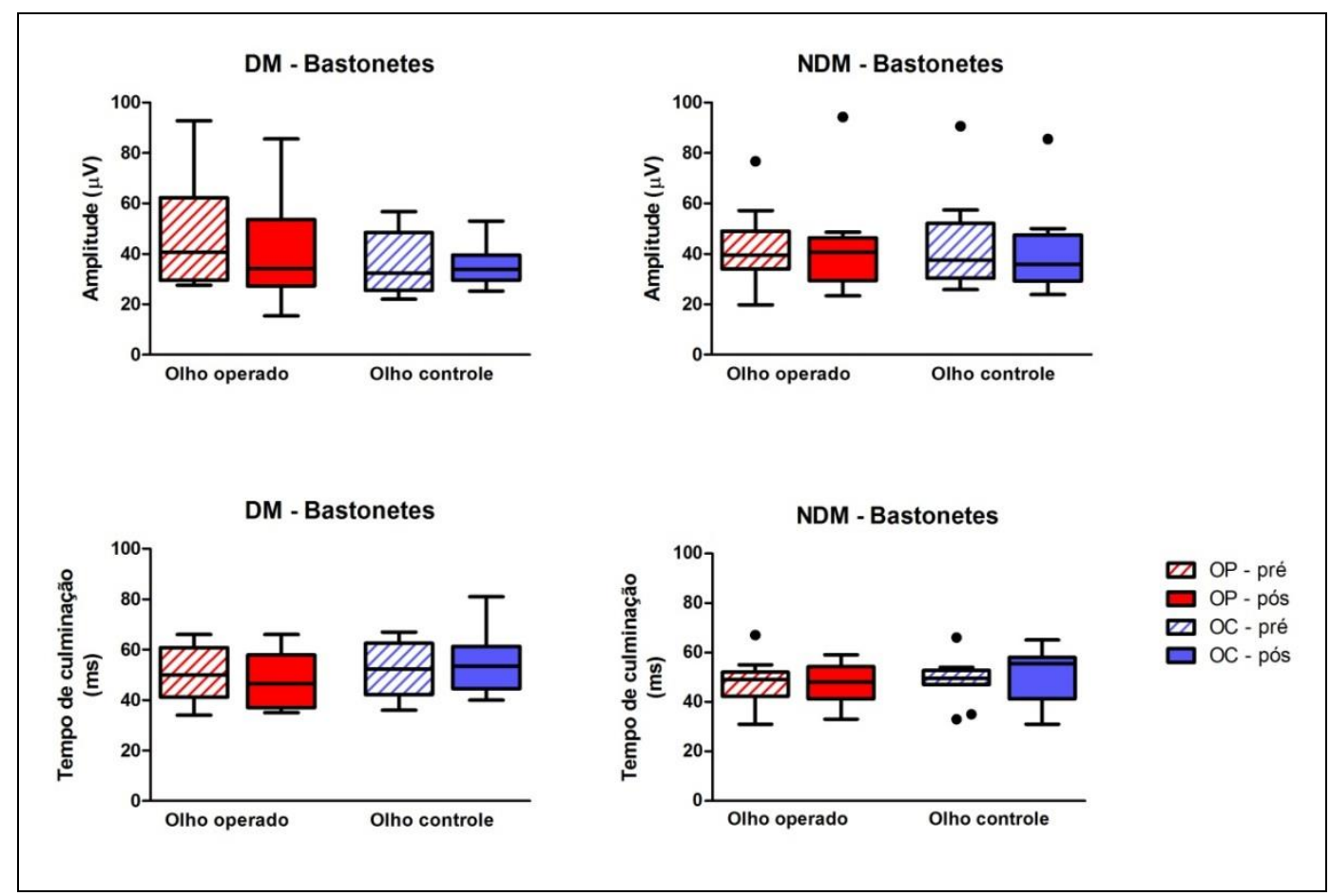

$\mu \mathrm{V}=$ microvolts; $\mathbf{m s = m i l i s e g u n d o s ;} \mathbf{D M}=$ diabético; $\mathbf{N D M}=$ não diabético; $\mathbf{O P}=$ olho operado; $\mathbf{O C}=0$ lho controle

Gráfico 2 - Representação gráfica em box plot das médias das amplitudes $(\mu \mathrm{V})$, tempo de culminação da onda-b $(\mathrm{ms})$ na máxima resposta e desvio padrão nos 2 grupos (DM e NDM)

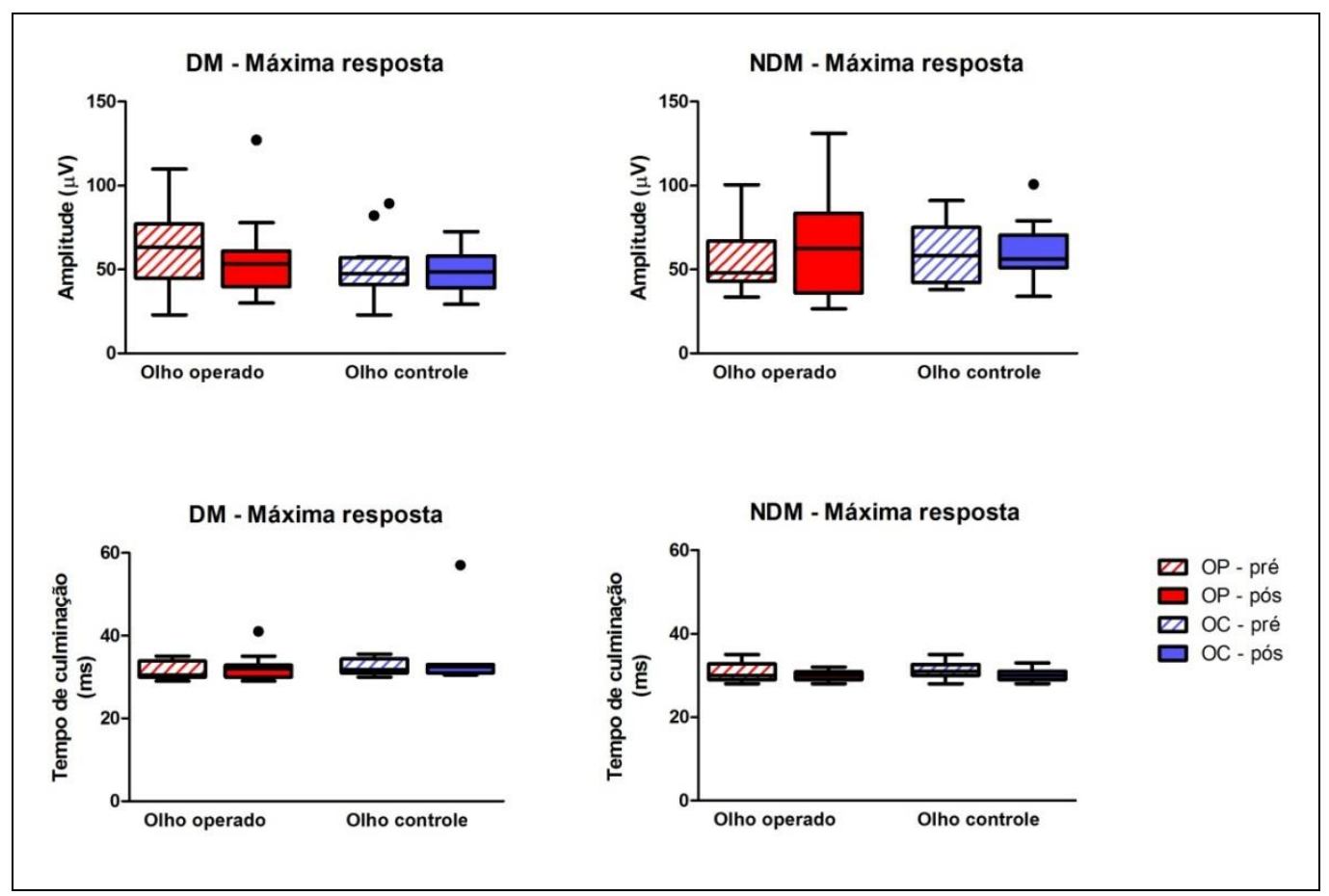

$\mu \mathrm{V}=$ microvolts; $\mathbf{m s}=$ =milisegundos; $\mathbf{D M}=$ diabético; $\mathbf{N D M}=$ não diabético; $\mathbf{O P}=$ olho operado; $\mathbf{O C}=\mathrm{olho}$ controle 
Gráfico 3 - Representação gráfica em box plot das médias da relação das ondas $b / a(\mu \mathrm{V})$ e desvio padrão nos 2 grupos (DM e NDM)

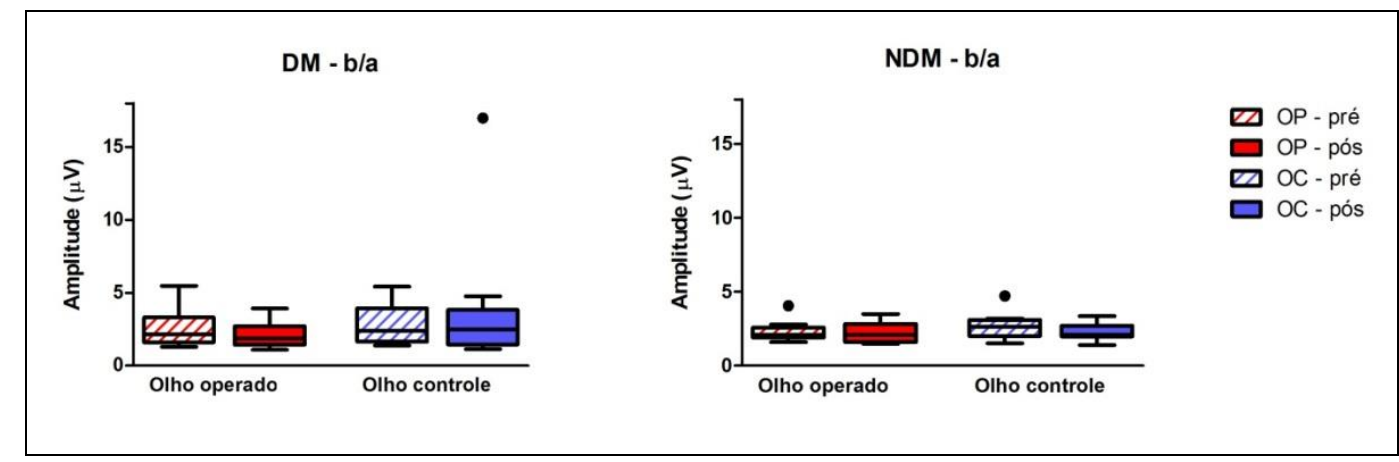

$\mu \mathrm{V}=$ microvolts; $\mathbf{D M}=$ diabético; $\mathbf{N D M}=$ não diabético; $\mathbf{O P}=$ olho operado; $\mathbf{O C}=0$ lho controle

Gráfico 4- Representação gráfica em box plot das médias do delta das amplitudes dos potenciais oscilatórios $(\mu \mathrm{V})$ e desvio padrão nos 2 grupos (DM e NDM)

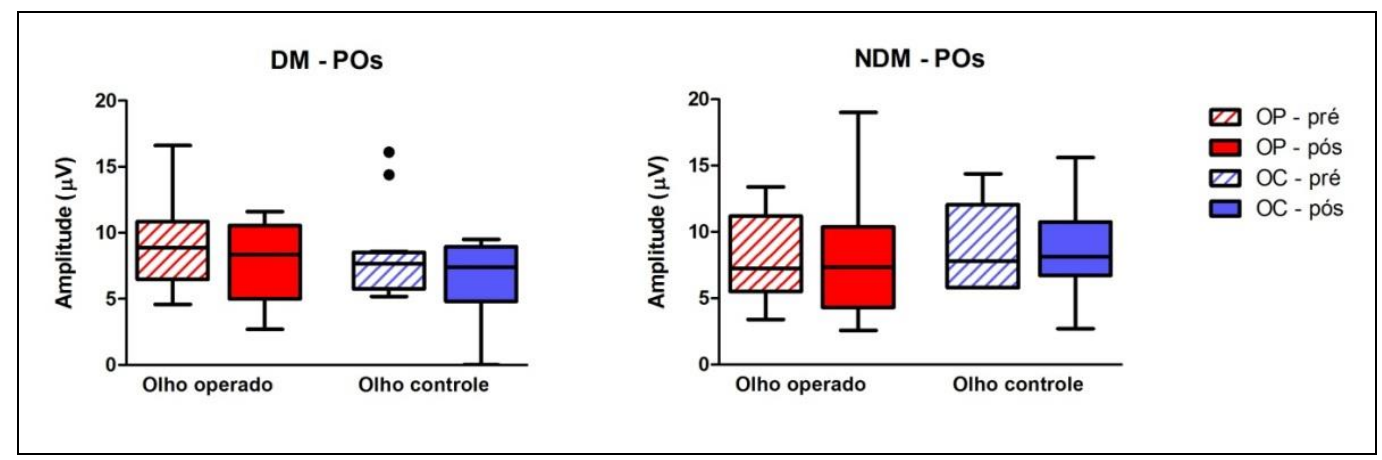

$\mu \mathrm{V}=$ microvolts; $\mathbf{D M}=$ diabético; $\mathbf{N D M}=$ não diabético; $\mathbf{O P}=$ olho operado; $\mathbf{O C}=$ =lho controle 
Gráfico 5 - Representação gráfica em box plot das médias das amplitudes $(\mu \mathrm{V})$, tempo de culminação da onda-b (ms) nas respostas de cones e desvio padrão nos 2 grupos (DM e NDM)

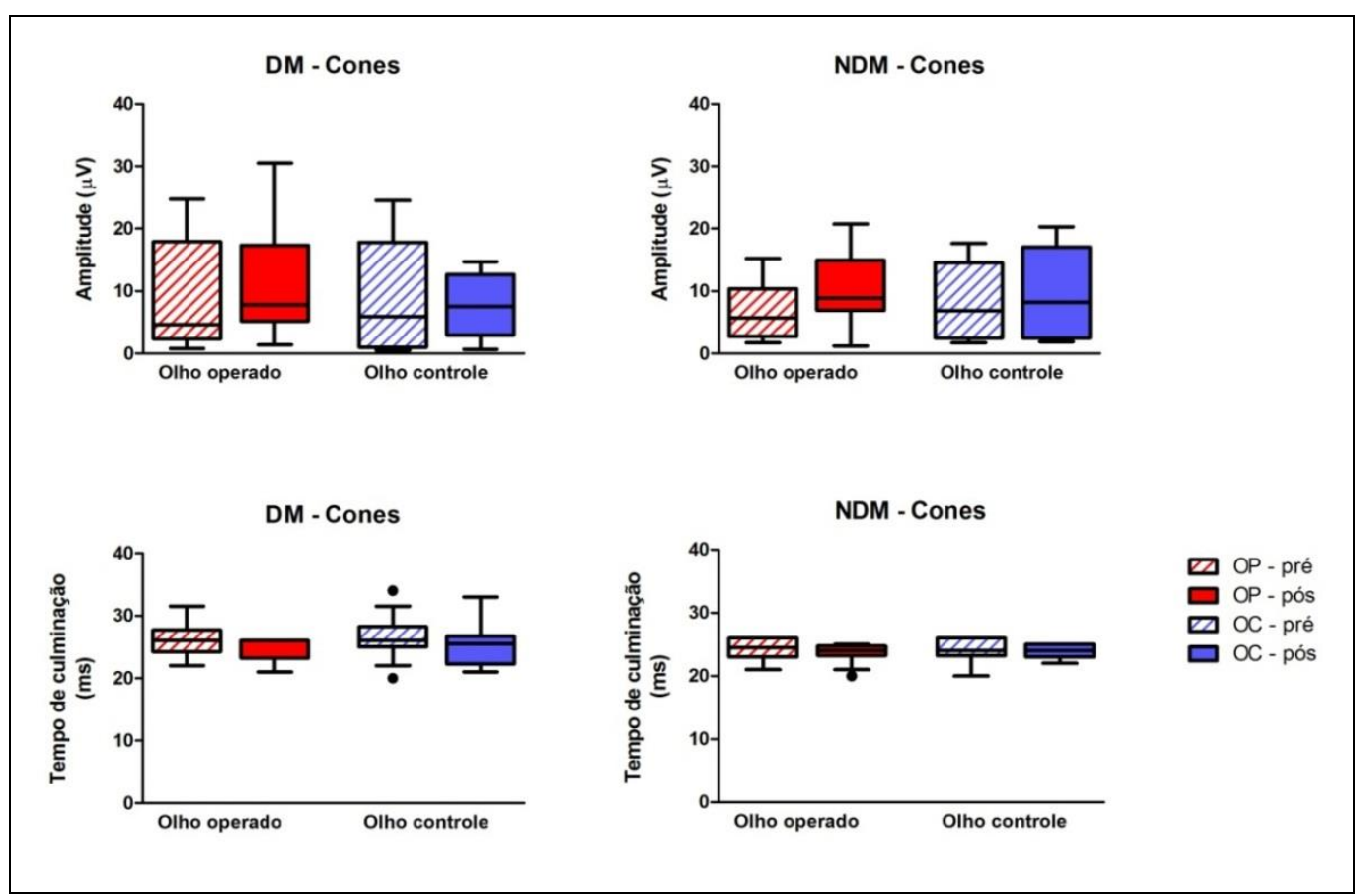

$\mu \mathrm{V}=$ microvolts; $\mathbf{m s = m i l i s e g u n d o s ;} \mathbf{D M}=$ diabético; $\mathbf{N D M = n a ̃ o ~ d i a b e ́ t i c o ; ~} \mathbf{O P}=$ olho operado; $\mathbf{O C}=0$ lho controle

Gráfico 6 - Representação gráfica em box plot das médias das amplitudes $(\mu \mathrm{V})$, tempo de culminação da onda-b (ms) na resposta de flicker a $30 \mathrm{~Hz}$ e desvio padrão nos 2 grupos (DM e NDM)

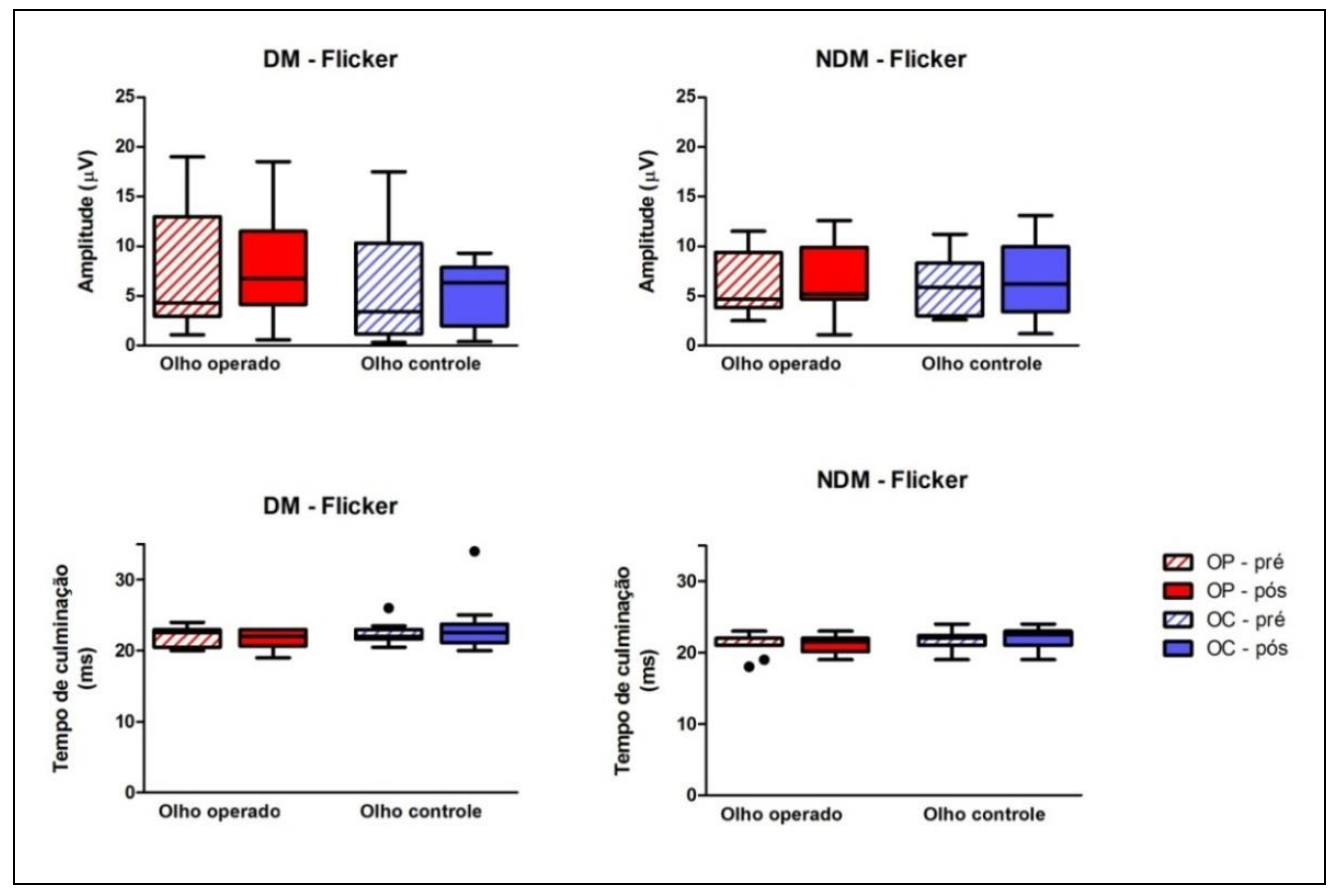

$\mu \mathrm{V}=$ microvolts; $\mathbf{m s}=$ =milisegundos; $\mathbf{D M}=$ diabético; $\mathbf{N D M}=$ não diabético; $\mathbf{O P}=$ olho operado; $\mathbf{O C}=0$ lho controle 


\section{DISCUSSÃo}

Com a evolução na medicina veterinária e consequentemente maior sobrevida dos animais de companhia, a oftalmologia veterinária diagnostica com maior frequência cães portadores de diversas oftalmopatias. Vários são os exames complementares que tem sido utilizados com maior frequência, e dentre eles podemos citar o eletrorretinograma de campo total que tem importância impar no auxílio diagnostico de lesões retinianas em animais com opacidade de meios.

Diversas são as doenças oculares secundárias ao DM no cão, tais como catarata, retinopatia diabética e ceratoconjuntivite (BEAM et al., 1999; CULLEN; WEBB, 2007a, b).

Como a catarata tem alta incidência nos cães diabéticos, a avaliação funcional ou mesmo anatômica da retina, não é frequentemente estudada e pouco se sabe sobre a evolução da retinopatia diabética nesta espécie.

Atualmente, a remoção cirúrgica da catarata em pacientes diabéticos ou não, é feita principalmente pela técnica de facoemulsificação, tanto na medicina humana como na medicina veterinária, devido à pequena incisão, menor tempo cirúrgico e baixa lesão nas estruturas intraoculares, resultando em menores complicações, principalmente relacionado a menor taxa de inflamação (MONTENEGRO; REZENDE, 2000).

Mesmo diante destas vantagens, alguns estudos relatam a progressão da retinopatia diabética no homem após facoemulsificação e acreditam que a patogênese desta afecção possa estar relacionada ao aumento da concentração de fatores angiogênicos em resposta ao trauma cirúrgico e inflamação (SHA; CHEN, 2010). Neste estudo, o tempo de ultrassom gerado durante a facoemulsificação entre os 2 grupos (DM e NDM) foi semelhante e acredita-se que não tenha influenciado na intensidade de inflamação.

Com o intuito de restabelecer a visão de pacientes que apresentem catarata diabética e que, por isso, necessitam de avaliação funcional da retina, emprega-se o eletrorretinograma de campo total (HVENEGAARD et al., 2010; SAFATLE et al., 2010d). O projeto utilizou Sistema Eletrorretinográfico Veris 2000 e a realização do eletrorretinograma de campo total prévio a cirurgia permitiu excluir pacientes que 
apresentavam ERG extinto ou respostas atenuadas compatíveis com degeneração retiniana.

Para a realização do exame é necessária a cooperação do paciente, sendo que o mesmo deve permanecer imóvel. A imobilização dos animais pode ser feita com o uso de sedação ou anestesia. A escolha do anestésico depende de vários fatores, tais como: espécie, equipamento eletrofisiológico, experiência do profissional com o fármaco, treinamento da equipe, além do teste eletrofisiológico estudado (TANSKANEN et al., 1996; YANASE; OGAWA, 1997; CHAUDHARY et al., 2003; HONSHO et al., 2004; KOMMONEN et al., 2007; WOODWARD et al., 2007; LIN et al., 2009).

Durante o procedimento, mesmo não sendo doloroso, há necessidade de evitar movimentos musculares, reduzir o stress, permitir a colocação dos eletrodos, além do posicionamento adequado do cão (NARFSTRÖM, 2002; HONSHO et al., 2004; ITOH et al., 2004; MENTZER et al., 2005; WOODWARD et al., 2007).

A influência dos fármacos no traçado do eletrorretinograma para sedação faz com que os pacientes sejam submetidos ao mesmo protocolo. Além de diferentes drogas terem ações antagônicas na condução nervosa da retina, a profundidade anestésica dentro de um mesmo protocolo já permite essa alteração (KOMMONEN; RAITTA, 1987; YANASE; OGAWA,1997; CHAUDHARY et al., 2003; ORIÁ et al., 2004; KOMMONEN et al., 2007; LIN et al., 2009; SAFATLE et al., 2010a).

Dependendo da escolha do anestésico, a alteração do ERG pode ser mínima como nos hipnóticos, ou importante quando utilizado barbitúricos ou anestésicos voláteis (TANSKANEN et al., 1996; YANASE; OGAWA, 1997; CHAUDHARY et al., 2003; NARFSTRÖM, 2006; SAFATLE et al., 2010a).

Com base nestas informações, todos os pacientes foram sedados seguindo 0 mesmo protocolo anestésico. O protocolo de sedação utilizando associação de atropina, xilazina e butorfanol por via intramuscular permitiu a colocação dos eletrodos e registros adequados, com baixo ruído. Para evitar ruídos, o bloqueio do nervo palpebral com lidocaína subcutânea no canto temporal ao bulbo ocular foi indispensável, pois promoveu acinesia palpebral, uma vez que o sistema Veris não permite remover possíveis interferências dos registros ocasionados pela movimentação palpebral.

Neste protocolo, as principais vantagens encontradas em comparação à anestesia geral foram: maior segurança, praticidade e centralização do bulbo ocular, 
além de recuperação rápida, tranquila, segura, isenta de agitação e tremores musculares. Quando o animal é anestesiado o bulbo ocular rotaciona, resultando em estimulação luminosa inadequada da retina. Desta forma, é necessário o bloqueio neuromuscular ou planos de anestesia mais profundos para sua centralização, sendo que em ambos há necessidade de intubação traqueal.

A atropina foi aplicada com o objetivo de diminuir a bradicardia resultante da xilazina e foi eficaz em todos os exames realizados.

Segundo Yu et al. (2007) a adaptação ao escuro para a realização do ERG em cães conscientes deve ser de no mínimo 20 minutos. A sedação então, promovida pela associação de xilazina e butorfanol permitiu realizar o procedimento de forma adequada, introduzindo a cabeça do cão no interior do Ganzfeld no tempo proposto, que foi de aproximadamente 30 minutos após a adaptação ao escuro. Ao término do exame todos os animais eram capazes de caminhar.

A adaptação ao escuro realizada no presente estudo recomendada pela ISCEV constou de 30 minutos e foi feita com auxílio de bandagem ao redor dos olhos e manutenção de sala escura, sendo bem tolerada pelos pacientes. Procurouse não ultrapassar o tempo sugerido para a adaptação, pois poderia resultar em amplitudes maiores na fase escotópica do ERG. O mesmo tempo de adaptação foi feito por Maheara et al. (2005).

O protocolo do ERG de campo total utilizado no projeto é o mesmo do recomendado pela ISCEV para o homem onde são realizados 5 respostas (MARMOR et al., 2009). Optou-se por seguir o protocolo padrão da ISCEV por considerá-lo mais completo e incluir os potenciais oscilatórios, uma vez que o trabalho consiste em avaliar a resposta eletrorretinográfica pré e pós facoemulsificação de cães diabéticos com catarata madura e hipermadura e observar alterações compatíveis com a retinopatia diabética.

A midríase de ambos os olhos foi obtida com instilação de colírios de tropicamida $1 \%$ e fenilefrina $10 \%$, previamente à colocação da bandagem e adaptação ao escuro, o que resultou em boa dilatação pupilar. Em geral, esta midríase é observada nos mamíferos com duração de 3 a 5 horas. Objetivou-se obter diâmetro pupilar igual ou superior a $6 \mathrm{~mm}$ de diâmetro, permitindo realização adequada do exame, uma vez que a retina pode ser estimulada amplamente pela luz (PETERSEN-JONES, 2006). 
As 5 respostas do exame foram realizadas em sala escura com auxílio de luz vermelha para a colocação dos eletrodos e monitoramento anestésico durante a fase escotópica do ERG.

A realização do ERG unilateral ou bilateral simultâneo depende da espécie, do aparelho e da indicação do exame (NARFSTRÖM, 2006). Neste estudo, os dois olhos foram estimulados simultaneamente com o auxílio do Ganzfeld.

$\mathrm{Na}$ medicina veterinária alguns estudos mostram certa dificuldade em se utilizar o Ganzfeld, pois além do custo e de difícil instalação, notou-se dificuldade em estimular corretamente os dois olhos simultaneamente e de manter a cabeça do animal no interior de uma esfera de $60 \mathrm{~cm}$ de diâmetro (MAHEARA et al., 2005). Com a sedação utilizada neste estudo os animais permaneceram tranquilamente com a cabeça no interior do Ganzfeld permitindo estimulação adequada da retina.

Este modelo de aparelho é dispendioso, porém obtém-se estimulação luminosa da retina uniforme, obtendo-se resposta bilateral, quando 0 animal introduz a cabeça no interior do mesmo. Neste estudo, o Ganzfeld utilizado tinha 38 cm de diâmetro, e mesmo assim, permitiu posicionar devidamente a cabeça do animal no interior do mesmo.

O tipo do eletrodo é um fator importante quando se avalia os registros do ERG. As características de condutibilidade dos eletrodos também podem influenciar nas respostas obtidas (HÉRBERT et al., 1996; MAHEHARA et al., 2005; MENTZER et al., 2005; BELLER et al., 2007; PEREIRA et al., 2013; ITOH et al., 2013). Em humanos, verificou-se que sob condições escotópicas, o eletrodo ERG-jet registra a onda- $b$ maior quando comparado com eletrodos DTL. Eletrodos não corneais são menos estáveis que os corneais, porém, Kuze e Uji (2000) mostraram similaridade quanto à estabilidade ao compararem eletrodo DTL com Burian Allen em pacientes humanos.

Sabendo que o eletrodo escolhido influencia nas respostas registradas, o eletrodo selecionado para este estudo foi o Burian Allen, pois além de ser um eletrodo de contato corneal, é bipolar e registra respostas com baixa interferência.

Maheara et al. (2005) utilizaram com sucesso, eletrodo monopolar LED tipo lente de contato em ambos os olhos simultaneamente, capazes de criar condição similar de estimulação luminosa da retina comparada com Ganzfeld e mesmo utilizando animais da mesma raça precisaram de 2 tamanhos diferentes de eletrodo. 
Neste estudo, utilizaram-se 4 tamanhos diferentes de eletrodo: neonato, infantil, pediátrico e adulto. Constatou-se a necessidade de tamanhos intermediários para que pudessem ser usados em diversas raças.

As pálpebras devem permanecer abertas durante todo o exame. Alguns autores utilizam pontos de reparo para a estabilização do olho, com o objetivo de manter o olho aberto, protegendo a córnea com solução protetora e não irritativa como a metilcelulose $0,5 \%$ (NARFSTRÖM, 2006).

A escolha deste eletrodo foi considerada boa, pois além de obter registros de qualidade, impediu o fechamento das pálpebras, funcionando como um blefarostato. Nos cães, é importante impedir a protrusão da membrana nictante durante o exame para sua perfeita realização. Após o ERG, não se observou lesão corneal em nenhum dos pacientes. Acredita-se que o uso de colírio anestésico e a proteção proporcionada pela metilcelulose foram responsáveis para que não ocorresse lesão.

Dentre as desvantagens do eletrodo Burian Allen podemos citar o custo, a dificuldade em obtê-lo e a variedade de tamanhos necessárias para as diversas raças de cães analisadas no estudo.

A interpretação do eletrorretinograma de campo total deve ser feita levando em consideração a espécie e idade. Quanto mais jovem o paciente, maiores são as amplitudes e quanto mais velho, menores são as amplitudes das respostas, semelhante ao que acontece no ERG humano (ITOH et al., 2004; NARFSTRÖM, 2006; SAFATLE et al., 2010c; ITOH et al., 2013). Atenuação das respostas ao fazer estudo comparativo entre os grupos, pode ser esperada, porém como amostra era heterogênea a comparação foi feita com o olho contralateral.

Foram selecionados, como mencionado anteriormente, animais diabéticos com catarata madura e hipermadura, pois o objetivo era comparar as alterações no ERGs de pacientes diabéticos portadores de catarata antes e após a cirurgia de catarata. A idade relatada na literatura por Marmor et al. (1982); Feldman e Nelson (2004); Landry et al. (2004); Davidson et al. (2005); Fall et al. (2007) e Nelson (2010) para o desenvolvimento do DM (de 4 a 14 anos) corresponde a idade observada no presente estudo, que apresentaram idade média de 9 anos. Acredita-se que um intervalo menor de idade seria mais adequado para comparar os resultados, porém deparou-se com dificuldade em selecionar cães diabéticos para o ERG e os animais acometidos eram ,em geral, de meia idade a idosos. 
Após o diagnóstico da doença, o tempo de evolução de catarata segundo estudos é de 6 a 30 meses (BEAM et al., 1999; SCHAER, 2003), Nos animais avaliados, foi observado opacidade total da lente em média, 6 meses do diagnóstico da doença.

Segundo Beam et al. (1999), as raças mais predispostas a desenvolverem catarata diabética foram as não esportivas como as braquicefálicas e Shar Peis, devido à gravidade da doença e a dificuldade em regular os níveis séricos de glicose pela insulinoterapia, e de acordo com Landry et al. (2004), Labrador, Schnauzer, e Pug. Neste estudo, avaliaram-se várias raças, sendo a mais comum Poodle Miniatura. Animais sem raça definida tiveram expressão significativa neste estudo.

Narfström (2006) afirma que não é possível comparar ERG de raças distintas por apresentarem diferenças anatômicas, mesmo empregando um único protocolo anestésico. Ainda segundo Narfström, o ideal seria que cada laboratório obtivesse valores de normalidade para cada espécie e raça, com pelo menos 3 grupos de idade (juvenil, adulto e idoso).

Neste estudo, não foi possível selecionar uma raça específica devido a diversidade encontrada e, portanto, avaliaram-se diversas raças nos 2 grupos (diabéticos e não diabéticos). Para análise, seria importante selecionar uma amostra maior para verificar as alterações eletrorretinográficas, mas a maioria dos animais diabéticos apresentavam outras doenças sistêmicas e estes foram excluídos da pesquisa, limitando desta forma o número de animais. Sabendo destas interfências, as respostas indivíduais obtidas do ERG pré e pós à facoemulsificação foram analisadas comparando o olho selecionado para a cirurgia com o olho controle (olho não operado) e de um indivíduo com o outro. O efeito da cirurgia e do tempo de DM foi ainda avaliado por meio do cálculo das diferenças entre as respostas no momento pré e pós 6 meses de cada olho (delta OP e delta OC).

Quanto ao sexo, as fêmeas (15) foram mais acometidas que os machos (9). No entanto, Davison et al. (2005) observaram que esta proporção tem diminuído nos últimos 20 anos, pois neste trabalho foram selecionados 253 cães sendo 138 fêmeas (54,5\%) e 116 machos (47,0\%).

Landry et al. (2004) observaram retinopatia diabética em $21 \%$ dos cães submetidos à facoemulsificação. Sem a utilização do ERG, a avaliação da retina só poderia ser feita nos pacientes com catarata após sua remoção cirúrgica, como foi feito neste estudo. 
Estudos afirmam que a retinopatia diabética descrita no cão assemelha-se a retinopatia diabética de fundo, ou não proliferativa do homem que é caracterizada pelo aumento da espessura da membrana basal dos capilares retinianos, dilatação das veias retinianas, perda de pericitos, microaneurismas, hemorragia retiniana e infarto da camada de fibras nervosas. A retinopatia proliferativa que é comum no homem, resultando em baixa importante de visão, não é frequente no cão, principalmente por necessitar de prolongado tempo de DM para o início de sua manifestação (BARNETT, 1981; ENGERMAN; KERN, 1995; LANDRY et al., 2004; CULLEN; WEBB, 2007b; ABRAMS et al., 2011). Neste estudo, a média de duração do DM no primeiro exame foi de 10 meses e o segundo exame foi realizado quando esses pacientes tinham média de duração do DM de 18 meses. O tempo de duração do DM pode ter influenciado para que os pacientes avaliados não apresentassem esses sinais.

No homem com diabete melito insulino-dependente, o déficit visual é resultado tanto da lesão vascular como de alterações metabólicas que acometem a mácula, retina, nervo óptico e via visual. As avaliações funcionais destas estruturas podem ser confirmadas por testes eletrofisiológicos como ERG de campo total, ERG por reversão de padrões e potenciais visuais evocados (MOTTA et al., 2008).

Parisi et al. (1997) concluíram que as alterações na via visual do homem surgem no início do diagnóstico do DMID. As alterações das camadas mais internas da retina e da mácula aparecem após 1 ano da doença e as alterações das camadas mais externas e médias da retina surgem após 10 anos da doença.

Fatores de risco para o desenvolvimento da retinopatia diabética no cão portador de DM espontânea não foram bem estudados (LANDRY et al., 2004), mas no homem o tempo de evolução do DM é o fator de risco mais importante, seguido pela hiperglicemia crônica e hipertensão arterial (HENRICSSON et al., 1996; BOSCO et al., 2005, ABBATE et al., 2011).

O intervalo médio entre o diagnóstico do DM e a identificação da retinopatia diabética no cão de acordo com Cullen e Webb (2007b) é de 3 a 5 anos. Landry et al. (2004) observaram que esse intervalo é de 1,4 ano (média 0,5 a 3,2 anos). 0 tempo médio de duração do DM nos cães avaliados variou do primeiro para o segundo exame de 10 a 18 meses. 
Neste estudo, embora tenha havido grande variação no valor sérico de glicose durante o eletrorretinograma de campo total, os animais estavam com bom controle glicêmico no período do exame, sendo esta variação momentânea devido ao jejum e quantidade de insulina aplicada. Dos animais avaliados todos tinham pressão arterial dentro dos valores de normalidade, portanto acredita-se que estes fatores possam ter contribuído para que não apresentassem sinais expressivos da retinopatia diabética.

Segundo Briggs et al. (2000) é possível verificar se os cães apresentam controle glicêmico adequado por meio de estudo retrospectivo avaliando a glicemia dos animais e a dosagem sérica de frutosamina, que é um indicador de controle glicêmico dos últimos 15 dias. Com base nestes critérios foi coletada a glicemia e a frutosamina de todos os pacientes no momento do exame do ERG. No primeiro e segundo exame esses cães apresentavam dosagem sérica de glicemia média indicando bom controle glicêmico (240,3mg/dL e $199,6 \mathrm{mg} / \mathrm{dL}$ respectivamente), quanto a frutosamina 7 dos 12 cães diabéticos apresentavam média indicando controle glicêmico ruim (522,5 $\mu \mathrm{mol} / \mathrm{le} 537,0 \mu \mathrm{mol} / / \mathrm{respectivamente)}$.

Os altos níveis séricos de glicose podem resultar em lesão retiniana, pois a hiperglicemia interfere nas vias de metabolismo celular e processo de transdução (HANCOK; KRAFT, 2004).

Com a análise estatística observou-se que não houve diferença significativa nos grupos estudados (diabéticos e não diabéticos) entre os valores obtidos do ERG antes e 6 meses após a facoemulsificação, tanto no OP quanto no olho OC, o olho operado não apresentou alteração significativa com o olho contralateral nos 2 grupos. Este fato pode estar relacionado com o aumento da concentração de glutamato no vítreo que é tóxico para os neurônios retinianos, resultando em diminuição da função retiniana (HANCOK; KRAFT, 2004). Para tanto, neste estudo evitou-se administrar fármacos que ocasionassem hiperglicemia como antiinflamatórios esteroidais ao grupo diabético, e por isso todos os pacientes deste grupo, foram tratados com anti-inflamatório não esteroidal tópico e oral.

No grupo diabético observou-se tendência de queda das amplitudes de bastonetes OP e OC; máxima resposta OP e OC; potenciais oscilatórios OP e OC; flicker a $30 \mathrm{~Hz} \mathrm{OC}$ e na relação das ondas b/a do OP. Essa tendência de queda pode estar relacionada no $\mathrm{OC}$ à progressão da retinopatia diabética ou envelhecimento do 
animal, já no OP, o trauma cirúrgico também pode ter contribuído, além do envelhecimento e da retinopatia diabética.

Houve tendência de aumento nas amplitudes do grupo DM nas respotas de cones do OP e flicker a $30 \mathrm{~Hz}$ do OP. Esse aumento no OP pode ser explicado pela ausência de opacidade de meios.

Tendência de diminuição do tempo de culminação da onda- $b$ foi observada na resposta de bastonetes OP grupo DM e NDM; máxima resposta OP grupo DM e NDM; todas as respostas de cones; flicker a $30 \mathrm{~Hz}$ OP grupo DM e NDM, pode ser explicada pela ausência de opacidade de meios. A presença da catarata no olho não operado dificulta a passagem da luz, enquanto no olho operado, com a ausência de opacidade lenticular, não há interferência na passagem de estimulo luminoso e a resposta pode ser obtida em menor tempo.

Houve tendência de aumento do tempo de culminação da onda- $b$ na resposta de bastonetes OC nos 2 grupos; na máxima resposta OP e OC grupo DM e flicker a $30 \mathrm{~Hz}$ OC grupo NDM. A tendência de aumento do tempo de culminação da onda- $b$ deve estar relacionada a presença da catarata, envelhecimento da retina e nos pacientes diabéticos a retinopatia diabética.

Ao compararmos as diferenças entre OP e OC em cada grupo (DM e NDM) não observou-se diferença estatisticamente significantes. Quando comparou-se entre os grupos (DM e NDM), os valores médios obtidos das respostas nos momentos pré OP, pós OP, pré OC e pós OC observou-se diferença significativa no tempo de culminação da onda-b na máxima resposta do OP no momento pós, no tempo de culminação da onda- $b$ na máxima resposta $\mathrm{OC}$ no momento pós e tempo de culminação da onda-b da resposta de cones no momento pré cirurgia. Essas diferenças podem ser justificadas pela amostra heterogênea, e por isso realizou-se como citado anteriormente comparação com o olho contralateral.

As diferenças obtidas entre as respostas do ERG entre OP e OC (entre os grupos) observou-se diferença estatisticamente significantes na amplitude da máxima resposta no momento prévio a cirurgia, indicando que a diferença entre o olho operado e olho controle no momento pré foi maior no grupo DM.

Quando comparou-se o grupo diabético com o grupo não diabético, não foi observado diminuição dos POs como seria esperado, pois sabe-se que a esta 
diminuição representa lesão vascular nas camadas mais internas da retina, caracterizada pela retinopatia diabética.

Vários estudos relatam diminuição da amplitude dos POs, considerando como indicador eletrofisiológico de isquemia retiniana mais sensível da retinopatia diabética (PARISI et al., 1997). Neste estudo observou tendência de diminuição do potencial oscilatório do grupo diabético OP e OC e no grupo não diabético OP. No grupo diabético esta diminuição pode estar relacionada com a progressão da retinopatia diabética e no grupo não diabético por envelhecimento da retina ou inflamação ocasionado pela remoção da catarata.

Alguns autores consideram a amplitude da onda- $b$ indicador eletrofisiológico tão sensível como POs na detecção da retinopatia diabética. Por outro lado, Hancock e Kraft (2004) discordam desta afirmação, pois em estudo realizado em ratos observaram redução da amplitude na maioria dos animais, mas não em todos e por isso consideram os POs mais sensíveis.

Nos cães, além da retinopatia diabética, a hemorragia retiniana pode ocorrer secundária a várias doenças sistêmicas como hipertensão arterial sistêmica, doenças imunomediadas, trombocitopenia, coagulopatias, doenças infecciosas e síndrome de hiperviscosidade que resultam em diversos sintomas clínicos e rápida progressão da lesão retiniana (GELATT, 2007; MAHEARA et al., 2007; SLATTER, 2008). No entanto, a seleção dos cães para o estudo foi realizada excluindo os que apresentassem alguma doença sistêmica que justificasse alteração retiniana comprometendo o resultado obtido do ERG. Os animais foram submetidos à avaliação clínica e cardiológica previamente à cirurgia.

Dentre os vários estudos realizados em humanos avaliando as alterações do eletrorretinograma observou-se redução da amplitude e aumento do tempo de culminação da onda- $b$ nos portadores de DM tipo 1 sem alterações clínicas de retinopatia (TORREN; MULDER, 1993).

Segundo Landry et al. (2004) as lesões observadas à fundoscopia após facoemulsificação nos cães estão relacionadas com a retinopatia diabética e é mais frequente e precoce do que se tem conhecimento. Segundo os autores, a confirmação desta hipótese poderia ser realizada com novos estudos como fluoangiografia, histologia retiniana, mensuração da pressão sanguínea e qualidade do controle glicêmico. Por outro lado, segundo Fall et al. (2007) a sobrevida destes animais após o diagnóstico do DM é de aproximadamente 3 anos. Acredita-se que 
seja necesserário acompanhamento à longo prazo para observar estas alterações, pois como citado anteriormente as lesões estão relacionadas com tempo do DM, controle metabólico e ocorrência de hipertensão arterial, no entanto, a maioria dos cães são diagnósticados com DM em idade avançada.

As alterações eletrorretinográficas observadas neste estudo são sugestivas com retinopátia diabética, porém para confirmar tal hipótese, acredita-se que seja necessário selecionar uma amostra mais homogênea quanto à raça e à idade, além de acompanhamento dos pacientes por um período maior. Nesse período mais longo de acompanhamento, a realização de exames como fundoscopia e tomografia de coerência óptica seriam importantes para observar possíveis sinais de RD.

Segundo Muñana (1995) cegueira secundária a RD ainda não foi relatada no cão. Em geral, as lesões não são graves e na maioria dos casos tem perfil de enfermidade subclínica. Todos os pacientes que participaram do estudo recuperaram a visão após a cirurgia, sugerindo que a inflamação pós cirúrgica foi controlada com a medicação prescrita nos 2 grupos estudados e a lesão retiniana secundária ao diabete é discreta, interferindo de maneira leve na visão dos cães.

No cão diabético, como a presença da catarata é frequente e impossibilita a fundoscopia, o ERG de campo total é um exame indispensável para avaliar e acompanhar a função retiniana destes pacientes. A cirurgia de facoemulsificação foi responsável por possibilitar a visão aos animais que apresentavam catarata diabética, sem intercorrências pós cirurgicas. 


\section{CONCLUSÃO}

Face aos dados obtidos no presente estudo, nas condições apresentadas, pode-se concluir que:

1- o ERG de campo total utilizando o Ganzfeld pode ser realizado no cão submetido à sedação e o exame é útil para avaliar a função retiniana de cães diabéticos portadores de catarata antes do procedimento cirúrgico;

2- a facoemulsificação representa mínimo impacto na evolução da retinopatia diabética;

3- a remoção cirúrgica da catarata não deve ser contraindicada, por resultar em melhoria da visão. 


\section{REFERÊNCIAS}

ABBATE, M.; CRAVEDI, P.; ILIEV, I.; REMUZZI, G.; RUGGENENTI, P. Prevention and Treatment of Diabetic Retinopathy: Evidence from Clinical Trials and Perspectives. Current Diabetes Reviwes, v. 7, n. 3, p. 190-200, 2011.

ABRAMS, K. L.; STABILA, P. F.; KAUPER, K.; ELLIOTT, S. Vascular endothelial growth factor in diabetic nondiabetic canine cataracts patients. Veterinary

Ophthalmology, v. 14, n. 2, p. 93-99, 2011.

ADKINS, E. A.; HENDRIX, D. V. H. Cataract evaluations and treatment in dogs. Compedium on Continuing Education Practising Veterinarian, v .25, n. 11, p. 813-825, 2003.

ADKINS, E. A.; HENDRIX, D. V. H. Outcomes of dogs presented for cataract evaluation: a retrospective study. Journal of the American Animal Hospital Association, v. 41, p. 235-240, 2005.

AGUIRRE, G. D.; RUBIN, L. F. Progressive retinal atrophy (rod dysplasia) in the Norwegian Elkhound. Journal of the American Veterinary Medical Association, v. 158, n. 2 , p. 208-218, 1971.

BAGLEY, L. H.; LAVACH, J. D. Comparison of postoperative phacoemulsification results in dogs with and without diabetes mellitus: 153 cases (1991-1992). Journal of American Veterinary Medical Association, v. 205, n. 8, p.1165-1169, 1994.

BARNETT, K. C. Diabetic retinopathy in the dog. British Journal of Ophthalmology, v. 65, n. 5, p.312-314, 1981.

BEAM, S.; CORREA, M. T.; DAVIDSON, M. G. A retrospective-cohort study on the development of cataracts in dogs with diabetes melittus: 200 cases. Veterinary Ophthalmology, v. 2, n.3, p. 169-172, 1999.

BEELLER, P.; BARTHELMES, D.; SUTTER, F. K.; HELBIG, H.; FLEISCHHAURER, J. C. Comparison of performance and patient satisfaction of two of ERG electrodes. Klin Monatsbi Augenheilkd, v 224, n. 4, p. 265-268, 2007. 
BEDFORD, P. G. C. Enfermedades de la retina. In HERRERA, D. Oftalmología clínica en animales de compañía. Buenos Aires: Inter-Médica, 2007. p. 211-238.

BENETT, N. Monitoring techniques for diabetes mellitus in the dog and the cat. Clinical Techniques in Small Animal Practice, v.17, n. 2, p. 65-69, 2002.

BIRCH, G. D.; ANDERSON, M. S. Standardized full-field electroretinography. Archives of Ophthalmology, n. 110, p. 1571-1572, 1992.

BLOIS, S. L.; DICKIE, E.; KRUTH, S. A.; ALLEN, D. G. Multiple endocrine diseases in dogs: 35 cases (1996-2009). Journal of the American Veterinary Medical Association, v. 238, n. 12, p. 16161-1621, 2011.

BOSCO, A.; LERÁRIO, A .C.; SORIANO, D.; SANTOS, R. F.; MASSOTE, P.; GALVÃO, D.; FRANCO, A. C. H. M.; PURISH, S.; FERREIRA, A. R. Retinopatia Diabética. Arquivos Brasileiros de Endocrinologia \& Metabologia, v. 49, n. 2, p. 217-227, 2005.

BRAS, I. D.; COLITZ, C. M. H.; SAVILLE, W. J. A.; GEMENSKY-METZLER, A. J.; WILKIE, D. A. Posterior capsular opacification in diabetic and nondiabetic canine patients following cataract surgery. Veterinary Ophthalmology, v. 9, n. 5, p. 317323, 2006.

BRESNICK, G. H.; PALTA, M. Oscillatory potential amplitudes. Relation to severity of diabetic retinopathy. Archives of Ophthalmology, v. 105, n. 7, p. 929-33, 1987.

BRIGGS, C. E.; NELSON, R. W.; FELDMAN, E. C.; ELLIOT, D. A.; NEAL, L. A. Reliability of history and physical examination findings for assessing control of glycemia in dogs with diabetes mellitus: 53 cases (1995-1998). Journal of American Medical Veterinary Association, v. 217, n.1, p. 48-53, 2000.

BRIKSHAVANA, P. Success rate and postoperative complications of phacoemulsification in 25 cataractous eyes: a retrospective study in 20 dogs (20032005). Thai Journal of Veterinary Medicine, v. 37, n. 2, p. 53-60, 2005.

BROBST, D. F. Pancreatic function. In: KANEKO, J. J.; HARVEY, J. W.; BRUSS, M. L. Clinical biochemistry of domestic animals. 5th ed. San Diego: Academic Press, 1997. p. 353-366. 
BROOKS, D. E.; KOMÀROMY, A.; KÄLBERG, M. Comparative retinal ganglion cell and optic nerve morphology. Veterinary Ophthalmology, v. 2, n. 1, p. 3-11, 1999.

CATALÀ, J.; CASTANY, M. Pruebas electrofisiológicas: qué, cuando, como y por qué? (2ª parte). Annais d'Oftalmologia, v. 13, n. 2, p. 76-90, 2005.

CATCHPOLE, B.; RISTIC, J. M.; FLEEMAN, L. M.; DAVISON, L. J. Canine diabetes mellitus: can old dogs teach us new tricks?. Diabetologia, v. 48, n. 10, p. 1948-1956, 2005.

CATCHPOLE, B.; KENNEDY, L. J.; DAVISON, L. J.; OLLIER, W. E. R. Canine diabetes mellitus: from phenotype to genotype. Journal of Small Animal Practice, v. 49, p. $4-10,2008$.

CATCHPOLE, B.; ADAMS, J. P.; HOLDER, A. L.; SHORT, A. D.; OLLIER, W. E.; KENNEDY, L. J. Genetics of canine diabetes mellitus: Are the diabetes susceptibility genes identified in humans involved in breed susceptibility to diabetes mellitus in dogs?. The Veterinary Journal, v. 195, n. 2, p. 139-147, 2013.

CHAUDIEU, G.; MOLON-NOBLOT, S. Affections de la rétine. EMC-Vétérinaire, v. 1, p. 47-73, 2004.

CHAUDHARY, V.; HANSEN, R.; LINDGREN, H.; FULTON, A. Effects of telazol and nembutal on retinal responses. Documenta Ophthalmologica, v.107, p. 45-51, 2003.

CHEEMA, R. A.; AI-MUBARAK, M. M.; AMIN, Y. M.; CHEEMA, M. A. Role of combined cataract surgery and intravitreal bevacizumab injection in preventing progression of diabetic retinopathy: prospective randomized study. Journal Cataract and Refractive Surgery, v. 35, n.1, p. 18-25, 2009.

CHEN, S. J.; MAHADEVAPPA, M.; WEILAND, R. R.; HUMAYUN, M. Neural responses elicited by electrical stimulation of the retina. Transations of the American Ophthalmological Society, v. 104, p. 252-259, 2006.

CHEN, H.; ZHANG, M.; HUANG, S.; WU, D. The photopic negative response of flash ERG in nonproliferative diabetic retinopathy. Documenta Ophthalmologica, v. 117, n. 2, p. 129-35, 2008. 
CHEVILLE, N. F. Vias metabólicas anormais: introdução à patologia veterinária. São Paulo: Manole,1993. p 93-112.

CHIURCIU, J. L. V.; BRANDÃO, C. V. S.; RODRIGUES, A. C. L.; RANZANI, J. J. T.; FERREIRA, T. H.; PADOVANI, C. R. Use of viscoelastic substances for the phacoemulsification in dogs with cataract: Effects on the intraocular pressure, morphology of endothelial cells, and corneal thickness. Arquivo Brasileiro de Medicina Veterinaria e Zootecnia, v. 62, n. 3, p. 570-577, 2010.

CORRÊA, Z. M. S.; EAGLE JR., R. Aspectos patológicos da retinopatia diabética. Arquivos Brasileiros de Oftalmologia, v. 68, n. 3, p. 410-414, 2005.

CRAWFORD, T. N.; ALFARO, D. V.; KERRISON, J. B.; JABLON, E. P. Diabetic Retinopathy and Angiogenesis. Current Diabetes Reviews, v. 5, p. 8-13, 2009.

CULLEN, C. H.; WEBB, A. Ocular manifestations of systemic disease Part 1: the dog. In: GELATT, K. N. Veterinary ophthalmology. 4. ed. lowa: Blackwell Publishing, 2007a. p.1470-1537.

CULLEN, C. H.; WEBB, A. Ocular manifestations of systemic disease Part 2: The cat. In: GELATT, K. N. Veterinary ophthalmology. 4. ed. lowa: Blackwell Publishing, 2007b. p.1538-1587.

CRASTA, M.; CLODE, A. B.; McMULLEN JR., R. J.; PATE, D. O.; GILGER, B. C. Effect of three treatment protocols on acute ocular hypertension after phacoemulsification and aspiration of cataracts in dogs. Veterinary Ophthalmology, v. 13, n. 1, p. 14-19, 2010.

DANTAS, A. M. Eletrorretinografia. In: DANTAS, A. M.; COSTA, J. G. C.; NETO, L. P.; YAMANE, R.; ELIAS, C. A. Eletrofisiologia ocular. Rio de Janeiro: Editora Cultura Médica, 1995. p. 141-225.

DAVIDSON, M. G.; NELMS, S. R. Diseases of the canine lens and cataract formation. In: GELATT, K. N. Veterinary ophthalmology. 4. ed. lowa: Blackwell Publishing, 2007. p. 859-887.

DAVISON, L. J.; HERRTAGE, M. E.; CATCHPOLE, B. Study of 253 dogs in united kingdom with diabetes mellitus. Veterinary Record, v. 156, n. 15, p. 467-471, 2005. 
DIESTELHORST, M.; ASPACHER, F.; KONEN, W.; KRIEGLSTEIN, G. K.; HILGERS, R. D. Effect of dexamethasone $0,1 \%$ and predsinolone acetate $1 \%$ eye drops on the blood-aqueous barrier after cataract surgery: a controlled randomizede fluorophotometric study. Graefe's Archive for Clinical and Experimental Ophthalmology, v. 230, n. 5, p. 451-453, 1992.

EL-HAZARI, S. M.; RUIZ, R. S.; FELDMAN, R. M.; VILLANUEVA, G. V.; CHUANG, A. Z. Efficacy of preoperative versus postoperative ketorolac tromethamine $0,5 \%$ reducing inflammation after cataract surgery. Journal of Cataract and Refractive Surgery, v. 26, n. 11, p. 1626-1630, 2000.

ENGERMAN, R. L.; KERN T. S. Retinopathy in animals models of diabetes. Diabetes/Metabolism Reviws, v. 11, n. 2, p.109-120, 1995.

FALL, T.; HAMLIN, H. H.; HEDHAMMAR, A.; KÄMPE, O.; EGENVALL, A. Diabetes mellitus in a population of 180,000 insured dogs: incidence, survival and breed distribution. Journal Veterinary International Medicine, v. 21, p.1209-1216, 2007.

FELDMAN, E. C.; NELSON, R. W. Canine diabetes mellitus In: Canine and feline endocrinology and reproduction. 4 ed. St. Louis: Saunder, 2004. p.486-538.

FEIZ, V.; OBERG, T. J.; KURZ, C. J.; MAMALIS, N.; MOSHIRFAR, M. Nepafanec associated bilateral corneal melt after photorefractive keratectomy. Cornea, v. 28, n. 8, p. 948-950, 2009.

FISCHER, A. J.; REH, T. A. Potential of Müller glia to become neurogenic retinal progenitor cells. Glia, v. 43, p. 70-76, 2003.

FLEEMAN, L. M.; RAND, J. S. Management of canine diabetes. Veterinary Clinics of North America: Small Animal Practice, v. 31, n. 5, p. 855-880, 2001.

FORRESTER, J. V.; ANDREW, D. D.; McMENAMIN, P. G.; LEE, W. R. Anatomy of the eye and orbit In: The eye basic sciences and practice. 2. ed. London: W. B. Saunders, 2002. p. 1-98.

GELATT, K. N. Doenças e cirurgia do segmento posterior In: oftalmologia veterinária. São Paulo: Editora Manole, 2003. p. 253-294.

GELATT, K. N. Veterinary ophthalmology. 4 ed. lowa: Blackwell Publishing Ltda. 2007. v. 1, 1672 p. 
GIULIANO, E. A. Regional Anesthesia as an adjunct for eyelid surgery in dogs.

Topics in campanion animal medicine, v. 23: n. 1, p. 51-56, 2008.

GLOVER, T. D.; CONSTANTINESCU, G. M. Surgery for cataracts. Veterinary

Clinics of North America: Small Animal Practice, v. 27, n. 5, p. 1143-1173, 1997.

GONÇALVES, E. R.; FERNANDES, M. L.; TAKAHASHI, W. Y.; SUZUKI, H.

Eletrofisiologia ocular. In: OFTALMOLOGIA CBd. Retina e vítreo: clínica e cirurgia.

São Paulo: Roca, 2000. p. 185-225.

GONZÁLES-ALONSO-ALEGRE, E.; RODRIGUES-ALVARO, A. Spontaneous resorption of a dibetic cataract in geriatric dog. Journal of Small Practice, v. 46, n. 8, p. 406-408, 2005.

GUM, G. G. Electrophysiology in veterinary ophthalmology. Veterinary Clinics of North America Small Animal Practice, v. 10, n. 2, p. 437-454, 1980.

GUPTILL, L.; GLICKMAN, L.; GLICKMAN, N. Time trends and risk factors for diabetes mellitus in dogs: analysis of veterinary medical data base records (19701999). The Veterinary Journal, v. 165, n. 3, p. 240-247, 2003.

GRANITZ, U. Descreased vision and blindness in dogs- a retrospective study. Berliner Münchener Tierärztliche Wochenschrift, v. 107, n. 9, p. 295-299, 1994.

GROSS, J. L.; NEHME, M. Detecção e tratamento das complicações crônicas do diabetes melito: Consenso da Sociedade Brasileira de Diabetes e Conselho Brasileiro de Oftalmologia. Revista da Associação Médica Brasileira, v. 45, n. 3, p. 279-284, 1999.

HANCOCK, H. A.; KRAFT, T. W. Oscillatory potential analysis and ERGs of normal and diabetic rats. Investigative Ophthalmology \& Visual Science, v. 45, n. 3, p. 1002-1008, 2004

HECKENLIVELY J. R.; ARDEN, G. B. Testing levels of visual system. In:_.Principles and practice of clinical electrophysiology of vision.

Cambridge: The Mit Press, 2006. p. 623-630.

HEIER, J. S.; AWH, C. C.; BUSBEE, B. G.; WATERBURY, D.; DANIEL, P.; STOLLER, G. L.; CLEARLY, T. S. Vitreous nonsteroidal antiinflmatory drug concentration and prostaglandin E2 levels in vitrectomy patients treated with 
ketorolac $0.4 \%$, bromfenac $0.09 \%$, and nepafenac $0.1 \%$. Retina, v. 29 , n. 9 , p. 1310 1313, 2009.

HENDRIX, D.; SIMNS, M. Electroretinography in Hispaniolan Amazon Parrot (Amazona ventralis). Journal of Avian Medicine Surgery, v.18, n. 2, p. 89-94, 2004.

HENKES, H. E. Electroretinography in circulatory disturbances of the retina. I. Electroretinogram in cases of occlusion of the central vein or one of its branches. Archives of Ophthalmology, v. 49, p. 190-201, 1953.

HENRICSSON, M.; HEIJL, A.; JANZON, L. Diabetic retinopathy before and after cataract surgery. British Journal of Ophthalmology, v. 80, n. 9, p. 789-793, 1996.

HÉRBERT, M.; LACHAPELLE, P.; DUMONT, M. Reproducibility of electroretinograms recorded with DTL electrodes. Documenta Ophthalmologica, v. 91, p. 333-342, 1996.

HOENIG, M. Comparative aspects of diabetes mellitus in dogs and cats. Molecular and Cellular Endocrinology, v. 197, p. 221-229, 2002.

HONG, T.; MITCHELL, P.; LORYN, T.; ROCHTCHINA, E.; CUGATI, S.; WANG, J. J. Development and progression of diabetic retinopathy 12 monts after phacoemulsification cataract surgery. Ophthalmology, v. 116, n. 8, p. 1510-1514, 2009.

HONSHO, C. S.; ORIÁ, A. P.; LAZARO JUNIOR, L. P. V. M.; DOREA NETO, F.; LAUS, J. L. Organização de uma unidade de eletrorretinografia flash em Medicina Veterinária. Ciência Rural, v. 34, n. 4, p. 1097-1104, 2004.

HURN, S. D.; HARDMAN, C.; STANLEY, R. G. Day-blindness in three dogs: clinical and electroretinographic findings. Veterinary Ophthalmology, v. 6, n. 2, p. 127-30, 2003.

HVENEGARD, A. P.; SAFATLE, A. M. V.; ROSSI JR, J. L..; BARROS, P. S. M. Catarata diabética: do diagnóstico ao retorno da capacidade visual. MEDVEPRevista Científica de Medicina Veterinária - pequenos Animais e Animais de estimação, v. 8, n. 24, p. 85-91, 2010. 
ITOH, Y.; MAEHARA, S.; OSAWA, A.; TAKIYAMA, N.; IGARASHI, O.; SAITO, A.; MIZUKI, N. Age related changes in electrorretinogram in Beagle dogs. In: AMERICAN COLLEGE OF VETERINARY OPHTHALMOLOGISTS ANNUAL MEETING, 35., oct. 2004, Washington, DC. Abstract... Washington, DC: ACVO, 2004. p. 7.

ITOH, Y.; MAEHARA, S.; ITOH, N.; YAMASHITA, K.; IZUMISAWA, Y. Electroretinography recordings using a light emitting diode active corneal electrode in healthy beagle dogs. Journal of Veterinary Science, v. 14, n. 1, p. 77-84, 2013.

KANEKO, J. J.; MATTHEEUWS, D.; ROTTIERS, R. P.; VERMEULEN, A. Renal function, insulin secretion, and glucose tolerance in mild streptozotocin diabetes in the dog. American Journal of Veterinary Research, v. 39, n. 5, p. 807-809, 1978.

KANSKI, J. J. Doenças vasculares retinianas In: Oftalmologia clínica uma abordagem sistemática. 5 ed. Rio de Janeiro: Elsevier Editora Ltda, 2005. p. 439486.

KERN, T. S.; LENGERMAN, R. L. Vascular lesions in diabetes are distributed nonuniformly within the retina. Experimental Eye Research, v. 60, n. 5, p. 545-549, 1995.

KIM, S. J.; FLACH, A. J.; JAMPOL, L. M. Nonsteroidal anti-inflammatory drugs in ophthalmology. Survey of Ophthalmology, v. 55, n. 2, p. 108-133, 2010.

KLEIN, H. E.; KROHNE, S. G.; MOORE, G. E.; STILES, J. Postoperative complications and visual outcomes of phacoemulsification in 103 dogs (179 eyes): 2006-2008. Veterinary Ophthalmology, v. 14, n. 2, p. 114-120, 2011.

$\mathrm{KOCH}$, S. A.; RUBIN, L. F. Distribution of cones in retina of the normal dog. American Journal of Veterinary Research, v. 33, n. 2, p. 361-363, 1972.

KOMAROMY, A. M.; SMITH, P. J.; BROOKS, D. E. Electroretinography in dogs and cats. Part I. Retinal morphplogy and physiology. The Compendium on Continuing Education, v. 20, p. 343-354, 1998a.

KOMAROMY, A. M.; SMITH, P. J.; BROOKS, D. E. Electroretinography in dogs and cats. Part II. Technique, interpretation and indications. The Compendium on

Continuing Education, v. 20, p. 355-366, $1998 \mathrm{~b}$. 
KOMAROMY, A.; BROOKS, D. E.; DAWSON, W. W.; KÄLLBERG, M. E.; OLLIVIER, F. J.; OFRI, R. Technical issues in electrodiagnostic recording. Veterinary Ophthalmology, v. 5, p. 85-91, 2002.

KOMAROMY, A. M.; ANDREW, S. E.; SAPP JR, H. L.; BROOKS, D. E.; DAWSON $W$. W. Flash electroretinography in standing horses using the DTL microfiber electrode. Veterinay Ophthalmology, v. 6, n. 1, p. 27-33, 2003.

KOMMONEN, B.; RAITTA, C. Electroretinography in Labrador retrievers given ketamine-xylazine anesthesia. American Journal of Veterinary Research, v. 48, n. 9, p. 1325-1331, 1987.

KOMMONEN, B.; HYVÄTTI, E.; DAWSON, W. W. Propofol modulates inner retina function in Beagles. Veterinary Ophthalmology. v. 10, n. 2, p. 76-80, 2007.

KOSKINEN, L.; RAITTA, C.; KOMMONEN, B. Fluorescein angiography in homozygote and carrier state of progressive retinal atrophy of the poodle; comparative aspects with human retinitis pigmentosa. Acta Ophthalmologica, v. 63, n. 3, p. 297-304, 1985.

KRISTINSSON, J. K.; GUDMUNDSSON, J. R.; STEFÁNSSON, E.; JÓNASSON, F.; GíSLASON, I.; THÓRSSON, A. V. Screening for diabetic retinopathy. Acta Ophthalmologica Scandinavica, v. 73, n. 6, p. 525-528, 1995.

KUZE, M.; UJI, Y. Comparision between Dwason, Trick, and Litzkow electrode and contact lens electrode used in clinical electroretinography. Japanese Journal Ophthalmology, v. 44, p. 374-380, 2000.

LANDRY, M. P.; HERRING, I. P.; PANCIERA, D. L. Fundoscopic findings following cataract extraction by means of phacoemulsification in diabetic dogs: 52 cases (1993-2003). Journal of American Veterinary Medical Association, v. 225, n. 5, p. 709-716, 2004.

LAUS, J. L. Cirurgia del Cristalino. In: HERRERA, D. Oftalmología clínica en animales de compañia. Buenos Aires: Inter-Médica, 2007. p. 161-177.

LEE, J.; KIM, K.; JANG, H.; LEE, B.; KIM, J. Y.; JEONG, S. The normal electroretinogram in adult heathy Shih Tzu dogs using the HMsERG. Journal of Veterinary Science, v. 10, n. 3, p. 233-238, 2009. 
LEWIS, G. P.; CHAPIN, E. A.; LUNA, G.; LINBERGK. A.; FISHER, S. K. The fate of Müller's glia following experimental retinal detachment: nuclear migration, cell division, and subretinal glial scar formation. Molecular Vision, v. 16, p. 1361-1372, 2010.

LI, X.; SUN, X.; HU, Y.; HUANG, J.; ZHANG, H. Electroretinographic oscillatory potentials in diabetic retinopathy. An analysis in the domains of time and frequency. Documenta Ophthalmologica, v. 81, n. 2, p. 173-179, 1992.

LIN, S. L.; SHIU, W. C.; LIU, P. C.; CHENG, F. P.; LIN, Y. C.; WANG, W. S. The effects of different anesthetic agents on short electroretinography protocol in dogs. Journal of Veterinary Medical Science, v. 71, n. 6, p. 763-768, 2009.

LORENZ, M. D.; CORNELIUS, L. M.; FERGUSON, D. C. Terapêutica clínica em pequenos animais. Rio de Janeiro: Interlivros, 1996. p. 63-72.

MAEHARAS, S.; ITOH, N.; ITOH,Y.; WAKAIKI, S.; TSUZUKI,K.; SENO, T.; KUSHIRO, T.; YAMASHITA, K.; IZUMISAWA,Y.; KOTANI, T. Eletroretinography using contact lens electrode with built in light source in dogs. Journal of Veterinary Medical Science, v. 67, n. 5, p. 509-514, 2005.

MAEHARA, S.; ITOH, N.; WAKAIKI, S.; YAMASAKI, A.; TSUZUKI, K.; IZUMISAWA, $Y$. The effects of cataract stage, lens-induced uveitis and cataract removal on $E R G$ in dogs with cataract. Veterinary Ophthalmology, v. 10, n. 5, p. 308-312, 2007.

MARASCHIN, J. F.; MURUSSI, N.; WITTER, V.; SILVEIRO, S. P. Classificação do diabete melito. Arquivos Brasileiros de Cardiologia, v. 95, n. 2, p. 40-46, 2010.

MARMOR, M.; WILLEBERG, P.; GLIKMAN, L. T.; PRIESTER, W. A.; CYPESS, R. H.; HURVITZ, A. I. Epizootiologic patters of diabetes mellitus in dogs. American Journal of Veterinary Research, v. 43, n. 3, p. 465-470, 1982.

MARMOR, M. F.; ZRENNER, E. Standard for Clinical electroretinography (1999 Update). Documenta Ophthalmologica, v. 97, p. 143-156, 1999.

MARMOR, M. F.; HOLDER, G. E.; SEELIGER, M. W.; YAMAMOTO, S. Standard for clinical electroretinography (2004 update). Documenta Ophthalmologica, v. 108, n. 2, p. 107-14, 2004. 
MARMOR, M. F.; FULTON, A. B.; HOLDER, G. E.; MIYAKE, E. M.; BRIGELL, M.; BACH, M. ISCEV Standard for full-field clinical electroretinography (2008 update). Documenta Ophthalmologica, v. 118, n. 1, p. 69-77, 2009.

MARTIN, C. L. Vitreous and ocular fundus. In: Ophthalmic disease in veterinary medicine. London: Manson Publishing, 2005. p. 401-470.

MATHEWS, M. K.; MERGES, C.; McLEOD, D. S.; LUTTY, G. A. Vascular Endothelial Growth Factor and Vascular Permeability Changes in Human Diabetic Retinopathy. Investigative Ophthalmology and Visual Science, v. 38, n. 13, p. 2729-2741, 1997.

MAZZAFERRO, E. M.; GRECO, D. S.; TURNER, A. S.; FETTMAN, M. J. Treatment of feline diabetes mellitus using an a-glucosidase inhibitor and a low-carbohydrate diet. Journal of Feline Medicine and Surgery, v. 5, n. 3, p. 183-189, 2003.

MENDONÇA, R. H. F.; TAKAHASHI, W. Y. Eletrorretinografia. In: DANTAS, A. M.; ALENCAR, S.; CASTANHEIRA-DINIS, A.; MENDONÇA, R. H. F.; TAKAHASHI, W. Y. Eletrofisiologia da visão. Rio de Janeiro: Cultura Médica, 2010. p.149-183.

MENTZER, A. E.; EIFLER, D. M.; MONTIANI-FERREIRA, F.; TUNTIVANICH, N.; FORCIER, J. Q.; PETERSEN-JONES, S. M. Influence of recording electrode type and reference electrode position on the canine electroretinogram. Documenta Ophthalmologica, v. 111, n. 2, p. 95-106, 2005.

MILLICHAMP, N. J. Retinal degeneration in the dog and cat. Veterinary Clinics of North America- Small animal practice, v. 20, n. 3, p. 799-835, 1990.

MITRA, R. A.; BORRILLO, J. L.; DEV, S.; MIELER, W. F.; KOENIG, S. B.

Retinopathy progression and visual outcomes after phacoemulsification in patients with diabetes mellitus. Archieves of Ophtahlmology, v. 118, n. 7, p. 912-917, 2000.

MOELLER, E.; BLOCKER, T.; ESSON, D.; MADSEN, R. Postoperative glaucoma in the Labrador Retriever: Incidence, risk factors, and visual outcome following routine phacoemulsification. Veterinary Ophthalmology, v. 14, n. 6, p. 385-394, 2011.

MONTENEGRO, L.; REZENDE, F. Transição extracapsular versus facoemulsificação. In: REZENDE, F. Cirurgia de catarata. Rio de Janeiro: Editora Cultura Médica; 2000. p. 176-86. 
MONTI, F.; BELLAN, B.; BERARDI, S.; PERUCCIO, C. The clinical picture of diabetic retinopathy in the dog. Folia Veterinaria Latina, v. 6, p. 249-274, 1976.

MOORE, D. L.; McLELLAN, G. J.; DUBIELZIG, R. R. A study of the morphology of canine eyes enucleated or eviscerated due to compli-cations following phacoemulsification. Veterinary Ophthalmology, v. 6, n. 3, p. 219- 226, 2003.

MOTTA, M. M. S.; COBLENTS, J.; MELO, L. G. N. Aspectos atuais no diagnóstico do edema macular diabético. Revista Brasileira de Oftalmologia, v. 68, n. 1, p. 5963, 2008.

MUÑANA, K. R. Long-term complications of diabetes mellitus, part I: retinopathy, nephropathy, neuropathy. The Veterinary Clinics of North America, v. 25, n. 3, p. 715-730, 1995.

MUNGER, R. J.; LAUS, J. L.; MARTINS, B. C.; RIBEIRO, A. P.; ORTIZ, J. P. D. Afecções da lente. In: LAUS, J. L. Oftalmologia clínica e cirúrgica em cães e gatos. São Paulo: Roca, 2009. p. 111-149.

NARFSTRÖM, K. Electroretinography in veterinary medicine -easy or accurate? Veterinary Ophthalmology, v. 5, n. 4, p. 249-251, 2002.

NARFSTRÖM, K. Electroretinographic testing in larger animals. In: HECKENLIVELY, J.; ARDEN, G. Ed. Principles and practice of clinical electrophysiology of vision. Cambridge: The Mit Press, 2006. p. 923-33.

NARFSTRÖM, K.; PETERSEN-JONES, S. Disease of the canine ocular fundus. In: GELATT, K. N. Veterinary ophthalmology. 4. ed. lowa: Blackwell Publishing, 2007. p. 944-1025.

NEGRETTO, A. D.; ROSA, A. A. M.; NAKASHIMA, A. A.; ORTEGA, K. C.; MION, J. D.; OYAMADA, M. K.; NAKASHIMA,Y. Avaliação da retinopatia hipertensiva através do potencial oscilatório do eletrorretinograma. Arquivos Brasileiros de Oftalmologia, v. 71, n. 1, p. 38-42, 2008.

NEHEMY, M. B.; CAMPOS, W. R.; OREFICE, F.; PARANHOS, F. R. L. Manifestações Oftalmológicas de Doenças Sistêmicas In: KARA-JOSE, N.; ALMEIDA, G. A. Senilidade ocular. 1. ed. São Paulo: Editora Roca, 2001. p.1-9. 
NELSON, R. W.; FELDMAN, E. C. Diabetes mellitus canino. In: KIRK, R. W.

Atualização terapêutica veterinária. São Paulo: Manole, 1988. v. 2, p. 1252-1261.

NELSON, R. W. Distúrbios do pâncreas endócrino. In: ETTINGER, S. J. Tratado de medicina interna veterinária, 3.ed., São Paulo, 1992. p.1752-1798.

NELSON, R. W. Distúrbios do pâncreas endócrino. In: NELSON, R. W.; COUTO, C. G. Medicina interna de pequenos animais. 2 ed.,Rio de Janeiro: Guanabara Koogan, 2001a, p. 582.

NELSON, R. W. Hiperglicemia. In: NELSON, R. W.; COUTO, C.G. Medicina interna de pequenos animais. 2 ed., Rio de Janeiro: Guanabara Koogan, 2001b, p. 580.

NELSON, R. W. Diabete melito. In: ETTINGER, S. J.; FELDMAN, E. C. Tratado de Medicina Interna Veterinária, v. 2, 5 ed. Rio de Janeiro: Guanabara Koogan, 2004. p. 1516-1539.

NELSON, R. W. Canine diabetes mellitus. In: ETTINGER, S. J.; FELDMAN E. C. Textbook of veterinary internal medicine. 7th ed., v. 2, St Louis, Missouri: Elsevier Saunders, 2010. p. 1782-1796.

NGUYEN, P.; DUMON, H.; BIOURGE, V.; POUTEACE, E. Measurement of postprandial incremental glucose and insulin changes in health dogs: influence of food adaptation and length of time of blood sampling. Journal of Nutrition, v. 128, n. 12, p. 2659s-2662s, 1998. Supplement.

NICHOLS, R. Recognizing and treating canine and feline diabetes mellitus. Veterinary Medicine, v. 87, n. 3, p. 211-222, 1992.

NOWROUZIAN, I.; SCHELS, H. F.; GHODSIAN, I.; KARIMI, H. Evaluation of the anaesthetic properties of ketamine and ketamine/xylazine/ atropine combination in sheep. Veterinary Record, v. 108, p. 354-356,1981.

NUSINOWITZ, S.; HECKENLIVELY, J. R. Evaluating retinal function in the mouse retina with the electroretinogram. In: HECKENLIVELY, J. R.; ARDEN, G. A.

Principles and practice of clinical electrophysiology of vision. 2. ed. Cambridge: The MIT Press, 2006. 899-909. 
OFRI, R.; DAWSON, W. W.; FOLI, F.; GELATT, K. N. Chronic ocular hypertension alters local retinal responsiveness. British Journal of Ophtlhalmology, n. 77, p. 502-508, 1993.

OFRI, R. Clinical electrophysiology in veterinary ophthalmology- the past, present and future. Documenta Ophthalmologica, v. 104, n. 1, p. 5-16, 2002.

OFRI, R. Lens. In: MAGGS, D. J.; MILLER, P. E.; OFRI, R. Slatter's fundamentals of veterinary ophthalmology. 4. ed. St Louis: Saunders Elsevier, 2008. p. 258-276.

OLLIVIER, E. J.; SAMUELSON, D. A.; BROOKS, D. E.; LEWIS, P. A.; KALLBERG, M. E.; KOMAROMY, A. M. Comparative morphology of the tapetum lucidum (among selected species). Veterinary Ophthalmology, v. 7, n. 1. p. 11-22, 2004.

ONO, K.; YASUDA, K.; IWATA, H.; NAKAYAMA, H.; HASEGAWA, A.; TOMODA, I. Fluorescein angiogram in diabetic dogs. Japanese Journal of Veterinary Science, v. 48, n. 6, p. 1257-1261, 1986.

ORIÁ, A. P.; LÁZARO JR, L. P.; HONSHO, C. S.; DOREA NETO, F. A.; LAUS, J. L. Considerations about electrorretinography in dogs. Ciência Rural, Santa Maria, v. 34 n. 1, p. 323-328, 2004.

OSTROV, C. S.; SIRKIN, S. R.; DEUTSCH, W. E.; MASI, R. J.; CHANDLER, J. W.; LINDQUIST, T. D. Ketorolac, prednisolone, and dexamethasone for postoperative inflammation. Clinical Therapeutics, v. 19, n. 2, p. 259-272, 1997.

PARISI, V.; UCCIOLI, L.; MONTICONE, G.; PARISI, L.; MANNI, G.; IPPOLITI, D.; MENZIGER, G.; BUCCI, M. Electrophysiological assessment of visual function in IDDM patients. Electroencephalography and clinical Neurophysiology, v. 104, p. 171-179, 1997.

PARK, S. A.; YI, N. Y.; JEONG, M. B.; KIM, W. T.; KIM, S. E.; CHAE, J. M.; SEO, K. $M$. Clinical manifestations of cataracts in small breed dogs. Veterinary

Ophthalmology, v. 12, n. 4, p. 205-210, 2009.

PARRY, H. B.; TANSLEY, K.; THOMSON, L. C. The electroretinogram of the dog. Journal of Physiology, v. 120, p. 28-40, 1953. 
PATZ, A.; MAUMENEE, A. E. Studies on diabetic retinopathy 1.Retinopathy in a dog with spontaneous diabetes mellitus. American Journal of Ophthalmology, v. 54, p. 532-541, 1962.

PEREIRA, A. L.; MONTIANI-FERREIRA, F.; SANTOS, V. R.; SALOMÃO, S. R.; SOUZA, C.; BEREZOVSKY, A. Electroretinography in dogs using a fiber electrode prototype. Brazilian Journal of Medical and Biological Research, v. 46, n. 3, p. 257-262, 2013.

PETERSEN-JONES, S.; TUNTIVANICH, N.; MONTIANI-FERREIRA, F.; KHAN, N. Electroretinograms of dog and chicken. In: HECKENLIVELY, J. R.; ARDEN, G. A. Principles and practice of clinical electrophysiology of vision. 2. ed. The MIT Press, 2006. p. 911-921.

POLLACK, A.; DOTAN, S.; OLIVER, M. Progression of diabetic retinopathy after cataract extraction. British Journal of Ophthalmology, v. 75, n. 9, p. 547-51, 1991.

PIZZOL, M. M.; ESTEVES, J. F.; SCCOCO, C. A.; ROGGIA, M. F.; ROSA, C. M.; LAMBERT, J. H. F.; CANANI, L. H. Catarata e diabetes mellitus tipo 1. Arquivos Brasileiros de Oftalmologia, São Paulo, v. 71, n. 4, p. 564-567, 2008.

RAND, J. S.; FLEEMAN, L. M.; FARROW, H. A.; APPLETON, D. J.; LEDERER, R. "Canine and feline diabetes mellitus: nature or nurture?" Journal Nutrition, v. 134, n. 8, p. 2072s-2080s, 2004. Suplement.

RANDALL, D. J.; ECKERT, R.; BURGGREN, W. W.; FRENCH, K. Eckert animal physiology: mechanisms and adaptations. 4th ed. New York: W. H. Freeman and Co.1998. $727 \mathrm{p}$.

REZENDE, F. F.; REZENDE, F. Anatomia cirúrgica. In: REZENDE, F. Cirurgia de catarata. Rio de Janeiro: Editora Cultura Médica, 2000. p. 9-16.

RICHTER, M.; GUSCETTI, F.; SPIESS, B. Aldose reductase activity and glucoserelated opacities in incubated lenses from dogs and cats. American Journal of Veterinary Research, v. 63, n. 11, p. 1591-1597, 2002.

RUBIN, L. F. Clinical features of hemeralopia in the adult Alaskan malamute. Journal of the American Veterinary Medical Association, v. 158, n. 10, p. 1696-1698, 1971. 
SAFATLE, A. M. V.; SALOMÃO, S.; BEREZOVSKY, A.; SACAI, P.; FANTONI, D.; YASBEK, K.; BARROS, P. S. M. Retinal degeneration in a pit bull dog:

electroretinographic findings. Archieves of Veterinary Science, v. 10, n. 2, p. 119124, 2005.

SAFATLE, A. M. V.; GOMES, D.; OTUSKI, D. A.; SHIMAMURA, G. M.; HVENEGAARD, A. P. F. A.; LISAK, R. Estudo retrospectivo dos resultados do eletrorretinograma de campo total em cães da raça cocker portadores de catarata. In: CONGRESSO PAULISTA DE CLÍNICOS VETERINÁRIOS DE PEQUENOS ANIMAIS, 7., 2007, São Paulo. Anais...São Paulo: ANCLIVEPA, 2007. p. 228-230.

SAFATLE, A. M. V. Eletrorretinograma de campo total em cães diabéticos com catarata. 2008. 129 f. Tese (Doutorado em Medicina Veterinária) - Faculdade de Medicina Veterinária e Zootecnia, Universidade de São Paulo, São Paulo, 2008.

SAFATLE, A. M. V.; HVENEGAARD, A. P.; KAHVEGIAN, M.; L. MARTINS, T. L.; SHIMAMURA, G. M.; FANTONI, D. T.; BARROS, P. S. M. Padronização do eletrorretinograma de campo total em cães. Pesquisa Veterinária Brasileria, Rio de Janeiro, v. 30, n. 9, p.763-769, 2010a.

SAFATLE, A. M. V.; HVENEGAARD, A. P.; GOMES, D.; LEANDRO, D. C.; OTSUKI, D.; LISAK, R. Importância do eletrorretinograma de campo total (Full field ERG) em cães da raça Cocker Spaniel Inglês portadores de catarata. Pesquisa Veterinária Brasileira, Rio de Janeiro, v. 30, n. 2, p. 149-154, $2010 \mathrm{~b}$.

SAFATLE, A. M. V.; LISAK, R.; OTSUKI, D.; GOMES, D. Determinação dos valores normais do eletrorretinograma de campo total em cães da raça Poodle portadores de catarata de acordo com a faixa etária. Ciência Rural, Santa Maria, v. 40, p. 587593, n. 3, 2010c.

SAFATLE, A. M. V.; HVENEGAARD, A. P.; OTSUKI, D.; MARTINS, T. L.; KAHVEGIAN, M.; BEREZOVKY, A.; SALOMÃO, S. R.; BARROS, P. S. M. Comparison of full-field electroretinogram in diabetic and non diabetic dogs with cataracts. Pesquisa Veterinária Brasileira, v. 30, n. 12, p. 1071-1076, 2010d.

SALOMÃO, S. R. Eletrofisiologia Visual nas Uveítes. In: ABREU, M. T. O. Inflamações oculares. São Paulo: Editora Roca, 2002. p. 162-189.

SAMUELSON, D. A. Ophthalmic Anatomy. In: GELATT, K. N. Veterinary ophthalmology. 4. ed. lowa: Blackwell Publishing, 2007. p. 37-148. 33 
SANTOS, F. A. Diabetes Mellitus em cães e gatos: estudo retrospectivo de 35 casos clínicos. 2012. 132 f. Dissertação (Mestrado em Medicina Veterinária) Universidade Técnica de Lisboa, Faculdade de Medicina Veterinária, Lisboa , 2012.

SCHAER, M. Clinical medicine of the dog and cat. 2. Ed. London : Manson Publishing, 2003. 760 p.

SECCHI, C.; OLDANI, L.; PERUCCIO, C.; GUTTINGER, M.; BERRINI, A.; CALDORA, C.; POLI, G. Immunopathology of the eye: purification of canine retinal " $S$ " antigen. Comparative immunology, microbiology and infections diseases, $v$. 8, n. 3-4, p. 297-303, 1985.

SERRARBASSA, P. D.; DIAS, A. F. G.; VIEIRA, M. F. Novos conceitos em retinopatia diabética: dano neurológico versus dano vascular. Arquivos Brasileiros de Oftalmologia, v. 71, n. 3, p. 459-463, 2008.

SEVERNS, M. L.; JOHNSON, M. A.; BRESNICK, G. H. Methodologic dependence of electroretinogram oscillatory potential amplitudes. Documenta Ophthalmologica, $v$. 86, n. 1, p. 23-31, 1994.

SHAH, A. S.; CHEN, S. H. Cataract surgery and diabetes. Current Opinion in Ophthalmology, v. 21, n. 1, p. 4-9, 2010.

SIBAY, T. M.; HAUSLER, H. R. Eye findings in two spontaneously diabetic related dogs. American Journal of Ophthalmology, v. 63, n. 2, p. 289-294, 1967.

SIMONSEN, S. E. Prognostic value of ERG (oscillatory potentials) in juvenile diabetics. Acta Ophthalmologica, v. 123, p. 223-224, 1975. Supplement.

SIMS, M. H. Electrodiagnostic evaluation of vision. In: GELATT, K. N. Veterinary ophthalmology. 3. ed. Philadelphia: Lippincott Williams e Wilkins, 1999. p. 483-507.

SLATTER, D. Fundamentos de oftalmologia veterinária. 3. ed. São Paulo: Roca, 2005. $686 \mathrm{p}$.

SLATTER, D. Slatter's fundamentals of veterinary ophthalmology. 4th ed. Philadelphia: Saunders Elsevier, 2008. 478 p. 
SMALL, K. W.; STEFÁNSSON, E.; HATCHELL, D. L. Retinal blood flow in normal and diabetic dogs. Investigative Ophthalmology andVisual Science, v. 28, p. $672-$ $675,1987$.

SQUIRRELL, D.; BHOLA, R.; BUSH, J.; WINDER, S.; TALBOT, J. F. A Prospective, case controlled study of natural history of diabetic retinopathy and maculopathy after uncomplicated phacoemulsification cataract surgery in patients with type 2 diabetes. The British Journal of Ophthalmology, v. 86, p. 565-571, 2002.

STRUCK, H.; BARISZLOVICH, A. Comparison of $0.1 \%$ dexamethasone phosphate eye gel (Dexagel) and 1\% prednisolone acetate eye suspension in the treatment of post-operative inflammation after cataract surgery. Graefe's Archive for Clinical and Experimental Ophthalmology, v. 239, n. 10, p. 737-742, 2001.

TANSKANEN, P.; KYLMA, T.; KOMMONEN, B.; KARHUNEN, U. Propofol influences the electroretinogram to a lesser degree than thiopentone. Acta Anaesthesiologica Scandinavica, v. 40, p.480-485, 1996

TORREN, K. V. D.; MULDER, P. Comparison of second and third oscillatory potentials with oscillatory potential power in early diabetic retinopathy. Documenta Ophthalmologica, v. 83, p. 111-118, 1993.

TUNTIVANICH, P.; TUNTIVANICH, N. Phacofragmentation and Aspiration in Canine Mature Cataract: Surgical technique, Success rate and Complications. Thai Journal of Veterinary Medicine, v. 37, n. 2, p. 33-45, 2007.

TZEKOV, R.; ARDEN, G. B. The electroretinogram in diabetic retinopathy. Survey of Ophthalmology, v. 44, n. 1, p. 53-60, 1999.

VILELA, M.; FERREIRA, P.; MENHEGHI, M. R. Retina e Vítreo In: VILELA, M. Condutas em oftalmologia ambulatoriais e emergenciais. Rio de Janeiro: Editora Cultura Médica, 1998. p. 190-220.

WACHTMEISTER, L. Basic research and clinical aspects of the oscillatory potentials of the electroretinogram. Documenta Ophthalmologica, v. 66, n. 3, p. 187-94, 1987.

WALDE, I.; SCHÄFFER, E.; KÖSTLIN, R. Considerações anatômicas e fisiológicas. In:_Atlas de clínica oftalmológica do cão e do gato. São Paulo: Manole, 1998. p. 3-16. 
WEICHSLER, N.; HERRERA, D. Electrorretinografia: uso clinico. In: HERRERA, D. Oftalmología clínica en animales de compañia. Buenos Aires: Inter-Médica, 2007. p. $73-83$.

WILCOCK, B. P. Eye, eyelids, conjunctiva, and orbit. In McGAVIN, M.; ZACHERY, J. F. Pathologic basis of veterinary disease. 4th ed. Missouri: Elsevier. 2007. p. 1349-1412.

WILKIE, D. A.; GEMENSKY-METZLER, A. J.; COLITZ, G. M. I. L.; BRAS, I. D.; KUONEN, V. J.; NORRIS, K. N.; BASHAM, G. R. Canine cataracts, diabetes mellitus and spontaneous lens capsule rupture: A retrospective study of 18 dogs. Veterinary Ophthalmology, v. 9, n. 5, p. 328-334, 2006.

WILKIE, D. A.; COLITZ, C. M. H. Updateon veterinary cataract surgery. Current Opinion in Ophthalmology, v. 20, n. 1, p. 61-68, 2009.

WILLIAMS, D. L.; BOYDELL,I I. P.; LONG, R. D. Current concepts in the management of canine cataract: A survey of techniques used by surgeons in Britain, Europe and the USA and a review of recent literature. Veterinay Record, v. 138, n. 15, p. 347-35, 1996.

WILLIAMS, D. L. Oxidation, antioxidants and cataract formation : a literature review. Veterinary Ophthalmology, v. 9, n. 5, p. 292-298, 2006.

WOODWARD, W. R.; CHOI, D.; GROSE, J.; MALMIN, B.; HURST, S.; PANG, J.; WELEBER, R. G.; PILLERS, D. A. M. Isoflurane is na effective alternative to ketamine/xylazine/acrepromazine as na anesthetic agent for the mouse electroretinogram. Documenta Ophthalmologica, v. 115, p. 187-201, 2007.

YANASE, J.; OGAWA, H. Effects of halothane and sevoflurane on the electroretinogram of dogs. American Journal of Veterinary Research, v. 58, n. 8, p. 904-909, 1997.

YOSHIDA, A.; KOJIMA, M.; OGASAWARA, H.; ISHIKO, S. Oscillatory potentials and permeability of blood-retinal barrier in noninsulin-depedent diabetic patients whithout retinopaty. Ophthalmology, v. 98, p. 1266-1271, 1991.

YU, H.; JEONG, M.; PARK, S.; KIM, W.; KIM, S.; CHAE, J.; YI, N.; SEO, K. The determination of dark adaptation time using electroretinography in conscious Miniature Schnauzer dogs. Journal of Veterinary Science, v. 8, n.4, p. 409-414, 2007. 
APÊNDICE A - Eletrorretinograma de campo total de cães diabéticos seguindo o protocolo da ISCEV
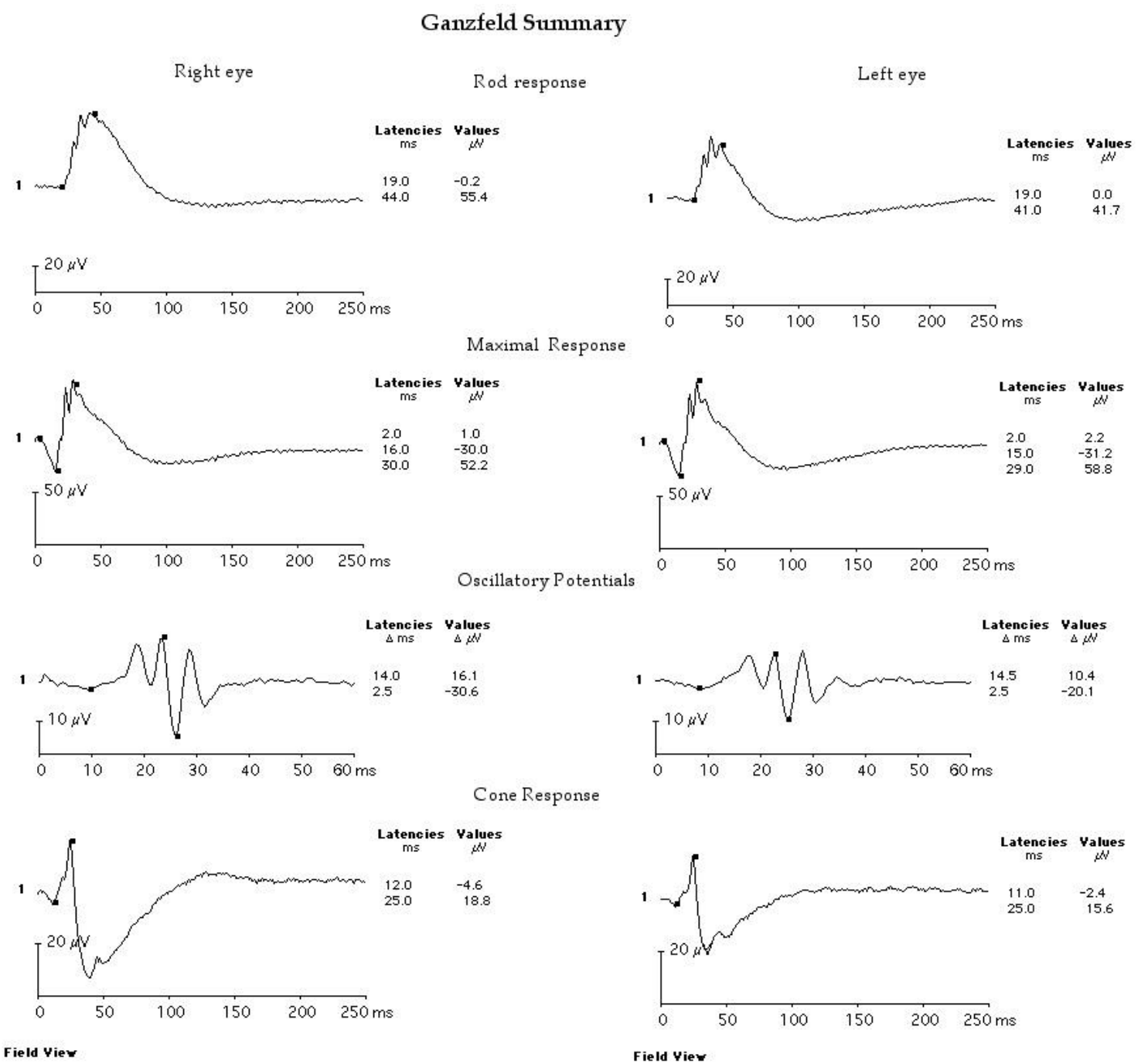

Field View

Field View

$30 \mathrm{~Hz}$ Flicker
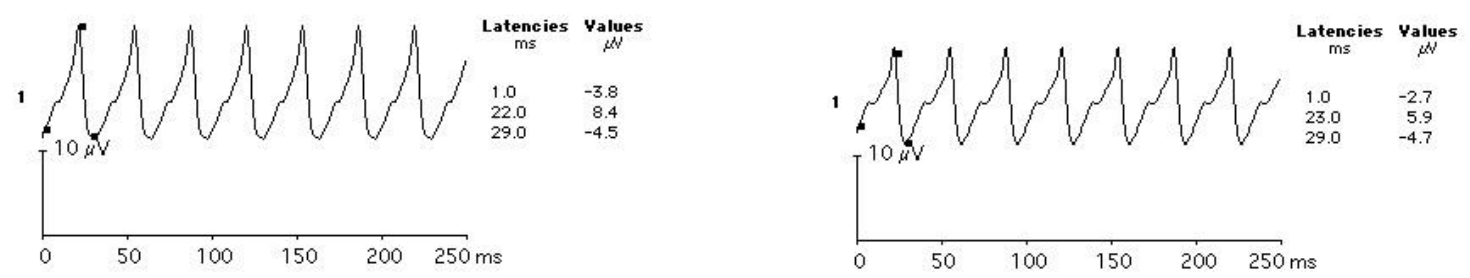

Animal 7L, SRD, fêmea, 7 anos, pré cirurgia de catarata 
APÊNDICE A - Eletrorretinograma de campo total de cães diabéticos seguindo o protocolo da ISCEV - Continuação

Ganzfeld Summary
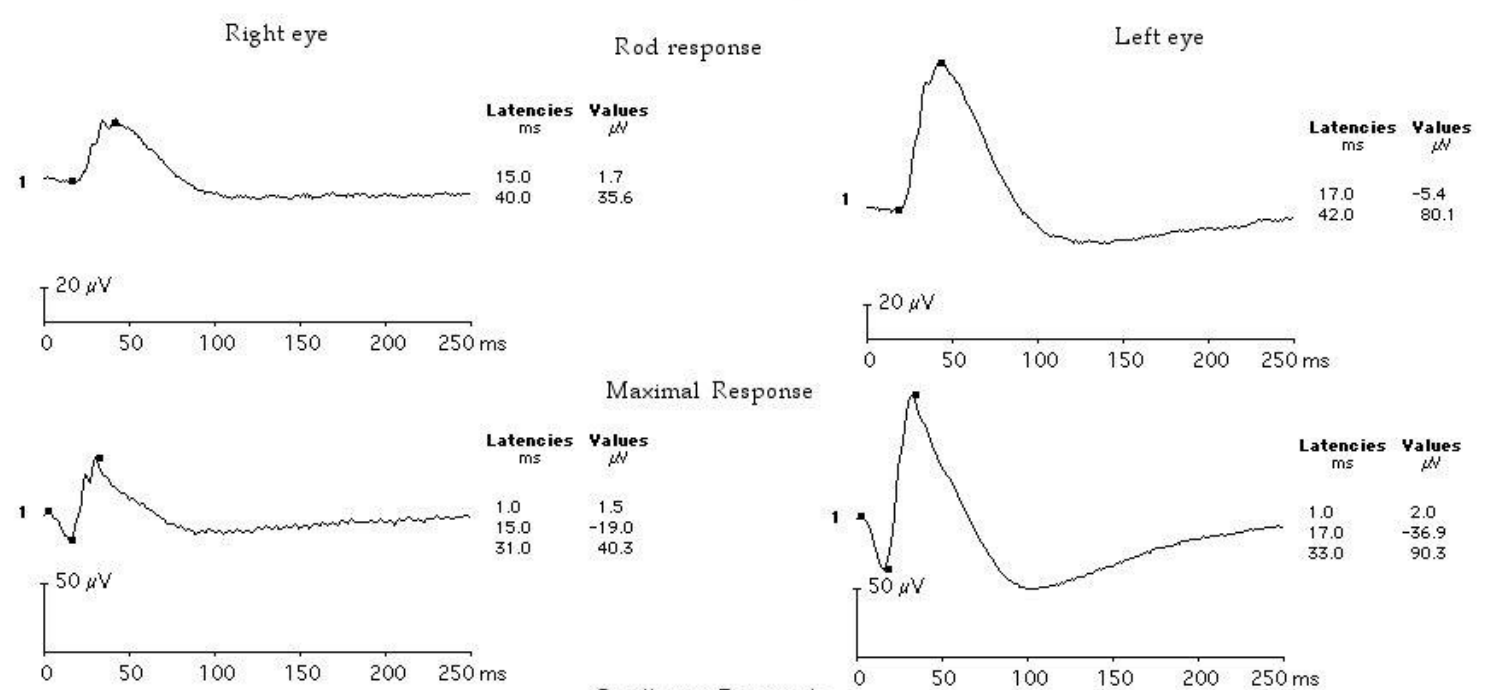

-19.0
40.3

Oscillatory Potentials
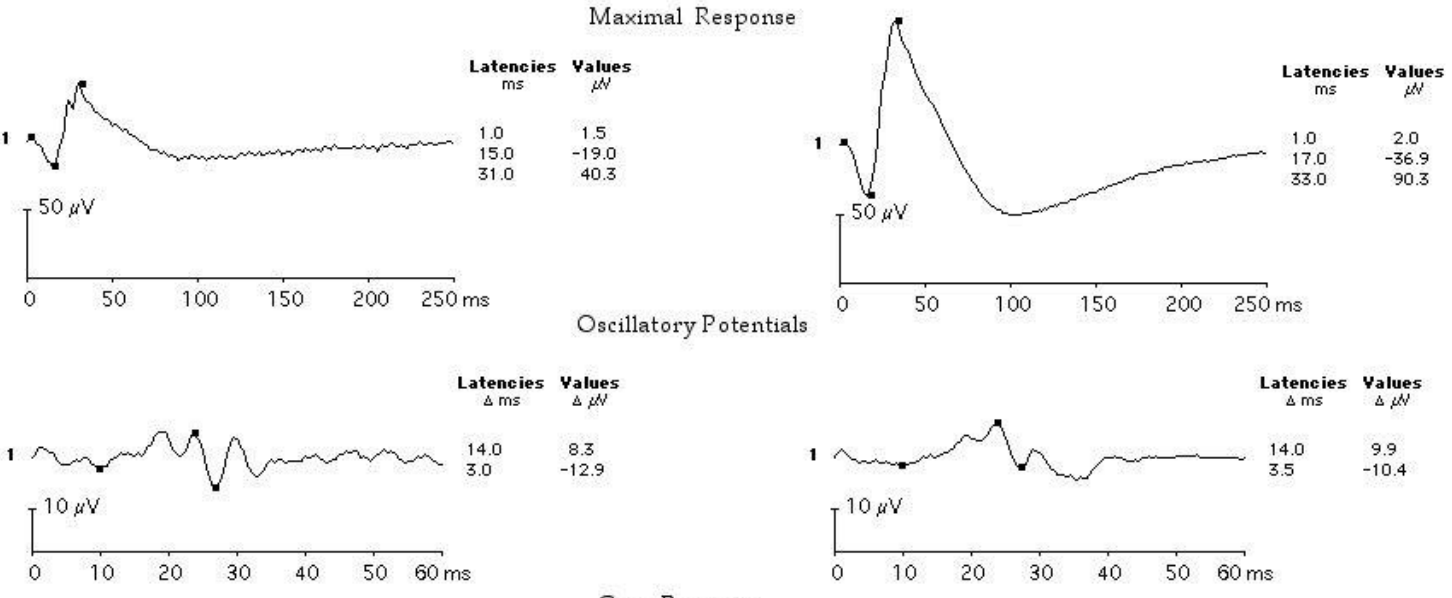

$\underset{\Delta \mathrm{ms}}{\operatorname{Latencies}} \underset{\Delta \mu N}{\text { Values }}$

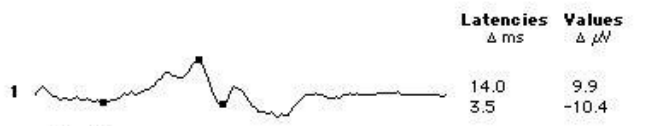

$\begin{array}{lc}14.0 & 8.3 \\ 3.0 & -12.9\end{array}$

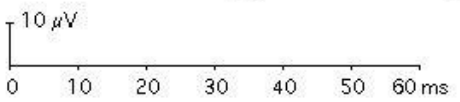

Cone Response
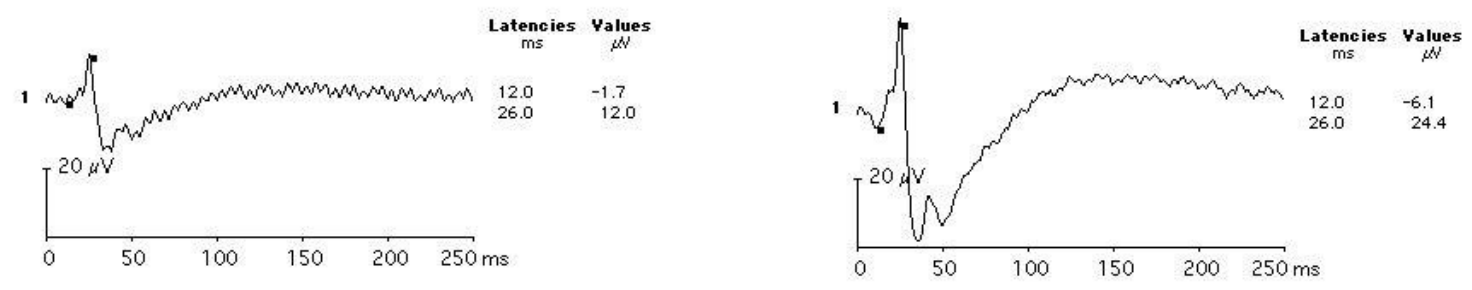

Field Vie $=$

Field Yiev

$30 \mathrm{~Hz}$ Flicker
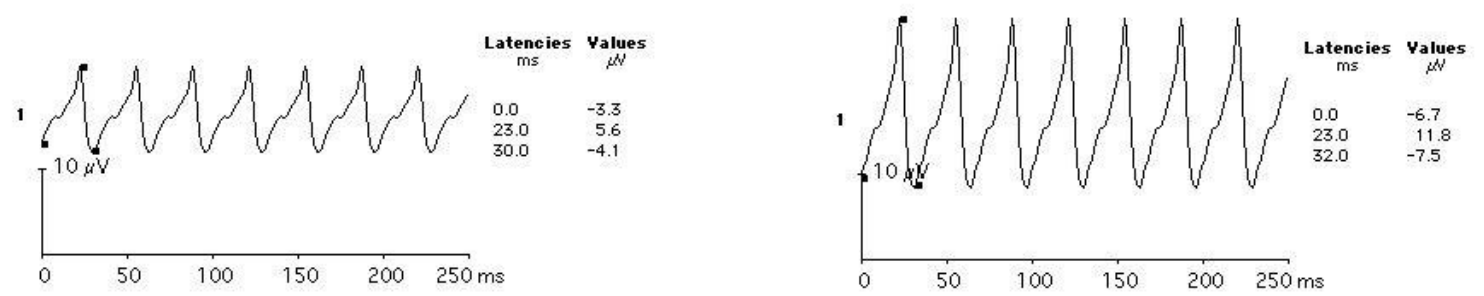

Animal 7L, SRD, fêmea, 7 anos, 6 meses pós facoemulsificação em olho esquerdo 
APÊNDICE A - Eletrorretinograma de campo total de cães diabéticos seguindo o protocolo da ISCEV - Continuação

\section{Ganzfeld Summary}

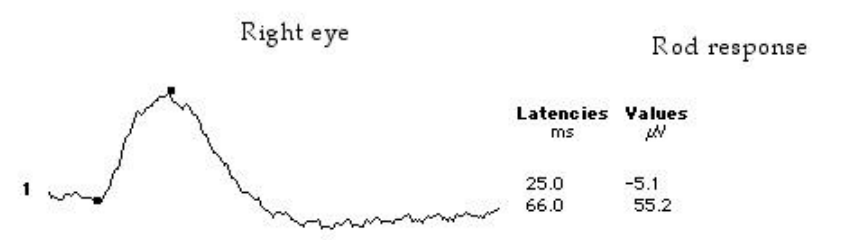

Left eye
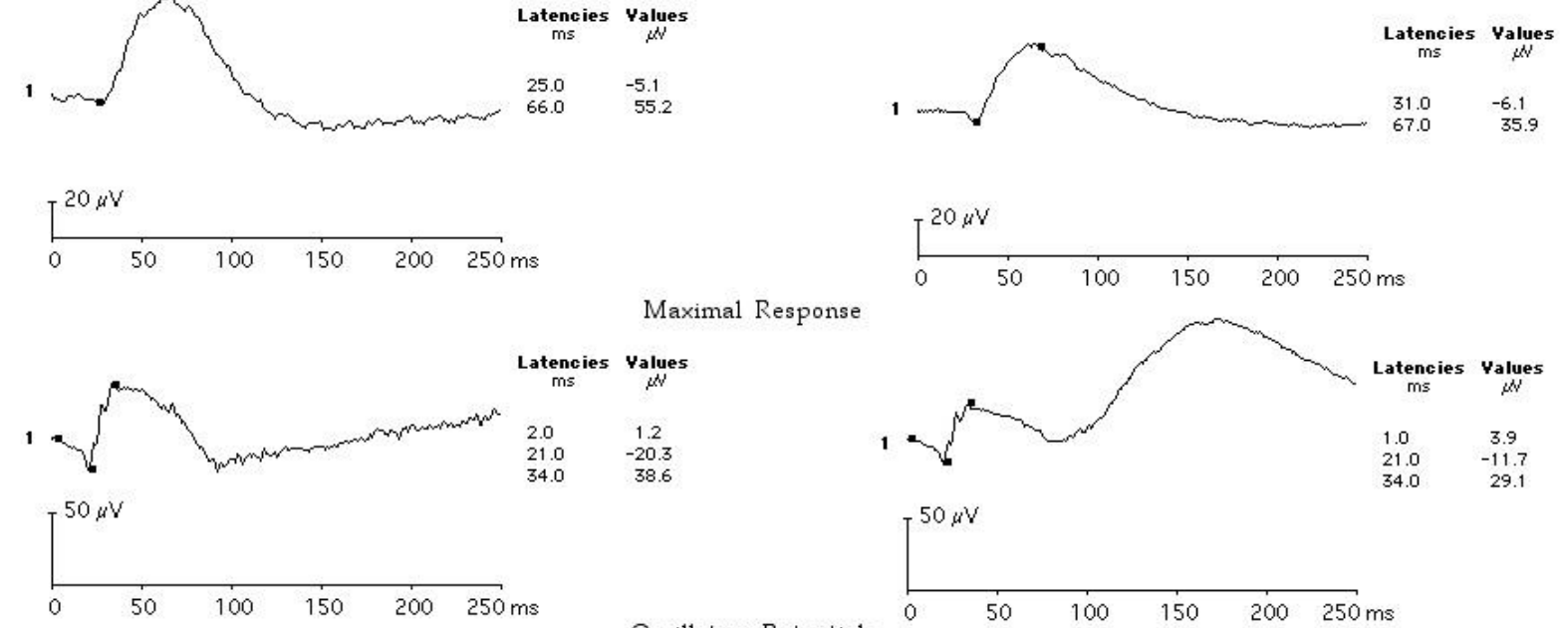

Maximal Response
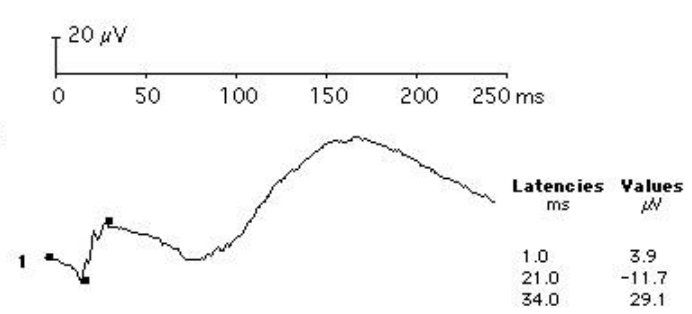

1.2
-20.3
38.6

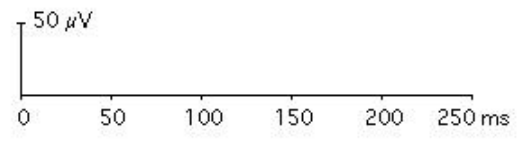

Oscillatory Potentials

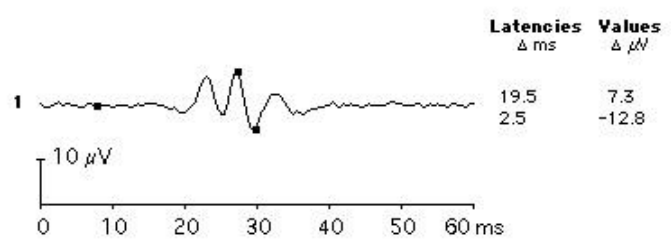

\section{Cone Response}
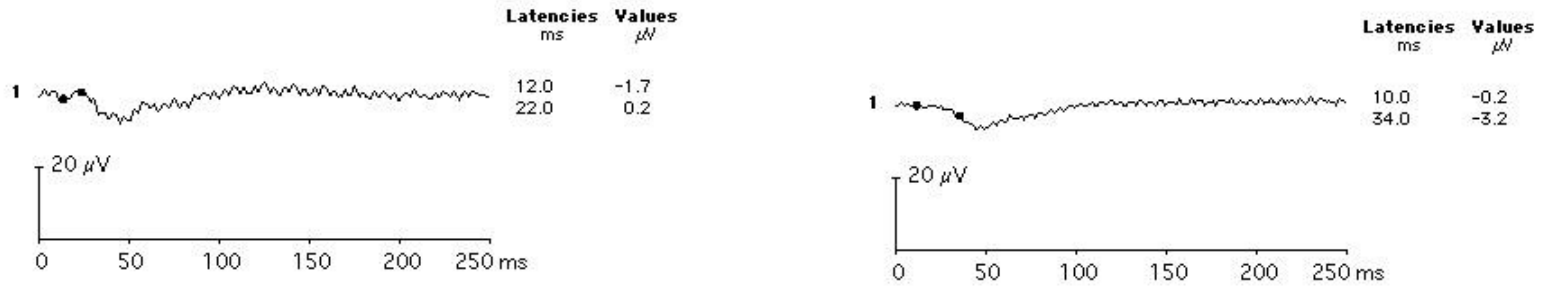

Field Yiew

Field Viev

$30 \mathrm{~Hz}$ Flicker
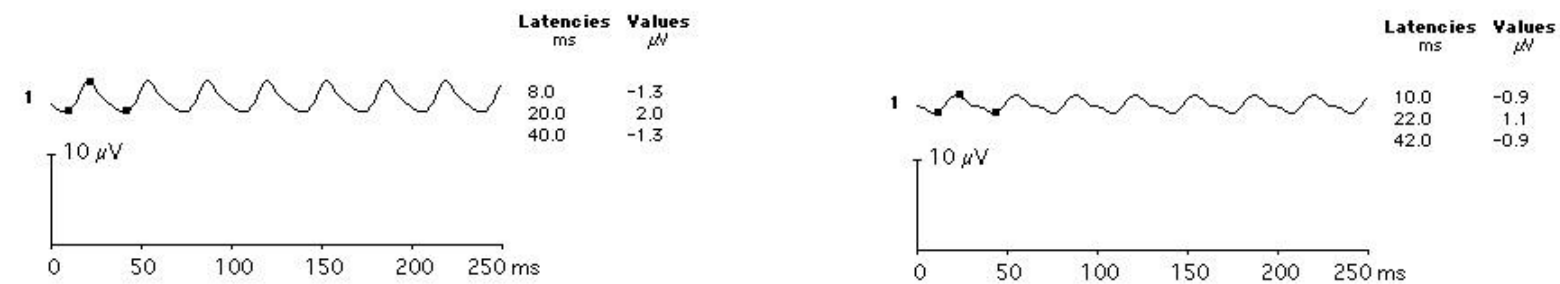

Animal 3U, SRD, fêmea, 11 anos, pré cirurgia de catarata 


\section{APÊNDICE A - Eletrorretinograma de campo total de cães diabéticos seguindo o} protocolo da ISCEV - Continuação

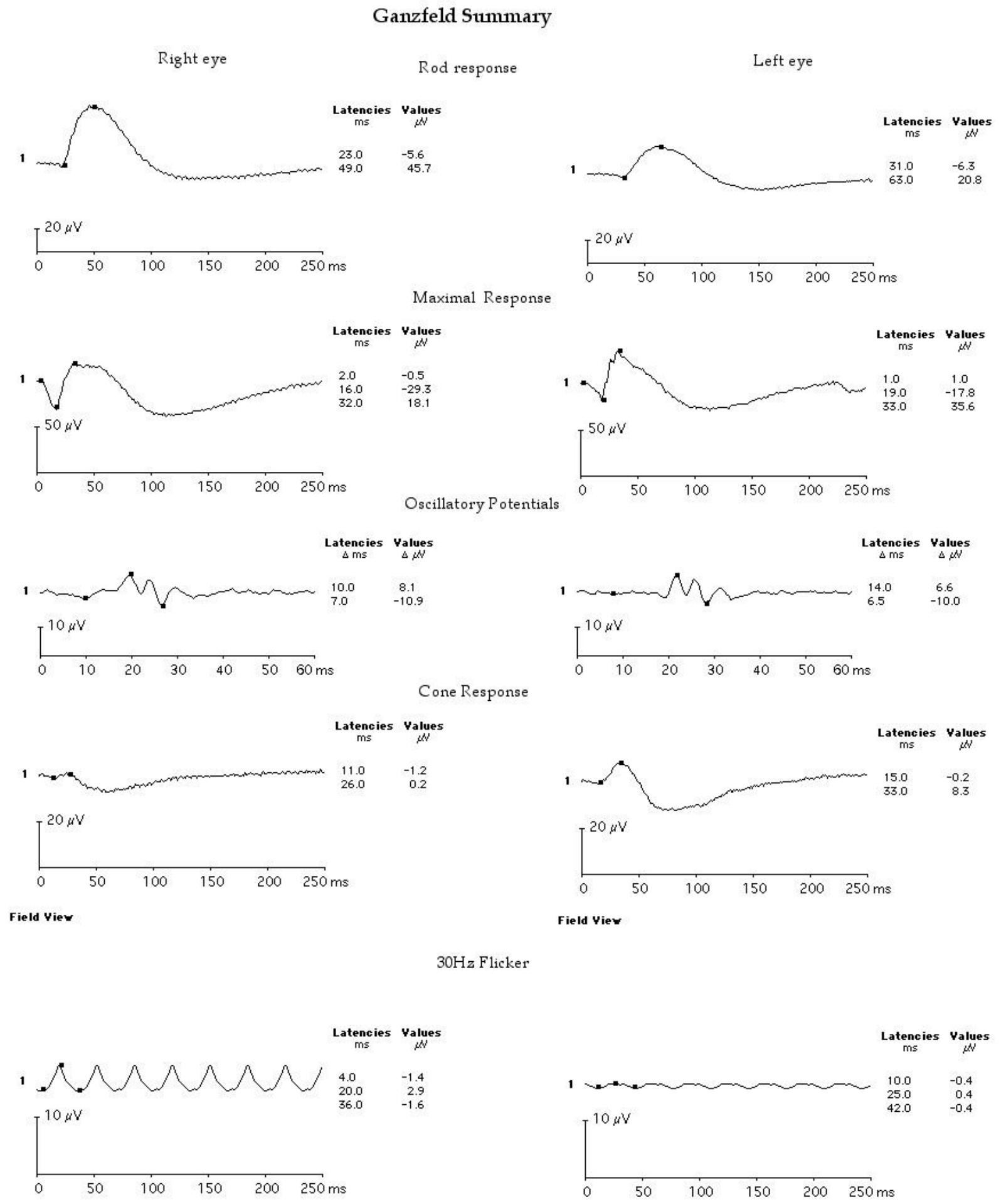

Animal 3U, SRD, fêmea, 11 anos, 6 meses pós facoemulsificação em olho direito 